\title{
Missouri's Medicaid Contraction and Consumer Financial Outcomes
}

\section{James Bailey}

Providence College and

Federal Reserve Bank of Philadelphia Consumer Finance Institute

Visiting Scholar

\section{Nathan Blascak}

Federal Reserve Bank of Philadelphia

Consumer Finance Institute

\section{Vyacheslav Mikhed}

Federal Reserve Bank of Philadelphia

Consumer Finance Institute

ISSN: 1962-5361

Disclaimer: This Philadelphia Fed working paper represents preliminary research that is being circulated for discussion purposes. The views expressed in these papers are solely those of the authors and do not necessarily reflect the views of the Federal Reserve Bank of Philadelphia or the Federal Reserve System. Any errors or omissions are the responsibility of the authors. Philadelphia Fed working papers are free to download at: https://philadelphiafed.org/researchand-data/publications/working-papers.
|ND2R-42

PUBLISHED

November 2020

REVISED

February 2023






\title{
Missouri's Medicaid Contraction and Consumer Financial Outcomes*
}

\author{
James Bailey \\ Providence College \\ Department of Economics
}

\author{
Nathan Blascak \\ Consumer Finance Institute \\ Federal Reserve Bank of \\ Philadelphia
}

\author{
Vyacheslav Mikhed $\dagger$ \\ Consumer Finance Institute \\ Federal Reserve Bank of \\ Philadelphia
}

\section{February 2023}

\begin{abstract}
In July 2005, the state of Missouri implemented a series of cuts to its Medicaid program. These cuts resulted in the elimination of the Medical Assistance for Workers with Disabilities program, more stringent eligibility requirements, and less generous Medicaid coverage for eligible individuals. Overall, the reforms removed about 100,000 Missourians from the program and reduced the value of the insurance for the remaining enrollees. Using data from the Medical Expenditure Panel Survey, we show how these cuts increased out-of-pocket medical spending for individuals living in Missouri. Using individual-level credit bureau data and employing a border discontinuity differences-in-differences empirical strategy, we show that the Medicaid reform led to increases in both credit card borrowing and debt in third-party collections. The magnitude of our estimates suggests there may be important asymmetries in the financial effects of shrinking a public health insurance program when compared with a public health insurance expansion.
\end{abstract}

Keywords: Medicaid, health insurance, consumer credit

JEL Codes: I13, I18, G51, G52

\footnotetext{
*We would like to thank Robert M. Hunt, Thanh Lu, and seminar participants at the 2019 Consumer Finance Round Robin, the 2019 Boulder Summer Conference on Consumer Financial Decision Making, the Federal Reserve Bank of Kansas City, and the Federal Reserve Bank of Philadelphia for their helpful comments. Prakash Mishra, Sean McCrary, Peter Psathas, and Jacob Reichlin provided excellent research assistance. We thank Anna Tranfaglia and Veronika Konovalova for their help with maps. Research in this paper was conducted using the CFACT Data Center, and the support of the Agency for Healthcare Research and Quality (AHRQ) is gratefully acknowledged. The results and conclusions in this paper are those of the authors and do not indicate concurrence by AHRQ or the Department of Health and Human Services. The views expressed in this paper are solely those of the authors and do not necessarily reflect the views of the Federal Reserve Bank of Philadelphia or the Federal Reserve System. Any errors or omissions are the responsibility of the authors.

†Mikhed: (corresponding author) Consumer Finance Institute, Federal Reserve Bank of Philadelphia, 10 Independence Mall, Philadelphia, PA 19106; slava.mikhed@phil.frb.org. Blascak: Consumer Finance Institute, Federal Reserve Bank of Philadelphia, 10 Independence Mall, Philadelphia, PA 19106; nathan.blascak@phil.frb.org. Bailey: Providence College, 1 Cunningham Square, Providence, RI 02918; jbailey6@providence.edu.
} 


\section{Introduction}

What is the value of Medicaid, and how do Medicaid recipients react to changes in the program? These questions have increased in importance as many states have expanded their programs in response to the Affordable Care Act (ACA), while others consider new forms of Medicaid reforms and restrictions such as work requirements. Since Medicaid's origin in 1965, the general trend has been to expand eligibility. The program originally tied Medicaid eligibility to eligibility for cash assistance (Aid for Families with Dependent Children), but it has since expanded to cover some disabilities, long-term care, and low-income individuals without children. Because of these expansions, potential Medicaid recipients have generally opted to take advantage of their eligibility, which has led to enrollment increasing from 4 million individuals in 1966 to 73.8 million in $2017 .^{1}$

The body of research on the effects of Medicaid expansions is extensive and has covered a wide variety of outcomes, including health, employment, provider behavior, and consumer financial health. This research on financial outcomes has generally found that individuals who received coverage (or were eligible for coverage) received substantial financial benefits, including reduced out-of-pocket (OOP) medical spending (Finkelstein et al., 2012; Baicker et al., 2013), reduced medical debt in collections (Finkelstein et al., 2012; Hu, Kaestner, Mazumder, Miller, and Wong, 2018; Miller, Hu, Kaestner, Mazumder, and Wong, 2021; Brevoort, Grodzicki, and Hackmann, 2020), higher credit scores (Miller et al., 2021; Brevoort et al., 2020) and a lower likelihood of bankruptcy (Gross and Notowidigdo, 2011). These financial benefits to recipients are unsurprising, given that Medicaid coverage is relatively generous as health insurance, covering most medical services with low to zero premiums and cost sharing.

While this previous research is well identified and provides estimates of the financial effects of recent Medicaid expansions, it does not necessarily indicate what the effects of future Medicaid program contractions would be. Expansions and contractions to a public program could have asymmetric effects along several dimensions, and research on Tennessee's 2005 Medicaid

\footnotetext{
${ }^{1}$ In terms of overall population, Medicaid covered 2 percent of all Americans in 1968 and 22.6 percent by 2017. For more information, see https://www.macpac.gov/publication/medicaid-enrollment-and-total-spending-levelsand-annual-growth/.
} 
reform suggests this to be the case for Medicaid for general hospitalizations (Ghosh and Simon, 2015), behavioral health-care hospitalizations (Maclean, Tello-Trillo, and Webber, 2020), and financial well-being (Argys, Friedson, Pitts, and Tello-Trillo, 2020). Understanding the impacts of program contractions are of particular interest, given the current policy landscape as recent proposals for Medicaid program reforms most commonly discussed by states are not just simple reversals of the recent expansions of eligibility to low-income adults. Instead, states have been (1) proposing either new forms of eligibility requirements, such as work requirements, or more frequent income verification, (2) making their programs less generous to recipients by introducing or increasing premiums, deductibles, and copays, or (3) removing coverage for certain types of services. ${ }^{2}$

To examine the effects of a public insurance program contraction on consumer financial outcomes, we study the effect of a major reform to Missouri's Medicaid program in 2005. This reform resulted in approximately 100,000 Missourians losing their Medicaid eligibility and lower benefit generosity for the remaining enrollees. Unlike Tennessee's Medicaid reform, in which the majority of the changes were centered on the disenrollment of a specific subpopulation from the program, Missouri's reform was much broader in scope.

In the first half of this paper, we show that the contraction of Missouri's Medicaid program led to lower Medicaid enrollment and health-care spending. Using data from the restricted version of the Medical Expenditure Panel Survey (MEPS), we first estimate that the probability of an individual in Missouri being on Medicaid declined by 4 percentage points in the years following the reform. Zuckerman, Miller, and Pape (2009) estimated that the uninsured rate in Missouri increased by 1.7 percentage points following the reform; we find point estimates in this range, though none are statistically significant when appropriately conservative standard errors are used.

\footnotetext{
${ }^{2}$ While states have substantial control of their Medicaid programs, each state's program must meet certain federal standards, such as offering certain benefits or covering certain populations. Reforms to a state's Medicaid program that would vary from the federal government standards are done via Section 1115 demonstrations (also known as Section 1115 waivers), which are approved by the U.S. Department of Health and Human Services (HHS). The waivers are intended to give states additional flexibility in designing their Medicaid programs. For more information, see https://www.medicaid.gov/medicaid/section-1115-demonstrations/about-section-1115demonstrations/index.html.
} 
We find that the Medicaid cut led to a significant 30 percent increase in OOP medical spending. Previous studies have shown that Medicaid expansions generally decrease OOP expenses for low-income populations (i.e., Medicaid-eligible populations) by 28 percent to 33 percent (Blavin, Karpman, Kenney, and Sommers, 2018; Gotanda, Jha, Kominski, and Tsugawa, 2020). Although our estimates are roughly in-line with these prior results, we focus on Missouri's overall population instead of the Medicaid-eligible population. This implies that our estimates are likely to serve as a lower bound for the overall effect on OOP expenses for the Medicaideligible population.

In the second half of the paper, we provide evidence that Missouri's Medicaid contraction led to increased financial strain for Missouri residents by using individual-level credit report data from the Federal Reserve Bank of New York Consumer Credit Panel/Equifax Data (CCP). To estimate the causal effect of the Medicaid contraction on financial health, we implement a border discontinuity differences-in-differences (DID) empirical design to compare individuals living in census blocks within a 10-mile radius on either side of the Missouri state border. Similar to other studies that have used anonymized credit bureau data, we estimate intent-to-treat (ITT) effects as we are unable to observe insurance status for the individuals in the CCP data.

Consistent with our earlier results that the Medicaid contraction increased overall OOP health-care spending, we find that individuals in Missouri had higher amounts of debt in thirdparty collections, owned more bankcards, and held higher bankcard balances. We estimate that the Medicaid contraction led to increases of 0.058 accounts in third-party collections and \$103 in debt owed to a third-party debt collector five to 10 quarters after the reform took place, which represent 21 percent and 24.6 percent increases relative to their prereform means, respectively. We also find that the number of bankcards held increased by 0.02 accounts (1 percent) in our event study specifications. Back-of-the-envelope calculations for average-treatment-on-thetreated (ATT) effects suggest that bankcard accounts owned increased by 0.096, and debt in collections increased by $\$ 494$.

Our results for debt in collections, an often-used measure of financial distress when using credit report data, are on the lower end of those reported in the prior literature. Estimates from studies on recent Medicaid expansions have found that debt in collections can be reduced by 
$\$ 390$ to \$1,231 (Finkelstein et al., 2012; Hu et al., 2018; Brevoort et al., 2020; Miller et al., 2021). Because our estimates fall in the lower end of those from previous research, we argue that financial effects from a contraction in Medicaid are asymmetric to those from an expansion. Given that losing health insurance is both qualitatively and quantitatively different than gaining health insurance, one may expect these effects to be asymmetric (Garthwaite, Gross, and Notowidigdo, 2014; Ghosh and Simon, 2015; Mazumder and Miller, 2016; DeLeire, 2019; TelloTrillo, 2021). Qualitatively, our results are consistent with those of Argys et al. (2020), who also found that individuals in Tennessee experienced worse financial outcomes after the state contracted its Medicaid program. However, our estimates are smaller than theirs, which is likely because of the different nature of each state's Medicaid contraction.

We identify two major reasons why Missouri's Medicaid contraction could be particularly informative about the potential effects of future Medicaid program cuts. First, because Medicaid has predominately expanded over time, there are relatively few studies about Medicaid contractions, and the few studies that have been done have largely focused on Tennessee's 2005 cut. $^{3}$ By adding a second case with Missouri, we can establish which results are "stylized facts" about Medicaid cuts and which are idiosyncratic effects in a single state. Second, the Missouri contraction affected populations and parts of the program that are very different from the recent ACA expansions and the 2005 Tennessee cut, which primarily affected childless adults. Instead, the Missouri cut, which contracted or eliminated specific programs and made overall coverage generally less generous, has more in common with potential future Medicaid reforms currently being discussed by various states, such as the introduction of work requirements. Given the Supreme Court's previous decisions regarding the ACA, these kinds of reforms may be more likely to be pursued in the future.

\footnotetext{
${ }^{3}$ This is in part because the population affected by the TennCare cut in 2005 (childless adults) was very similar to the population that gained access to Medicaid via the Affordable Care Act (ACA) in 2014.
} 


\section{Background and Literature}

\section{A. MISSOURI'S MEDICAID PROGRAM CONTRACTION}

After the 2001 recession, the state of Missouri faced a series of severe budget shortfalls that totaled more than $\$ 2$ billion (Kruckemeyer and Blouin, 2004). To address these budget deficits, then-Missouri Governor Matt Blunt enacted a series of cuts to social service programs, including the state's Medicaid program. On April 26, 2005, Blunt signed bill SB539 into law, which enacted a number of reforms to shrink the size of the state's Medicaid program.

Taking effect on July 1, 2005, the law led to a number of immediate changes in the Medicaid program. First, the bill required premiums of 1 percent to 5 percent of income from the Children's Health Insurance Program (CHIP) participants whose incomes exceeded 150 percent of the Federal Poverty Level (FPL) (Procter, 2005). ${ }^{4}$ These premiums rose proportionately with the income of the household. Families with incomes above 150 percent FPL and access to employer-sponsored health insurance (ESI) were made ineligible for CHIP if the monthly cost of the ESI plan was less than or equal to $\$ 335$ (Zuckerman et al., 2009). ${ }^{5}$ Income eligibility for working parents was lowered from 75 percent of FPL to 17 percent-22 percent and elderly and disabled individuals with incomes of 85 percent-100 percent of FPL lost eligibility (Ferber, 2007; Zuckerman et al., 2009). The bill also eliminated the Medical Assistance for Workers with Disabilities (MAWD) program (Procter, 2005), a Medicaid buy-in program for low-income disabled workers.

Along with eligibility changes, the bill required copayments for both an expanded range of Medicaid services and for prescription drugs for nearly all Medicaid beneficiaries. Thousands of elderly beneficiaries were shifted to spenddown-based eligibility, which required that they first spend a proportion of their own income or their own assets to receive benefits (Hargraves, 2008). Finally, a number of services, including dental and optometrist services, were no longer covered under the bill, affecting approximately 370,000 of the remaining Medicaid enrollees (Procter,

\footnotetext{
${ }^{4}$ Prior to the passage of SB539, only families with an income above 225 percent of the FPL were required to pay premiums on CHIP plans.

${ }^{5}$ This kind of policy is known as an affordability test.
} 
2005). ${ }^{6}$ As a result of the cuts, the state experienced a 14 percent decline in total monthly Medicaid enrollment, a 20 percent drop in elderly Medicaid enrollment, and an increase in uninsured emergency room visits by the end of 2006 (Zuckerman et al., 2009).

On September 18, 2007, Blunt announced a new three-phase health-care initiative called Insure Missouri, which was intended to reform the state's public insurance program and restore Medicaid coverage. Phase I of the Insure Missouri initiative was enacted on February 1, 2008, and implemented a new program called Ticket to Work, which would replace the former MAWD program and aid workers with disabilities (Shield, 2007). ${ }^{7}$ While Insure Missouri proposed a reversal of the earlier eligibility cuts and an expansion of Medicaid coverage, the new bill did not attempt to reverse the copayments clause or service cuts of the original SB539 bill, leaving the majority of the overall 2005 reform in place (Shield, 2007). Table 1 summarizes the Missouri Medicaid Reforms in 2005-2007.

\section{B. OTHER POLICY CHANGES}

In addition to the Medicaid program contraction in 2005, the state of Missouri implemented budget cuts across other state departments and programs to help shrink the state's deficit. From 2002 to 2004, the state of Missouri made significant cuts to the state's elementary, secondary, and higher education systems and to the state's corrections system. These cuts resulted in college tuition increases, reduced correctional department staff, and lower funding to regional crime labs. The state also made cuts to its social services programs in 2002-2004, including to its Medicaid program, prior to the 2005 contraction. These changes included cuts to a state family planning program, a reduction in Medicaid income eligibility for working parents, and cuts to the department of mental health. While the total dollar amount of these other reductions is quite large in aggregate, the cuts to the Medicaid program were a significant percentage of the total

\footnotetext{
${ }^{6}$ Other benefits and services that were no longer covered included hearing aids, prosthetics, wheelchairs, durable medical equipment, hospice, and rehabilitative therapy (Zuckerman et al., 2009).

${ }^{7}$ Phases II and III of Insure Missouri, which would have restored coverage for working parents and childless adults with incomes between 100 percent and 185 percent of the FPL and encouraged small businesses to provide employer-based insurance, were never implemented (Ferber, 2007).
} 
dollar value of all the state's budget cuts and made up almost the entirety of the cuts to the state's safety net programs, in terms of both dollars and number of people affected.

The budget cuts in Fiscal Year 2005, as was the case in the previous years, affected many departments and programs in Missouri. However, unlike other years, the contraction of the Medicaid program was responsible for the majority of the budget reduction in this year, accounting for approximately 84 percent of the total dollar reduction in the state budget (over $\$ 395$ million). Also similar to the budget cuts in the previous years, there were no major cuts to other safety net programs, such as the Temporary Assistance to Needy Families (TANF) program. Targeting budget cuts was primarily focused on the state's Medicaid program, suggesting that we should expect to see the majority of the effects for our sample population to come from the Medicaid contraction.

\section{MEDICAID STUDIES: MANY EXPANSIONS, FEW CUTS}

Since its inception in 1965, the Medicaid program has grown tremendously, with total state and federal spending of almost $\$ 600$ billion by 2017 . Despite the size and scope of the program, major cuts to Medicaid and associated research have been relatively rare. The majority of studies on Medicaid cuts focus on Tennessee's 2005 reform, in which approximately 170,000 individuals were disenrolled from its Medicaid program. Comparing the results from these previous studies with the body of literature on Medicaid expansions suggests that the effects from gaining and losing access to Medicaid may not be symmetric. Given that there are relatively few studies examining Medicaid cuts, studying Missouri's reform presents an opportunity to further the literature.

Compared with the Tennessee reform, there are relatively fewer studies that have taken advantage of the Missouri policy experiment. Zuckerman et al. (2009) examined what happened to both enrollees and providers in Missouri after the 2005 reform using both the CPS and administrative data. They found that after the reform, the uninsured rate increased, Medicaid enrollment declined, a larger uncompensated care burden on providers emerged, and community health clinics shifted their revenue sources to more government grants. 
Garthwaite, Gross, and Notowidigdo (2018) conduct a commuting zone-level analysis to determine the effect of this fiscal tightening on the costs of uncompensated care in hospitals. They find that uninsured visits at surrounding hospitals rise after the closure of a hospital, but insured visits do not seem to rise as dramatically, suggesting insured visits are more discretionary than uninsured visits. This result is tested using Missouri data from the Current Population Survey (CPS). The paper's use of the Missouri reform is rather limited, however, as the authors use it more as a case study. Overall, the authors argue that the policy changes described previously do have an impact on the uninsured population.

For the Tennessee case, studies have shown that individuals affected by that Medicaid reform also experienced worse outcomes afterward. Ghosh and Simon (2015) use data from the Agency of Healthcare Research and Quality's (AHRQ) State Inpatient Database and find that the share of hospitalizations covered by Medicaid decreased, while the share of uninsured hospitalizations rose by nearly 61 percent, largely because of emergency department visits, and are not linked to a lack of preventive care. Tarazi, Green, and Sabik (2017) also find that the Tennessee Medicaid disenrollment decreased access to care and insurance coverage for lowincome nonelderly adults. Similar to Ghosh and Simon (2015), Tello-Trillo (2021) finds that the TennCare disenrollment led to worse self-reported health and decreased the number of visits to a primary care physician. He also finds evidence of decreased and delayed access to medical care, with approximately 30 percent of individuals affected by the reform changing their primary place of care. Deleire (2019), using data from the Survey of Income and Program Participation, confirms the previous findings that the Medicaid cut led to worse self-reported health and worsened access to care. Similar to the other studies, he also finds that doctor visits and dental visits declined after the TennCare reform.

While the literature documents that both contractions and expansions of Medicaid coverage have significant effects on the health and finances of affected individuals, there is little evidence that these effects are symmetric. For example, Garthwaite et al. (2014) find that the Medicaid cut in Tennessee led to a large increase in labor supply: A 6.9 percentage point increase in the proportion of childless adults without public insurance led to an increase in employment of up to 5.7 percentage points. The authors find that 97 percent of the change in employment is 
explained by workers working for private employers who provide ESI. In contrast, Ham and Ueda (2021) and DeLeire (2019) separately conduct updated analyses of the TennCare disenrollment and find that the Garthwaite et al. (2014) results are sensitive to both the choice of data used in the analysis and the type of standard errors used to conduct statistical inference. The two papers conclude that there is a large amount of uncertainty regarding the impact of the TennCare Medicaid change and that a zero effect of the TennCare disenrollment on employment cannot be ruled out. Similarly, Baicker, Finkelstein, Song, and Taubman (2014) find that individuals who received Medicaid coverage through the Oregon health-insurance experiment did not experience a change to their labor force participation or to their earnings. However, it is unclear if this difference in labor outcomes is because of an asymmetric effect of Medicaid expansions and contractions, the difference in the affected populations, since Oregon's expansion was below the FPL, while Tennessee's cut included incomes between 100 percent and 175 percent FPL, or to other state-level idiosyncrasies. Earlier expansions that targeted pregnant women led to sizable decreases in employment (Dave, Decker, Kaestner, and Simon, 2015), which may imply that differences may be driven by certain subpopulations.

\section{MEDICAID AND FINANCIAL DISTRESS}

The recent literature on the effect of Medicaid expansions on individual financial outcomes is most relevant to this study. Several studies have estimated how the ACA's Medicaid expansions affect individuals' financial health. Medicaid eligibility has been shown to reduce bankruptcies, mostly among low-income and high-childhood neighborhoods (Gross and Notowidigdo, 2011). Catastrophic medical expenditures drastically decrease after individuals gain access to Medicaid (Baicker et al., 2013), and individuals may be able to take fewer payday loans (Allen, Swanson, Wang, and Gross, 2017). Hu et al. (2018) use a synthetic control method and data on individual credit outcomes and find that ACA's Medicaid expansions led the average recipient to owe $\$ 1,140$ less in debt in collections. Brevoort et al. (2020), using similar data and a DID empirical strategy, find a similar reduction of medical debt in collections of $\$ 1,231$ per new Medicaid recipient. They further emphasize that Medicaid brings as much value to households in the form of improved credit and the ability to borrow at lower interest rates as it does in direct reduction of OOP health 
expenditures. Miller et al. (2021) focus on Michigan's ACA Medicaid expansion and find a smaller $\$ 515$ reduction in debt in collections per new Medicaid recipient. The smaller estimate for the decline in debt in collections may be attributable to their ability to link credit report data to administrative data on Medicaid enrollment.

While previous literature makes it clear that receiving free or subsidized health insurance improves the finances of recipients, the more difficult question is whether recipients value this insurance above its cost. Finkelstein, Hendren, and Luttmer (2019) find that the average Medicaid recipients value Medicaid substantially less than they would value the cash spent to provide them with Medicaid, and that up to 60 percent of the value of Medicaid functions as a transfer to providers for the uncompensated care they would otherwise provide. Like most other recent empirical work on Medicaid, Finkelstein, Hendren, and Luttmer (2019) focus on an expansion of Medicaid to low-income nondisabled adults, and their results do not necessarily apply to other populations.

Argys et al. (2020) is the paper most similar to ours, which is the only previous study to estimate the effect of a Medicaid contraction on individual financial outcomes. Using individuallevel data on credit and debt outcomes, the authors find that credit scores declined in counties that had more Medicaid recipients relative to counties with fewer recipients following Tennessee's 2005 Medicaid cut. In some specifications, they find increases in delinquent debt and personal bankruptcy. Given that theirs is the first paper to analyze the individual financial effects of a Medicaid cut, we view our contribution as continuing the process of determining the extent to which the financial distress of such contractions is generalized (rather than a function of a particular place and time). Argys et al. (2020) focus solely on measures of distress, such as Risk Score and delinquent accounts, while we consider more broad measures of an individual's finances, such as the number of credit cards or amount of card debt.

\section{Medicaid Coverage and Medical Expenditures Analysis}

\section{A. MEDICAL EXPENDITURE DATA AND EMPIRICAL APPROACH}

To analyze the effect of the Missouri Medicaid contraction on consumer financial outcomes, we first establish that medical expenditures changed as a result of the reform. To do this, we use 
data from the Household Component of the Medical Expenditure Panel Survey (MEPS), which surveys about 40,000 individuals per year with extensive questions on their health spending, health status, health insurance, and demographics. We use the restricted version of the MEPS, which has information on the state of residence for each respondent, allowing us to identify individuals in the data who were subject to the Missouri Medicaid contraction. ${ }^{8}$ We use MEPS data to study the effect of the Missouri cuts on Medicaid receipt and on a number of different measures of health spending.

Table 2 shows the summary statistics for our variables of interest and our control variables. Our summary statistics show that Missouri is generally similar to the rest of the country and to its border states, with its largest observed difference being a smaller Hispanic population. Medicaid recipients, by contrast, are quite different from nonrecipients along almost every measure. In particular, the Medicaid population includes a larger fraction of children, which skews many measures down, for example, age, educational attainment, and proportion married. Appendix Table 1A provides the summary statistics for these variables before and after the Missouri Medicaid contraction.

Because we lack the detailed individual-level geographic information of the consumer credit data set we use in the following section (though benefiting from more extensive demographic controls), our MEPS analysis employs a simple state-level (DID) empirical strategy that compares individuals residing in Missouri with individuals living in other neighboring states before and after the Missouri Medicaid cut. We exclude Tennessee from the control group because it also reformed its Medicaid program in 2005. Our DID specification takes the following form:



$$
\begin{aligned}
& +\phi X_{i s t}+\epsilon_{i s t} \text {. }
\end{aligned}
$$

\footnotetext{
${ }^{8}$ The publicly available version of the MEPS does not include information on the state of residence for respondents. For information on the difference between the restricted and publicly available version of the MEPS, see https://meps.ahrq.gov/data stats/onsite datacenter.jsp.
} 
$\sigma_{s}$ is a vector of state fixed effects (FEs), $\tau_{t}$ is a vector of year FEs, and $X_{\text {ist }}$ represents individuallevel demographics (gender, race, ethnicity, education, marital status, family size, and age dummies). $\beta_{1}$ is our coefficient of interest, representing the treatment effect of living in Missouri in the years after the 2005 Medicaid cut. We consider several dependent variables $y_{i s t}$ : dummy variables indicating insurance status (Medicaid, Uninsured), the natural log of several healthspending measures (total health spending, Medicaid spending, and OOP (self/family) health spending), and a dummy indicating whether the individual had any OOP health-care spending. All regressions use MEPS-provided person weights. ${ }^{9}$

The common approach for estimating standard errors in DID studies that use state-level policy changes is to use cluster-robust standard errors (Bertrand, Duflo, and Mullainathan, 2004). However, this poses a number of challenges in our empirical setting because we have very few clusters in our data sample (eight states in total), and only one of these clusters receives treatment. It is well known that statistical inference in situations with few clusters is challenging and requires different methods other than the standard cluster-robust standard errors (Cameron and Miller, 2015; MacKinnon and Webb, 2018). Given that we have few clusters and that the size of the clusters is not equal (see Appendix Table $\mathbf{3 A}$ ), traditional standard error calculations are likely inappropriate, as we do not meet the necessary assumptions of large number of clusters. ${ }^{10}$ To estimate proper standard errors, we follow Garthwaite et al. (2014) and Tello-Trillo (2021) and use a version of their modified block-bootstrap procedure. This is a two-stage resampling procedure where we first sample states with replacement, then we resample individuals within each state (when the set of resampled states includes Missouri). In Appendix B, we present results of a series of Monte Carlo simulations to provide evidence of the appropriateness of this modified block-bootstrap method relative to other methods of estimating standard errors, since we have less than half the number of clusters in the Garthwaite et al. and Tello-Trillo studies. The results from our simulations show that our modified block-bootstrap procedure produces

\footnotetext{
${ }^{9}$ To test if our results are sensitive to the use of sample weights, we conduct a robustness check where we do not include the MEPS sample weights. Results from this test are in Appendix Table 2A.

${ }^{10}$ Wild bootstrap techniques require that cluster sizes should be equal. Randomization inference performs poorly when the size of the treated cluster is larger or smaller than the average control cluster and may not be valid (MacKinnon and Webb, 2020).
} 
rejection rates closer to the target of 5 percent when compared with the other standard errors estimation methods. ${ }^{11}$

\section{B. RESULTS}

We also conduct event-study analyses that interact the Missouri dummy with a vector of year dummy variables from 2000 to 2007, rather than only interacting it with a post-2005 dummy variable as in the standard DID framework. This allows us to consider whether any trends in insurance coverage or health spending in Missouri relative to control states existed prior to the 2005 cut, though we should note that the MEPS is not well powered for single years in Missouri, especially compared with the credit bureau data set we use in the next section. Our event study results are shown in Figure 1.

For our five dependent variables of interest, we see little evidence of statistically significant pretrends. The event study estimates for the postcontraction years indicate that Medicaid enrollment and spending decreased following the reform, while OOP spending seemed to increase, especially in the second full year after the contraction. We also note that our event study estimates are statistically significant for Medicaid enrollment and OOP medical spending in 2007 only, which is not surprising given the potential power issues we mentioned previously. To overcome this power issue, we estimate Equation (1) with the simple postreform dummy variable that is equal to one, if the year occurs after the Medicaid contraction instead of the vector of year dummies used in the event study analysis.

Table 3 summarizes our DID estimates based on the specification in Equation (1). This table shows the direct effect of the Medicaid contraction: a significant 3.9 percentage point (pp) decline in Medicaid receipt. Our point estimates also show a 2.2pp increase in the uninsured rate and an 18 percent drop in Medicaid spending, though these estimates are not statistically

\footnotetext{
${ }^{11}$ We also note that the procedure outlined by Conley and Taber (2011) (hereafter, CT) does not apply to our empirical setting because their method is only valid when the number of control clusters approaches infinity (Hagemann, 2020). CT present evidence that their procedure has good finite sample properties with the number of groups equal to as low as $\mathrm{G}=42$ (their Monte Carlo simulations are done with $\mathrm{G}=50$ ), while Ham and Ueda (2021) argue that they can use the $\mathrm{CT}$ procedure with $\mathrm{G}=16$ when reanalyzing the TennCare disenrollment. Since we only have eight groups in our setting, it is highly unlikely that we have large enough $G$ to for us to have asymptotically valid CT estimates.
} 
significant. We find that OOP spending increased by a significant 30.3 percent, while the change in total health spending is positive but not statistically significant. This increase in OOP spending is primarily along the intensive margin, as the proportion of individuals reporting any OOP spending showed no significant change and a modest $1.7 \mathrm{pp}$ point estimate. Overall, these results indicate that Missouri residents were less likely to be covered by Medicaid and incurred higher OOP health-care expenditures after the reform. Given both of these results, we may expect overall financial outcomes to be worse for Missouri residents.

In addition to our main results, we perform several heterogeneity analyses to examine the impact of the reform on specific demographic groups we may expect to be affected by the Medicaid cut in Missouri. First, we report results for households with children. Because of the reduction in Medicaid eligibility for working parents, along with the introduction of new premiums and the affordability test for CHIP participants, we may expect to see significant effects for households with children, which is different than the Tennessee cut where only childless adults were affected. These results are reported in Appendix Table 4A. Relative to our main results, households with children experienced a larger decline in the probability of receiving Medicaid (5.9pp versus 3.9pp). Point estimates suggest an increase in the probability of being uninsured and higher OOP medical spending, but these results are not statistically significant. We note that in any heterogeneity analysis such as this that drops a large group, the smaller sample size amplifies any issues with statistical power.

In Appendix Table 5A, we report results restricting our sample to only include individuals under the age of 65. Though the Medicaid cut affected all low-income adults, older adults eligible for both Medicare and Medicaid (ages 65 and older) may have responded differently to the cut than adults who were eligible for Medicaid, but not yet eligible for Medicare (under the age of 65). ${ }^{12}$ We find that for adults younger than 65 , the Medicaid contraction had similarly sized effects on the likelihood of having Medicaid when compared with the effects for our full sample of all adults. For our spending variables, we observe that for adults younger than 65, OOP medical

\footnotetext{
${ }^{12}$ Specifically, we may expect that older adults who were eligible for both Medicare and Medicaid were less exposed to the Medicaid program cut since the majority of dual-eligible individuals would not have lost all access to health insurance.
} 
spending and total medical spending increase by a larger magnitude than for our full sample of all adults. This suggests that the Medicaid cut resulted in larger increases in medical spending for adults younger than 65 than for adults older than 65 . That adults younger than 65 experienced larger increases in medical spending relative to our full sample of all adults, despite both groups losing Medicaid at similar rates, suggests that younger adults were more adversely affected by the cut than older adults.

We also estimate a series of additional regressions to test if our main results are robust to alternate model choices. Results from reestimating Equation (1) without any individual control variables are reported in Appendix Table 6A and Figure A5. Although our summary statistics in Table 1 (and in Appendix Table 1A) generally do not show significant differences between individuals in the treatment and control states, we do note there are differences in race between the two groups. While our identification strategy should account for these level differences (assuming both Missouri and our control states have similar trends), we can test the sensitivity of results to the inclusion of these controls. The results from this robustness check are similar to our main results in Table 3, though they are larger in magnitude and the decline in Medicaid spending becomes statistically significant.

In Appendix Table 2A, we show the results of our main analysis with no sample weights; these results are broadly similar to our baseline results, showing a significant 3.5pp decline in Medicaid receipt and a 27.4 percent increase in OOP spending. We next perform a placebo test, checking whether our regressions find any significant effect on the 2005 Medicaid on demographics. Since Medicaid cuts likely should not produce significant changes to demographics on the two-year timescale we observe, these effects should be statistically insignificant. As Appendix Table 7A and Figure A6 show, this is generally what we find, though we do find a marginally significant 2 percent increase in the Hispanic population. Finally, we estimate regressions where we use nonlogged versions of our continuous variables. These results, shown in Appendix Table $\mathbf{8 A}$ and Figure A7, show a significant $\$ 150$ increase in OOP spending, with no significant effect on Medicaid or total health spending, which is consistent with our main results where our continuous variables are in logs. 


\section{Credit Panel Analysis}

\section{A. CONSUMER CREDIT DATA AND EMPIRICAL APPROACH}

To measure the effect of the Missouri Medicaid cuts on consumer financial outcomes, we use the Federal Reserve Bank of New York Consumer Credit Panel/ Equifax data (CCP), which is a 5 percent random and anonymized sample of all U.S. consumers with a credit bureau file from 1999 to the present. Individuals in the CCP are followed at a quarterly frequency and remain in the data set until they die, change their Social Security number, or no longer have a credit bureau file, which typically happens after an extended period of inactivity with the credit market. ${ }^{13}$ We construct our data set by taking all individuals living in Missouri and its neighboring states from Q1:2003-Q4:2007 in the CCP and excluding some geographies as described in the next paragraph. We exclude earlier years of data to avoid any effects from the 2001 recession, and we end our data in 2007 to avoid the effects of the Great Recession of 2008. We compute age for each individual based on the year of birth in the CCP. We match the CCP with the county-level demographic data from the BLS's Local Area Unemployment Statistics, the Census Bureau, the Small Area Income and Poverty Estimates, and the Old Age, Survivors and Disability Insurance data.

To account for geographic heterogeneity, we focus on individuals in the CCP who live in census blocks within a 10-mile bandwidth around the Missouri border to define treatment and control regions. We assign individuals who reside in Missouri census blocks within the 10-mile bandwidth to the treatment group and assign any individuals living in non-Missouri census blocks within the 10-mile bandwidth of the Missouri border to the control group. As mentioned previously, we exclude individuals who reside in Tennessee from the control group because Tennessee enacted its own Medicaid reform in 2005. Including individuals from Tennessee in the control group could potentially bias our results. Figure 2 illustrates this design, with the treatment group census blocks shaded in orange and the control group census blocks shaded in black. Our identifying assumption is that, in the absence of the Medicaid contraction, our credit

\footnotetext{
${ }^{13}$ See Lee and van der Klaauw (2010) for a more detailed overview of the CCP.
} 
variables would have evolved similarly on either side of the Missouri border. Our final sample is an unbalanced panel of 163,462 individuals with 3.08 million total observations.

Our main credit report variables of interest are the total number of bankcard accounts an individuals has, the total balance on those bankcard accounts, the amount of bankcard debt that is delinquent, the number of accounts that have been send to a third-party debt collector, the amount of debt that is owed to a third-party debt collector, and the individual's credit score. ${ }^{14}$ Table 4 provides summary statistics for these variables and for our control variables, and Appendix Table 9A provides similar summary statistics for the prereform period, Q1:2003Q2:2005. We also compare summary statistics for individuals in Missouri's border areas and nonborder areas in Appendix Table 10A and find these two groups to be similar along many dimensions, except for the percent of the population that is Black, which is larger in the border areas than the nonborder areas.

For the most of control variables, there are small economic differences between individuals living in Missouri border census blocks and non-Missouri border census blocks. The notable exception is the percent of the population that is Black, where Missouri border census blocks have double the Black population that of non-Missouri border census blocks (18 percent versus 9 percent, respectively). As a robustness check, in Section IV.E, we create a new subsample of our data by restricting the treatment and control areas to the 10-mile bandwidth of the Missouri border in the two largest metropolitan areas in Missouri, which are split by the state border: Kansas City and St. Louis.

Figure 3 shows the trends in broad economic conditions between our treatment and control areas. Similar to the statistics reported in Table 4, there are similar trends for the unemployment rate for border counties in Missouri and the surrounding states. Although countylevel statistics for income or GDP are not available for this period, Panel B of Figure 3 shows that state-level per-capita personal income had a similar trend in Missouri and the U.S. prior to the reform.

\footnotetext{
${ }^{14}$ Our credit score measure is the Equifax Risk Score, which is a proprietary credit score produced by Equifax that is similar to other risk scores used in the industry.
} 
To estimate the effects of the Medicaid cut on individuals' financial outcomes, we employ a DID framework that uses the policy discontinuity at the Missouri state border to compare individuals in Missouri with individuals living in states that border Missouri. Our estimating equation takes the following form:

$$
y_{i t}=\alpha_{0}+\boldsymbol{\beta}\left(\text { Treated }_{i} \times \tau_{t}\right)+\alpha_{1} \text { Treated }_{i}+\gamma \tau_{t}+\phi X_{i t}+\mu_{i}+\epsilon_{i t},
$$

where Treated ${ }_{i}$ is equal to one if an individual lives in a Missouri census block within the 10-mile bandwidth and $\tau_{t}$ is a vector of quarter dummy variables from Q1:2003 to Q4:2007. We use the second quarter of 2005, the quarter before the policy change implementation, as the base period. The vector $X_{i t}$ includes a second-order polynomial in age, county-level unemployment rate, the percent of the population at or below the FPL, the percent of the population that is disabled, and the percent of the population that is Black. Since the CCP is an individual-level longitudinal data set, we are also able to include individual fixed effects $\mu_{i}$. The coefficients of interest are captured in the vector $\beta$, which contains the estimates for each quarter before and after the policy change. Similar to our MEPS analysis, we implement our modified blockbootstrap procedure to estimate the appropriate standard errors. Because the CCP is a panel data set, we modified the two-stage resampling procedure so that in the second stage, we resample entire panels (i.e., all observations of an individual that is resampled) instead of individual observations like we did in the MEPS data.

In addition to the event study model in Equation (2), we estimate a traditional DID specification in which we interact the Missouri dummy with a single dummy variable for the postreform period (Q3:2005 to Q4:2007). Our estimating equation is now:

$y_{i t}=\alpha_{0}+\alpha_{1}$ (Treated $_{i} \times$ Post $\left._{t}\right)+\alpha_{2}$ Treated $_{i}+\gamma_{1}$ Post $_{t}+\phi X_{i t}+\mu_{i}+\epsilon_{i t}$.

All control variables in this specification are the same as in Equation (2), and we estimate our standard errors via our modified block-bootstrapped procedure. 


\section{B. RESULTS FOR CREDIT OUTCOMES}

Figure 4 shows the event study results from Equation (2) for our six credit variables of interest. ${ }^{15}$ Similar to our MEPS regressions in Section III, we use these event study results to assess if our data meet the parallel trends assumption, which is a necessary condition for our regression models to estimate causal effects. We do not observe evidence of pretrends in our credit outcomes, though we do note that our preperiod results for both amount of delinquent bankcard debt and amount of debt in third-party collections are imprecisely estimated (Panels C and E, respectively).

Panel A of Figure 4 shows that credit card balances increase by $\$ 100-\$ 140$ (2.4 percent3.3 percent) in the first year after the reform and continue to grow to $\$ 200$ (4.8 percent) by the second year (though these estimates are not significant), while the number of credit cards increases by $0.01-0.02$ (0.5 percent-1 percent). Unlike credit card balances, the number of credit cards owned (Panel B) declines in the second year after the reform. Point estimates for the amount of delinquent credit card debt (Panel C) are also positive but not statistically significant.

In Panel D of Figure 4, we see that in the four quarters immediately after the Missouri Medicaid contraction, there is an increase in the number of accounts in third-party collections by up to 0.03 accounts, which represents an approximately 10 percent increase relative to the prereform treatment group mean. Panel E shows that the amount of debt in third-party collections does not increase statistically significantly until first quarter 2007. In the five to 10 quarters after the reform, the number of accounts in third-party collections and the amount of debt in third-party collections are both significantly higher, with the number of accounts in thirdparty collections increasing by 0.08 and the amount of debt in collections increasing by almost $\$ 170$. Relative to the prereform average, this change in accounts in third-party collections represents a 29 percent increase, and the increase in debt in collections is a 41 percent change. We also observe a decrease in Risk Score in Panel F, which becomes statistically significant by 2007.

\footnotetext{
${ }^{15}$ Exact coefficient and standard error estimates are provided in Appendix Table 17A.
} 
It is worth noting that, during our sample period, some unpaid medical bills would go straight into third-party collections, which could appear on an individual's credit report in a short period of time. In contrast, if consumers with access to credit cards pay medical bills with their cards, we may expect delinquent debt on credit cards to increase with a lag. This could occur if consumers first obtain new credit cards and increase their credit card balances by paying medical bills, and then gradually default on these credit cards over time. Our empirical results in Figure 4 are consistent with this story, as we find that credit card debt and third-party collections increase more quickly than delinquent credit card debt after the reform.

Table 5 shows our standard DID results, with the top panel reporting results for the entire postreform period and the bottom panel reporting results when the postreform period is split into two periods. ${ }^{16}$ In the top panel, we find that in the 10 quarters after the Medicaid reform was implemented in June 2005 (from Q3:2005 to Q4:2007), individuals living in Missouri border census blocks had 0.017 more bankcard accounts and had \$113 higher bankcard balances; however, these estimates are not statistically significant. Consistent with our event study results, the fourth column in Table 5 shows that the number of third-party collections increased by a statistically significant 0.042 accounts.

However, it is clear from our event study results in Figure 4 that the effect of the Medicaid contraction on our financial outcomes grows over time. To better disentangle the short-run and longer-run effects of the policy change, we report separate DID effects for the first four quarters after the contraction was implemented, from Q3:2005 to Q2:2006 (the short run), and for the final six quarters of our sample, Q3:2006 to Q4:2007 (the long run). Results from these regressions are reported in the bottom panel of Table 5 . In the four quarters immediately after the Medicaid contraction, we see increases in credit card borrowing and the number of accounts in third-party collections, though none of the estimates is statistically significant. For the longerrun effects (five to 10 quarters after the reform), we see that bankcard balances and the number of accounts in third-party collections increase by larger magnitudes ( $\$ 147$ and 0.06 accounts,

\footnotetext{
${ }^{16}$ As a robustness check, we report results for specifications with county fixed effects and tract level clustering of standard errors in Appendix Figure A1 and Appendix Table 11A. Overall, these results are very similar to our main results in Table 5.
} 
respectively) than in the short run. In addition, we find statistically significant changes in the amount of debt in third-party collections $(\$ 103)$ and Risk Score $(-1.18)$ in the long-run period. ${ }^{17}$

Overall, these results are generally similar to those reported in Argys et al. (2020), though there are important differences between our studies and theirs. For measures of financial distress, our results are broadly in-line with Argys et al. in that shrinking a state's Medicaid program results in increased financial distress. However, the effects we estimate for Missouri's Medicaid contraction are both smaller in magnitude and are not as robust across our different measures when compared with Tennessee's policy change. For example, we do not find a statistically significant effect on delinquent bankcard debt and the effects for debt in collections and Risk Score occur with a significant lag. This is in contrast with the results from Argys et al., who find larger, statistically significant effects for Risk Score and delinquent debt that occur immediately after the TennCare disenrollment.

There are multiple reasons why our results may differ from theirs. First, our study uses a different empirical strategy than theirs, with the Argys et al. study only using a within-Tennessee variation to estimate a dose-response DID model, while ours uses an across-state variation using the canonical DID framework. Another reason for the differences is that the TennCare policy change was specifically a disenrollment of existing beneficiaries, with 170,000 childless adults losing Medicaid coverage, while the Missouri contraction was primarily a cut to benefit generosity that was combined with a disenrollment of specific subpopulations. Although significantly more individuals were disenrolled in the Tennessee Medicaid cut, all Medicaid beneficiaries were affected by the Missouri cut. If the disenrollment is the more significant of the policy changes, subsequently leading to even worse financial outcomes, we may expect to see larger effects because of the Tennessee cut than the Missouri cut.

To further examine this, we summarize the effects of several pre-ACA Medicaid changes (both expansions and contractions) in Appendix Table 14A by examining the number of individuals affected and the change in state-level Medicaid spending one year after the policy change. While the Missouri cut is relatively large in scope, with more than 470,000 people

\footnotetext{
${ }^{17}$ We also report results for additional financial distress variables in Appendix Tables $12 \mathrm{~A}$ and $13 \mathrm{~A}$ and Figure A8. We find some effects on the share of card balance severely delinquent, but these results are not robust.
} 
affected, we can see that in terms of Medicaid spending, it is one of the smallest pre-ACA policy changes, with the state experiencing a 3 percent decline in total Medicaid spending. In comparison, the Tennessee cut resulted in a 16 percent decline in state-level Medicaid spending. This is supporting evidence that the Tennessee cut was larger in magnitude, which is consistent with our results being smaller than those from the Argys et al. (2020) study. It is also important to note that, although our results differ, they do not necessarily contradict each other because of these differences in the scope of the two policy changes.

\section{ROBUSTNESS CHECKS}

To assess the stability of our main findings reported in the previous section, we conduct a number of robustness checks. Overall, our results are quite similar across specifications, which provides evidence that they are not driven by any specific modeling or sampling choices.

\section{C.1. EXCLUDING MOVERS}

If individuals decide to move in or out of Missouri because of the policy change, our results would be biased because of individuals selectively sorting into other states of residence. To test whether our results are sensitive to the inclusion of these individuals, we restrict our sample so that it only contains individuals who did not change their state of residence during our sample period and reestimate Equation (2). Event study results are reported in Appendix Figure $\mathbf{A} 2$ and are not significantly different from our main results.

\section{C.2. BALANCED PANEL}

In our main analysis, we did not require each individual to be present in every time period in our sample. If individuals are not present during specific time periods for nonrandom reasons (i.e., individuals selecting to stop interacting with the formal credit market and subsequently dropping out of the data), this would cause our results to be biased. Similar to our previous analysis in which we removed individuals who moved from Missouri and non-Missouri border regions during our sample period, we now restrict our analysis sample to consist only of individuals who are present in the data in all quarters from Q1:2003 to Q4:2007 and reestimate 
Equation (2). Event study results are reported in Appendix Figure A3 and are not meaningfully different from our main results.

\section{C.3. EXCLUDING INDIVIDUALS AGES 65 AND OLDER}

In all our previous analyses, we have included all adults ages 18 and older in our analytical sample, including older adults who are eligible for Medicare. However, older adults who are eligible for both Medicare and Medicaid may respond differently to the Medicaid cut than adults who are not eligible for both. This is because individuals who are dual eligible would not be at risk of losing insurance coverage because of the Medicaid cut, though they could be at risk of decreased benefits/increased cost sharing. To test if our results are sensitive to the inclusion of these individuals, we exclude all observations for individuals who are ages 65 and older from our sample and reestimate Equation (2). Results from these regressions are presented in Appendix Figure A4 and are very similar to our main results.

\section{C.4. Additional Heterogeneity Cuts}

We report our main DID estimates based on Equation (3) for the subsamples covered in Section IV.C and additional subsamples in Appendix Table 15A. This table shows that most effects are larger and statistically significant for subpopulations more likely to be affected by the Medicaid cut. For example, the effects on the number and amount of third-party collections and Risk Score are larger and significant for individuals younger than 65 compared with people older than 65 . Regions with above-the-median proportion of Black residents experience larger increases in card debt and collections and a decrease in Risk Score compared with regions with below-the-median proportion of Black population. We find similar results for regions with above-the-median share of disabled individuals, above-the-median poverty, and above-the-median unemployment, all of which are more likely to be affected by the Medicaid cut. The last two rows of Appendix Table 15A indicate that the effects of the cut are stronger in Kansas City and St. Louis, which is as expected because urban populations are more likely to rely on Medicaid. 


\section{AVERAGE TREATMENT EFFECTS AND POTENTIAL ASYMMETRY OF MEDICAID EXPANSIONS AND CONTRACTIONS}

Since we do not observe Medicaid status for individuals in the CCP, the estimates in Figure 4 and Table 5 are ITT effects. Because our ITT estimates average over individuals both affected and unaffected by the Medicaid program cut, we divide our DID coefficients by the percent of the population that was eligible for Medicaid in Missouri to generate a back-of-the-envelope estimate of the treatment effect. We use county data on the number of people eligible for Medicaid in Fiscal Year 2004 from the Missouri Department of Social Services and census data on county population to estimate the share of population eligible for Medicaid in Missouri border counties before the cut. The average percent of the population that was Medicaid eligible across all Missouri border counties in 2004 was 20.84 percent. $^{18}$

Using this Medicaid eligibility rate and results from our event study specification, we estimate a back-of-the-envelope average-treatment-on-the-treated (ATT) effect for the number of credit cards of $\frac{0.025}{0.2084}=0.12$ accounts. The $\$ 103$ estimate for debt in collections in the longrun period implies an ATT estimate for individuals with Medicaid of $\frac{\$ 65}{0.24}=\$ 494$. The estimates for the accounts in third-party collections imply an ATT effect of 0.20 additional accounts, though our long-run DID estimate implies an ATT of 0.278 accounts. Since we are considering all Medicaid enrollees, this increase in collections would be for both Medicaid recipients whose insurance became less valuable and for those who fully lost Medicaid.

While this increase in debt in third-party collections is sizable, it is relatively smaller in magnitude than the declines in third-party collections resulting from Medicaid expansions as reported by Hu et al. (2018), who found a decrease of $\$ 1,145$ after the ACA Medicaid expansion in 2014, and Brevoort et al. (2020) who found a decrease of \$1,231 in medical debt in collections after the ACA's Medicaid expansion. Our estimates are similar to those reported by Finkelstein

\footnotetext{
${ }^{18}$ Additional information on the data from the Missouri Department of Social Services is available here and information on the U.S. Census population is available here. To calculate the percent of Missouri's population that was Medicaid eligible in 2004, we first estimate the population of each border county in January 2004 by taking the simple average of the July 2003 and July 2004 census population estimates. We then divide the number of Medicaid-eligible individuals in each county by the estimated county population. Finally, we take a simple average of the share of the total population that is Medicaid eligible across all Missouri border counties.
} 
et al. (2012), who found a decrease of $\$ 390$ in debt in collections for individuals who received Medicaid in the Oregon health-insurance experiment and Miller et al. (2021), who found a decline of $\$ 515$ for individuals who enrolled in Medicaid in Michigan. Since our ATT estimate falls within the lower end of the range of previous results for debt in collections, we cannot completely rule out possible symmetric financial effects of Medicaid contractions and expansions. However, given that the majority of the prior literature finds larger effects, our results may suggest that the effect of a Medicaid program cut is smaller than the effect of an expansion of Medicaid for debt owed to third-party debt collectors.

There may also be financial spillover effects of the reform on non-Medicaid recipients. Only about half of the value of Medicaid accrues to its recipients, with the rest covering care that would otherwise be provided without full compensation, or would be covered by family, friends, or charities (Finkelstein et al., 2019). If friends and family members help cover medical bills of former Medicaid recipients in postreform Missouri, this could potentially lead to lower relative incomes for those individuals attempting to help out. In turn, this could lead these other groups to borrow more and have more trouble paying back debt, just as Medicaid recipients would. While the lower Medicaid spending could have lowered taxes in a way that benefited nonrecipients, much of this benefit would accrue to those outside of Missouri. At least half of Medicaid funding comes from the federal rather than state government, and this share in Missouri was 62 percent as of 2006 (Ferber, Bednarek, and Islam, 2005).

We chose to end our analysis in 2007 because of the partial Medicaid restoration in 2008 (Shield, 2007) and because of the difficulty of separating the effects of the Medicaid cut from state-specific effects of the Great Recession. However, even if the recession did not hit Missouri especially hard in conventional terms, an economic shock could still affect Missouri disproportionally if it lacked the safety net that other states have. In other words, the effect of a Medicaid cut becomes more severe when an economic crisis decreases incomes in a way that would have made more people eligible for Medicaid, except for the cut.

While we cannot credibly measure the longer-run effects of the cuts, we expect the effect of such a cut on some outcomes to persist or possibly grow over time. Although the reform first took effect in 2005, its effect is a continuous flow as people no longer receive benefits that were 
worth thousands of dollars per year, each year after the reform. Our credit measures, by contrast, are stock measures. For example, debt could gradually increase each year that Medicaid is not there to cover medical bills.

\section{E. BORDER CITY ANALYSIS}

In our main analysis, we compare census blocks near the Missouri state border with neighboring state census blocks on the other side of the border and find evidence of worse financial outcomes for Missouri residents because of Medicaid cuts. However, since Medicaid coverage differs in rural areas and urban areas in Missouri during our sample period (Zuckerman and Cook, 2006), if we include both rural and urban census blocks together in the treatment and control groups, this may lead us to less reliably estimate the causal effects of the Medicaid cut (Dube, Lester, and Reich, 2010).

To address this concern, we focus on the two largest urban areas in Missouri: Kansas City, and St. Louis, which straddle the Missouri state border. ${ }^{19}$ Similar to the full-border analysis, we select census blocks within a 10-mile bandwidth of the state border. Focusing on Kansas City and St. Louis (KC/STL) ensures that we have enough observations to credibly estimate our DID event study coefficients. ${ }^{20}$ Figure 5 shows the geographic breakdown of the two cities by census tract.

Similar to our main analysis of the full Missouri border, we estimate both an event study model and a traditional DID model with a single postreform dummy variable using Equations (2) and (3), respectively. Because we only have three clusters of varying size when using the border cities (one treated state, two control states), any established clustering method is unlikely to

\footnotetext{
${ }^{19}$ Part of the Kansas City MSA is in Kansas, and part of the St. Louis MSA is in Illinois.

${ }^{20}$ Although Zuckerman and Cook (2006) show that Medicaid coverage was less prevalent in Kansas City and St. Louis than in the rest of the state (11.6 percent versus 19.5 percent, respectively), 58 percent of the state's population resided in these cities. This disparity is even more evident in our CCP border sample, where approximately 75 percent of all observations are in the Kansas City and St. Louis (KC/STL) MSAs. Although a higher percentage of the noncity population received Medicaid coverage, because the CCP is a 5 percent random sample of individuals with a credit report, the likelihood we would observe a noncity individual with Medicaid is actually lower than the likelihood of observing an individual with Medicaid living in either of the two cities.
} 
produce valid results. ${ }^{21}$ Therefore, we present our results using a variety of different standard error methods, including a standard bootstrap procedure, in Appendix Table 16A. We find that tract-level clustering produces the most conservative (i.e., the largest estimated) standard errors of any of the procedures we use. Therefore, we present our results with this method in the main text and report our estimates with other methods in Appendix Table 16A. Our border city event study results are presented in Figure 6, and our DID results with standard errors clustered at the census-tract level are shown in Table 6.

For our event study results, the overall trends are generally similar to those in the main analysis, though the immediate response to the Medicaid contraction are more visible in the border cities analysis. As in our main analysis, we do not observe evidence of pretrends in our credit outcomes. However, unlike our main results, our estimates are more precisely estimated in the border city analysis.

In the first four quarters after the Medicaid contraction, we see that the number of accounts in third-party collections increased by 0.02 accounts, although the amount of debt owed in third-party collections did not increase by a statistically significant amount. By the end of the second year after the reform, both third-party collections measures increased in magnitude, which is similar to the trends we observed in our main results. That both estimates are larger than those found in our main analysis is consistent with our hypothesis that mixing both rural and urban geographies together yields more conservative estimates. We also observe that the number of bankcards and bankcard balances increased in the four quarters immediately after the Medicaid contraction. The 0.025 increase in the number of bankcards is similar in magnitude to our main analysis estimates, while the $\$ 190$ increase in bankcard balances is more than twice the size of the effect we found in the main analysis. The effects for both measures are also statistically significant.

In the second year after the reform, the increase in the number of bankcards declines slightly, while the increase in total bankcard balances grows to $\$ 350$ by the end of 2007 . Importantly, both of these changes in trends in 2007 are consistent with our main results. Our

\footnotetext{
${ }^{21}$ As mentioned previously, most procedures for producing correct standard errors for statistical inference with policy changes similar to ours require assumptions about the size of the clusters being equal or the number of control clusters going to infinity, neither of which applies in this case.
} 
estimates for delinquent credit card debt are not statistically significant immediately after the Medicaid cut, but they become significant in 2007, which is a trend we did not observe in our main results. Finally, our estimates for Risk Score show an immediate effect after the Medicaid contraction that grows over time, which is also consistent with our main results.

Results from our standard DID analysis on the border cities subsample in Table 6 are also in-line with our main results. We find evidence of an increase in the number of bankcards held and in bankcard balances and increases in the number of accounts and debt owed in third-party collections. Our DID estimate for a bankcard balance of \$235 is two times larger than the \$113 increase we estimated in the main analysis. This disparity in credit card borrowing results between the two analyses is not surprising since there were more low-income households in the non-KC/STL areas than in KC/STL (Zuckerman and Cook, 2006), and low-income households are less likely to have credit cards and they borrow less, conditional on having credit card accounts (Bricker et al., 2017). This estimate is also similar to the implied increase in OOP spending in the MEPS data in Table 3, which is equal to $\$ 210$ (30 percent $\times \$ 699$ average OOP spending in Missouri). The implied ATT effect of this increase is equal to $\frac{\$ 235}{0.1406}=\$ 1,671$, based on the percent of the population eligible for Medicaid in Fiscal Year 2004. ${ }^{22}$

For debt in third-party collections, our estimate of an \$88 increase is $\$ 27$ higher than in our main analysis, which translates to an ATT effect of $\frac{\$ 88}{0.1406}=\$ 626$. This effect from the border city analysis is smaller than the estimates from a number of previous studies that have examined the effects of access to Medicaid on debt in collections, but it falls well within the range established by the literature. ATT effect for the number of accounts in third-party collections is equal to 0.309 accounts, which is slightly larger than our main results.

We also provide separate short-run and long-run DID coefficients in the bottom panel of Table 6. We can see that for our border city analysis, the effect of the reform grows significantly over time, with coefficient magnitudes significantly larger and statistically significant in the longrun period when compared with the short-run period. Though the magnitude of the coefficients

\footnotetext{
${ }^{22}$ The average percent of population eligible for Medicaid on the Missouri side of Kansas City and St. Louis is 14.06 percent. This measure is computed in the same way as in our main analysis.
} 
significantly differs between our border city analysis and our main analysis in Table 5 , it is reassuring that the same pattern is present across both analyses.

\section{Conclusion}

Our study provides new evidence on the effect of a Medicaid contraction on the financial outcomes of those affected. Analyzing Missouri's 2005 Medicaid cut, we find substantial declines in Medicaid eligibility, coverage, and spending. This in turn led to higher OOP health-care spending, increased credit card borrowing, and increased financial strain for Missouri residents. These results are qualitatively similar to previous studies of recent Medicaid expansions and of the 2005 Medicaid cut in Tennessee (Argys et al., 2020) and reinforce the existing evidence that health insurance provides significant financial protections.

We estimate that the Medicaid cut led to a \$103 increase in debt in third-party collections in Missouri, which implies an average treatment-on-the-treated effect of approximately $\$ 494$ per Medicaid-eligible recipient. This result is broadly consistent with previous work that found Medicaid expansions reduced debt in collections by $\$ 390$ (Finkelstein et al., 2012) to $\$ 1,231$ (Brevoort et al., 2020) per new recipient. Comparing these estimates to ours, we argue that Medicaid expansions and contractions may have asymmetric effects on financial distress, with contractions having smaller effects than expansions. We also find evidence that the Medicaid contraction led to an increase in the number of credit cards of 0.025 , which translates to an ATT effect of 0.12 cards per person. These results, taken together, imply that a decrease in the generosity of health-insurance benefits have important spillovers into the credit market behavior of lower-socioeconomic status households.

Our results for financial distress seemingly contrast with those of Argys et al. (2020), as our estimates from Missouri imply relatively smaller financial effects because of the contraction, while Argys et al. (2020) find larger financial effects than the previous literature because of the TennCare disenrollment in Tennessee. While we find a different type of asymmetry, we do not believe our results necessarily contradict those of Argys et al. (2020) because of the qualitative differences in the Medicaid reforms between the two states. In particular, the Missouri Medicaid reform was primarily a reduction in the generosity of health insurance for the majority of 
Medicaid enrollees, while the Tennessee reform disenrolled a large number of participants from their program. It may also be the case that newly enrolled Medicaid beneficiaries examined in the previous studies have higher medical expenses, and thus experience larger financial benefits, than the Medicaid-eligible individuals in our study, who were already covered by Medicaid for some time.

The results from our study provide additional evidence on the indirect financial value of Medicaid. As shown in Brevoort et al. (2020), the credit market consequences of increased debt and unpaid bills can be substantial. Our results show that losing Medicaid benefits has real financial implications beyond the health-insurance effects on health-care spending and utilization. Given the current policy discussions that states are having regarding Medicaid reform, it is important to understand the potential financial spillover effects that may result from decreasing benefit generosity or restricting eligibility. In particular, acknowledging the presence of asymmetries in these effects is important to properly assess the costs and benefits of any policy change, especially for populations that may be either credit constrained or less able to take on and manage additional debt. 


\section{References}

Allen, Heidi, Ashley Swanson, Jialan Wang, and Tal Gross. (2017). "Early Medicaid Expansion Associated with Reduced Payday Borrowing in California." Health Affairs 36(10), 17691776. https://doi.org/10.1377/h/thaff.2017.0369.

Argys, Laura M., Andrew I. Friedson, M. Melinda Pitts, and D. Sebastian Tello-Trillo. (2020). "Losing Public Health Insurance: TennCare Reform and Personal Financial Distress." Journal of Public Economics 187 (article 104202).

Baicker, Katherine, Amy Finkelstein, Jae Song, and Sarah Taubman. (2014). "The Impact of Medicaid on Labor Market Activity and Program Participation: Evidence from the Oregon Health Insurance Experiment." American Economic Review 104(5): 322-328.

Baicker, Katherine, Sarah L. Taubman, Heidi L. Allen, Mira Bernstein, Jonathan Gruber, Joseph P. Newhouse, Eric C. Schneider, Bill J. Wright, Alan M. Zaslavsky, Amy Finkelstein, and the Oregon Health Study Group. (2013). "The Oregon Experiment - Effects of Medicaid on Clinical Outcomes." New England Journal of Medicine 368(18): 1713-1722.

Bertrand, Marianne, Esther Duflo, and Sendhil Mullainathan. (2004). "How Much Should We Trust Differences-in-Differences Estimates?" The Quarterly Journal of Economics 119(1), 249-275. https://doi.org/10.1162/003355304772839588.

Blavin, Fredric, Michael Karpman, Genevieve M. Kenney, and Benjamin D. Sommers. (2018). "Medicaid Versus Marketplace Coverage for Near-Poor Adults: Effects on Out-of-Pocket Spending and Coverage." Health Affairs 37(2): 299-307.

Brevoort, Kenneth, Daniel Grodzicki, and Martin B. Hackmann. (2020). "The Credit Consequences of Unpaid Medical Bills." Journal of Public Economics 187 (article 104203).

Bricker, Jesse, Lisa J. Dettling, Alice Henriques, Joanne W. Hsu, Lindsay Jacobs, Kevin B. Moore, Sarah Pack, John Sabelhaus, Jeffrey Thompson, and Richard A. Windle. (2017). "Changes in U.S. Family Finances from 2013 to 2016: Evidence from the Survey of Consumer Finances." Federal Reserve Bulletin 103(3). https://www.federalreserve.gov/publications/files/scf17.pdf.

Cameron, A. Colin, and Douglas L. Miller. (2015). "A Practitioner's Guide to Cluster-Robust Inference." The Journal of Human Resources 50(2): 317-372. https://doi.org/10.3368/jhr.50.2.317.

Conley, Timothy G., and Christopher R. Taber. (2011). "Inference with 'Difference in Differences' with a Small Number of Policy Changes." The Review of Economics and Statistics 93(1): 113-125. https://doi.org/10.1162/REST a 00049. 
Dave, Dhaval, Sandra L. Decker, Robert Kaestner, and Kosali I. Simon. (2015). "The Effect of Medicaid Expansions in the Late 1980s and Early 1990s on the Labor Supply of Pregnant Women." American Journal of Health Economics 1(2): 165-193.

DeLeire, Thomas. (2019). "The Effect of Disenrollment from Medicaid on Employment, Insurance Coverage, and Health and Health Care Utilization." Research in Labor Economics, Health and Labor Markets 47: 155-194.

Dube, Arindrajit, T. William Lester, and Michael Reich. (2010). “Minimum Wage Effects Across State Borders: Estimates Using Contiguous Counties." The Review of Economics and Statistics 92(4): 945-964. https://doi.org/10.1162/REST a 00039.

Ferber, Joel. (2007). "Insure Missouri: Early Observations." Legal Services of Eastern Missouri. http://www.mobudget.org/files/INSURE\%20MISSOURI\%20 FINAL2.pdf.

Ferber, Joel, Heather Bednarek, and Muhammad Islam. (2005). "The County Level Economic Impact of Proposed Cuts in Medicaid Spending in Missouri." Missouri Budget Project. http://www.mobudget.org/files/governorproposal.pdf.

Finkelstein, Amy, Sarah Taubman, Bill Wright, Mira Bernstein, Jonathan Gruber, Joseph P. Newhouse, Heidi Allen, Katherine Baicker, and the Oregon Health Study Group. (2012). "The Oregon Health Insurance Experiment: Evidence from the First Year." Quarterly Journal of Economics 127(3): 1057-1106.

Finkelstein, Amy, Nathaniel Hendren, and Erzo F.P. Luttmer. (2019). "The Value of Medicaid: Interpreting Results from the Oregon Health Insurance Experiment." Journal of Political Economy, forthcoming.

Garthwaite, Craig, Tal Gross, and Matthew J. Notowidigdo. (2014). "Public Health Insurance, Labor Supply, and Employment Lock." Quarterly Journal of Economics 129(2): 653-696.

Garthwaite, Craig, Tal Gross, and Matthew J. Notowidigdo. (2018). "Hospitals as Insurers of Last Resort." American Economic Journal: Applied Economics 10(1): 1-39.

Ghosh, Ausmita, and Kosali Simon. (2015). "The Effect of Medicaid on Adult Hospitalizations: Evidence from Tennessee's Medicaid Contraction." NBER Working Paper 21580.

Gotanda, Hiroshi, Ashish K. Jha, Gerald F. Kominski, and Yusuke Tsugawa. (2020). "Out-ofPocket Spending and Financial Burden Among Low Income Adults After Medicaid Expansion in the United States: Quasi-Experimental Difference-in-Difference Study." BMJ 368. https://doi.org/10.1136/bmj.m40. 
Gross, Tal, and Matthew Notowidigdo. (2011). "Health Insurance and the Consumer Bankruptcy Decision: Evidence from Expansions of Medicaid." Journal of Public Economics 95(7-8): 767-778. https://doi.org/10.1016/i.jpubeco.2011.01.012.

Ham, John C., and Ken Ueda. (2021). "The Employment Impact of the Provision of Public Health Insurance: A Further Examination of the Effect of the 2005 TennCare Contraction." The Journal of Labor Economics 39(S1): S199-S238. https://doi.org/10.1086/711560.

Hargraves, Julia M. (2008). “Financing Long-Term Care in Missouri: Limits and Changes in the Wake of the Deficit Reduction Act of 2005." Missouri Law Review 73(3).

Hu, Luojia, Robert Kaestner, Bhashkar Mazumder, Sarah Miller, and Ashley Wong. (2018). "The Effect of the Affordable Care Act Medicaid Expansions on Financial Wellbeing." Journal of Public Economics 163: 99-112. https://doi.org/10.1016/j.jpubeco.2018.04.009.

Kruckemeyer, Tom, and Amy Blouin. (2004). “Missouri's Revenue Situation: Is the Fiscal Crisis Really Over?" The Missouri Budget Project. http://www.mobudget.org/files/revenuesituation.pdf.

Lee, D., and W. van der Klaauw. (2010). "An Introduction to the Consumer Credit Panel." Federal Reserve Bank of New York Staff Report 479.

MacKinnon, James G., and Matthew D. Webb. (2018). "The Wild Bootstrap for Few (Treated) Clusters." The Econometrics Journal 21: 114-135. https://doi.org/10.1111/ectj.12107.

MacKinnon, James G., and Matthew D. Webb (2020). "Randomization Inference for Differencein-Differences with Few Treated Clusters." Journal of Econometrics 218(2): 435-450. https://doi.org/10.1016/j.jeconom.2020.04.024.

Maclean, Johanna Catherine, Sebastian Tello-Trillo, and Douglas Webber. (2020). "Losing Health Insurance and Behavioral Health Inpatient Care: Evidence from a Large-Scale Medicaid Disenrollment." NBER Working Paper 25936. https://www.nber.org/papers/w25936.

Mazumder, Bhashkar, and Sarah Miller. (2016). "The Effects of the Massachusetts Health Reform on Household Financial Distress." American Economic Journal: Economic Policy 8(3): 284-313.

Miller, Sarah, Luojia Hu, Robert Kaestner, Bhashkar Mazumder, and Ashley Wong. (2021). "The ACA Medicaid Expansion in Michigan and Financial Health." The Journal of Policy Analysis and Management 40(2): 348-375.

Procter, Brenda. (2005). "Poverty at Issue." University of Missouri Extension. https://web.archive.org/web/20060906182619/http://outreach.missouri.edu/cfe/poverty Lnews05/medicaid/paitfall05.pdf 
Shield, Charlie. (2007). "SB 577." Missouri Senate Government.

http://www.senate.mo.gov/07info/BTS Web/Bill.aspx?SessionType=R\&BillID=28834.

Tarazi, Wafa W., Tiffany L. Green, and Lindsay M. Sabik. (2017). "Medicaid Disenrollment and Disparities in Access to Care: Evidence from Tennessee." Health Services Research 52(3): 1156-1167.

Tello-Trillo, Sebastian. (2021). "Losing Public Health Insurance on Preventative Care, Health, and Emergency Department Use: Evidence from the TennCare Disenrollment." Southern Economic Journal, 88(1): 322-366.

Zuckerman, Stephen, and Allison Cook. (2006). "Geographic Variations in Health Insurance: A Profile of Missouri." Urban Institute. http://webarchive.urban.org/UploadedPDF/1001008 CoverMo8.pdf.

Zuckerman, Stephen, Dawn M. Miller, and Emily Shelton Pape. (2009). “Missouri's 2005 Medicaid Cuts: How Did They Affect Enrollees and Providers?" Health Affairs 28(2): 335345. 
Table 1: Major Dates of the Missouri Medicaid Reforms of 2005-2007

\begin{tabular}{ll}
\hline Event & Date \\
\hline Governor Matt Blunt signs SB539 & April 26, 2005 \\
Changes from SB539 go into effect & July 1, 2005 \\
Insure Missouri gets announced & September 18, 2007 \\
Phase I of Insure Missouri is enacted & February 2008 \\
Phase I rollout is completed & End of FY2009 \\
\hline
\end{tabular}


Table 2: Summary Statistics for Medical Expenditure Panel Survey Data

\begin{tabular}{|c|c|c|c|c|c|}
\hline & Total & No Medicaid & Medicaid & $\begin{array}{l}\text { Border } \\
\text { States }\end{array}$ & Missouri \\
\hline Medicaid & $12.0 \%$ & $0.0 \%$ & $100.0 \%$ & $11.5 \%$ & $12.9 \%$ \\
\hline Privately Insured & $66.4 \%$ & $74.4 \%$ & $7.5 \%$ & $67.5 \%$ & $68.0 \%$ \\
\hline Uninsured & $12.2 \%$ & $13.9 \%$ & $0.0 \%$ & $12.4 \%$ & $9.7 \%$ \\
\hline Total Medicaid Spending & $\$ 374$ & $\$ 55$ & $\$ 2,484$ & $\$ 307$ & $\$ 348$ \\
\hline Total OOP Spending & $\$ 678$ & $\$ 736$ & $\$ 260$ & $\$ 751$ & $\$ 699$ \\
\hline $\begin{array}{l}\text { Total Private Insurance } \\
\text { Spending }\end{array}$ & $\$ 1,477$ & $\$ 1,640$ & $\$ 286$ & $\$ 1,618$ & $\$ 1,481$ \\
\hline Total Health-Care Spending & $\$ 3,526$ & $\$ 3,429$ & $\$ 4,233$ & $\$ 3,813$ & $\$ 3,535$ \\
\hline $\begin{array}{l}\text { Percent with Any OOP } \\
\text { Spending }\end{array}$ & $78.0 \%$ & $81.0 \%$ & $56.0 \%$ & $79.6 \%$ & $81.5 \%$ \\
\hline Family Size & 3.2 & 3.1 & 3.9 & 3.1 & 3.1 \\
\hline Male & $48.9 \%$ & $49.7 \%$ & $43.0 \%$ & $49.1 \%$ & $49.6 \%$ \\
\hline Black & $9.4 \%$ & $7.9 \%$ & $20.3 \%$ & $7.6 \%$ & $10.8 \%$ \\
\hline Asian & $6.3 \%$ & $5.9 \%$ & $8.7 \%$ & $3.6 \%$ & $5.5 \%$ \\
\hline Hispanic & $14.1 \%$ & $12.4 \%$ & $26.7 \%$ & $7.8 \%$ & $2.8 \%$ \\
\hline Married & $41.4 \%$ & $45.5 \%$ & $11.9 \%$ & $43.0 \%$ & $43.7 \%$ \\
\hline High School Graduate & $59.4 \%$ & $64.7 \%$ & $21.0 \%$ & $59.9 \%$ & $60.0 \%$ \\
\hline College Graduate & $18.9 \%$ & $21.2 \%$ & $2.0 \%$ & $16.3 \%$ & $18.4 \%$ \\
\hline Age & 36.3 & 38.1 & 23.1 & 36.6 & 36.4 \\
\hline Average $\mathrm{N}$ (unweighted) & 263,227 & 212,813 & 50,461 & 27,165 & 5,053 \\
\hline Average N (weighted) & $192,572,505$ & $169,368,099$ & $23,204,406$ & $20,655,160$ & $4,091,980$ \\
\hline
\end{tabular}

Notes: Data are based on authors' calculations using individual level data from the weighted 2000-2007 MEPS. Means reported in all columns. All dollar amounts are in constant 2012 dollars. The Total, No Medicaid, and Medicaid columns include data from all 50 states. Border states include all those that border Missouri, except Tennessee. 
Table 3: Effect of Missouri Medicaid Cut on Insurance Status and Spending

\begin{tabular}{lcccccc}
\hline & $\begin{array}{c}\text { Medicaid } \\
\text { Receipt }\end{array}$ & Uninsured & $\begin{array}{c}\text { Medicaid } \\
\text { Spending }\end{array}$ & $\begin{array}{c}\text { OOP } \\
\text { Spending }\end{array}$ & $\begin{array}{c}\text { Any OOP } \\
\text { Spending }\end{array}$ & $\begin{array}{c}\text { Total } \\
\text { Spending }\end{array}$ \\
\hline $\begin{array}{l}\text { Missouri }_{i} \\
\times \text { Post2005 }_{t}\end{array}$ & $-0.039 * *$ & 0.022 & -0.180 & $0.303^{* * *}$ & 0.017 & 0.129 \\
& $(0.016)$ & $(0.014)$ & $(0.113)$ & $(0.107)$ & $(0.014)$ & $(0.115)$ \\
& & & & & & \\
State FEs & Yes & Yes & Yes & Yes & Yes & Yes \\
Year FEs & Yes & Yes & Yes & Yes & Yes & Yes \\
$R^{2}$ & 0.15 & 0.11 & 0.09 & 0.24 & 0.12 & 0.19 \\
$N$ & 26,714 & 26,714 & 26,714 & 26,714 & 26,714 & 26,714 \\
\hline
\end{tabular}

Notes: Based on authors' calculations using the restricted Medical Expenditure Panel Survey (MEPS) data. Spending dependent variables are natural logs of spending plus one. Standard errors calculated using a block bootstrap are reported in parentheses. $* * *$ indicates $\mathrm{p}<0.01, * *$ indicates $\mathrm{p}<0.05, *$ indicates $\mathrm{p}<0.10$. Control variables include state and year fixed effects, sex, race (Black, Asian), ethnicity (Hispanic), education (high school grad, college grad), marital status, family size, and age (dummies for each year). Data are from 2000-2007 with 2005 omitted as partially treated since the contraction happened halfway through the year. Spending is measured in constant 2012 dollars. Control states are Oklahoma, Kansas, Nebraska, lowa, Illinois, Kentucky, and Arkansas; Tennessee is omitted because of its own Medicaid reform in 2005. 
Table 4: Summary Statistics for the CCP Data and Control Variables

\begin{tabular}{lccccc} 
& \multicolumn{2}{c}{ Treatment Group } & \multicolumn{2}{c}{ Control Group } & \\
& $\mathrm{N}$ & Mean & $\mathrm{N}$ & Mean & Mean Difference \\
\hline Card balance & $1,133,542$ & 4265.44 & 649,742 & 4474.16 & $-208.73^{* * *}$ \\
Number of cards & $1,820,978$ & 1.99 & 995,613 & 2.07 & $-0.079^{* * *}$ \\
Amount delinquent on cards & $1,319,734$ & 260.94 & 738,838 & 236.02 & $24.92^{* * *}$ \\
Number of collections & $1,872,186$ & 0.32 & $1,022,151$ & 0.26 & $0.056^{* * *}$ \\
Amount in collections & 684,625 & 478.74 & 323,284 & 436.04 & $42.69^{* * *}$ \\
Risk Score & $1,780,140$ & 679.75 & 986,053 & 689.30 & $-9.55^{* * *}$ \\
Unemployment rate & $1,992,811$ & 5.64 & $1,083,542$ & 5.62 & $0.025^{* * *}$ \\
Percent in poverty & $1,992,811$ & 12.64 & $1,083,542$ & 11.45 & $1.19^{* * *}$ \\
Proportion disabled & $1,992,811$ & 0.03 & $1,083,542$ & 0.03 & $0.003^{* * *}$ \\
Proportion Black & $1,992,811$ & 0.18 & $1,083,542$ & 0.09 & $0.087^{* * *}$ \\
Age & $1,920,107$ & 48.95 & $1,045,779$ & 49.02 & $-0.073^{* *}$ \\
\hline
\end{tabular}

Notes: Based on authors' calculations using the CCP data. Age is individual level, based on year of birth in the CCP. The Risk Score is the Equifax Risk Score. The county-level demographic data are from the BLS's Local Area Unemployment Statistics, the Census Bureau, the Small Area Income and Poverty Estimates, and the Old Age, Survivors and Disability Insurance data. 
Table 5: Differences-in-Differences Results from the Consumer Credit Panel (CCP)

\begin{tabular}{|c|c|c|c|c|c|c|}
\hline & $\begin{array}{c}\text { Total } \\
\text { Bankcard } \\
\text { Balance (\$) }\end{array}$ & $\begin{array}{l}\text { Number of } \\
\text { Bankcards }\end{array}$ & $\begin{array}{c}\text { Amount } \\
\text { Delinquent } \\
\text { on } \\
\text { Bankcards } \\
\text { (\$) }\end{array}$ & $\begin{array}{c}\text { Number of } \\
\text { Accounts } \\
\text { in Third- } \\
\text { Party } \\
\text { Collections }\end{array}$ & $\begin{array}{l}\text { Amount in } \\
\text { Third- } \\
\text { Party } \\
\text { Collections } \\
\text { (\$) }\end{array}$ & $\begin{array}{c}\text { Risk Score } \\
\text { (points) }\end{array}$ \\
\hline $\begin{array}{l}\text { Post-Reform } \\
\text { Missouri }_{i} \\
\times{\text { Post } 2005_{t}}\end{array}$ & $\begin{array}{c}113.06 \\
(142.56)\end{array}$ & $\begin{array}{l}0.0166 \\
(0.015)\end{array}$ & $\begin{array}{c}3.863 \\
(13.267)\end{array}$ & $\begin{array}{c}0.042 * * \\
(0.020)\end{array}$ & $\begin{array}{c}60.667 \\
(48.389)\end{array}$ & $\begin{array}{l}-0.669 \\
(0.474)\end{array}$ \\
\hline Adj. $R^{2}$ & 0.693 & 0.840 & 0.510 & 0.431 & 0.142 & 0.884 \\
\hline $\begin{array}{l}\text { Post-Reform: } \\
\text { Missouri }_{i} \\
\times \text { Post_SR }_{t}\end{array}$ & $\begin{array}{c}66.684 \\
(118.593)\end{array}$ & $\begin{array}{l}\text { ong Run } \\
\qquad \begin{array}{c}0.018 \\
(0.012)\end{array}\end{array}$ & $\begin{array}{c}-3.981 \\
(11.060)\end{array}$ & $\begin{array}{c}0.020 \\
(0.016)\end{array}$ & $\begin{array}{c}5.863 \\
(70.797)\end{array}$ & $\begin{array}{c}0.038 \\
(0.409)\end{array}$ \\
\hline $\begin{array}{l}\text { Missouri }_{i} \\
\times \text { Post_LR }_{t}\end{array}$ & $\begin{array}{c}146.995 \\
(170.4)\end{array}$ & $\begin{array}{c}0.016 \\
(0.020)\end{array}$ & $\begin{array}{c}9.589 \\
(18.497)\end{array}$ & $\begin{array}{c}0.058 * * \\
(0.025)\end{array}$ & $\begin{array}{c}103.227^{* * *} \\
(37.621)\end{array}$ & $\begin{array}{c}-1.176 * * \\
(0.559)\end{array}$ \\
\hline Adj. $R^{2}$ & 0.694 & 0.840 & 0.510 & 0.431 & 0.143 & 0.884 \\
\hline$N$ & $1,773,808$ & $2,759,405$ & $2,048,236$ & $2,835,850$ & 982,240 & $2,724,926$ \\
\hline
\end{tabular}

Notes: Authors' calculations using data from the CCP. Missouri $i_{i}$ is an indicator variable for individuals living within 10 miles of the Missouri side of the Missouri border. In the top panel, Post $2005_{t}$ is a dummy variable equal to one for quarters between Q3:2005 and Q4:2007. In the bottom panel, Post_SR is a dummy variable equal to one for quarters between Q3:2005 and Q2:2006 and Post_LR is a dummy variable equal to one for quarters between Q3:2006 and Q4:2007. Block bootstrapped standard errors are reported in parentheses. ***, **, * denote significance at the 0.01, 0.05, and 0.10 levels. Risk Score is the Equifax Risk Score. 
Table 6: Differences-in-Differences Results from Consumer Credit Panel (CCP), Kansas City/St. Louis Sample

\begin{tabular}{|c|c|c|c|c|c|c|}
\hline & $\begin{array}{c}\text { Total } \\
\text { Bankcard } \\
\text { Balance }(\$)\end{array}$ & $\begin{array}{l}\text { Number of } \\
\text { Bankcards }\end{array}$ & $\begin{array}{c}\text { Amount } \\
\text { Delinquent } \\
\text { on } \\
\text { Bankcards } \\
\text { (\$) }\end{array}$ & $\begin{array}{l}\text { Number of } \\
\text { Accounts } \\
\text { in Third- } \\
\text { Party } \\
\text { Collections }\end{array}$ & $\begin{array}{l}\text { Amount in } \\
\text { Third- } \\
\text { Party } \\
\text { Collections } \\
\text { (\$) }\end{array}$ & $\begin{array}{l}\text { Risk Score } \\
\text { (points) }\end{array}$ \\
\hline \multicolumn{7}{|l|}{ Post-Reform } \\
\hline $\begin{array}{l}\text { Missouri }_{i} \\
\times{\text { Post } 2005_{t}}\end{array}$ & $\begin{array}{c}235.1^{* * *} \\
(54.03)\end{array}$ & $\begin{array}{c}0.0167^{*} \\
(0.00793)\end{array}$ & $\begin{array}{c}5.771 \\
(8.747)\end{array}$ & $\begin{array}{c}0.0434 * * * \\
(0.00471)\end{array}$ & $\begin{array}{c}88.27 * * * \\
(23.10)\end{array}$ & $\begin{array}{c}-0.896 * * \\
(0.290)\end{array}$ \\
\hline Adj. $R^{2}$ & 0.693 & 0.844 & 0.515 & 0.439 & 0.144 & 0.886 \\
\hline \multicolumn{7}{|c|}{$\begin{array}{l}\text { Post-Reform: Short Run and Long Run } \\
\text { Missouri }_{i}\end{array}$} \\
\hline$\times$ Post_SR & $\begin{array}{l}155.6 * * \\
(50.13)\end{array}$ & $\begin{array}{l}0.0193 * * \\
(0.00744)\end{array}$ & $\begin{array}{l}-7.307 \\
(8.537)\end{array}$ & $\begin{array}{c}0.0216 * * * \\
(0.00502)\end{array}$ & $\begin{array}{l}55.38 * * \\
(20.79)\end{array}$ & $\begin{array}{l}-0.112 \\
(0.276)\end{array}$ \\
\hline $\begin{array}{l}\text { Missouri }_{i} \\
\times \text { Post_LR }_{t}\end{array}$ & $\begin{array}{c}303.6 * * * \\
(64.01)\end{array}$ & $\begin{array}{c}0.0146 \\
(0.00921)\end{array}$ & $\begin{array}{c}16.81 \\
(10.89)\end{array}$ & $\begin{array}{c}0.0609 * * * \\
(0.00565)\end{array}$ & $\begin{array}{c}115.5^{* * *} \\
(29.64)\end{array}$ & $\begin{array}{c}-1.532 * * * \\
(0.347)\end{array}$ \\
\hline Adj. $R^{2}$ & 0.693 & 0.844 & 0.515 & 0.439 & 0.144 & 0.886 \\
\hline$N$ & $1,347,815$ & $2,078,696$ & $1,555,993$ & $2,134,076$ & 736,088 & $2,048,047$ \\
\hline
\end{tabular}

Note: Based on authors' calculations using data from the CCP. Risk Score is the Equifax Risk Score. Missouri $i_{i}$ is an indicator variable for living within 10 miles of the Missouri border in Kansas City or St. Louis. In the top panel, Post $2005_{t}$ is a dummy variable equal to one for quarters between Q3:2005 and Q4:2007. In the bottom panel, Post_SR is a dummy variable equal to one for quarters between Q3:2005 and Q2:2006 and Post_LR is a dummy variable equal to one for quarters between Q3:2006 and Q4:2007. Robust standard errors are clustered at the census tract level and reported in parentheses. ${ }^{* *}, * *$, and ${ }^{*}$ denote significance at the $0.01,0.05$, and 0.10 levels, respectively. 
Figure 1: MEPS Event Study Results

Panel A: Probability of Having Medicaid

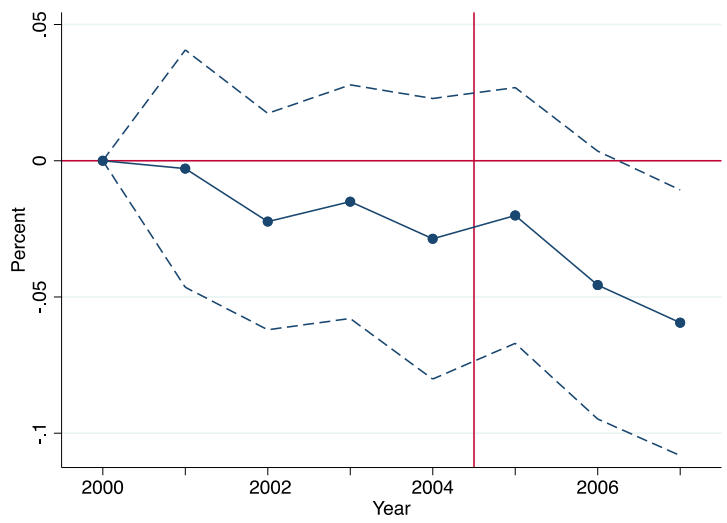

Panel C: Medicaid Spending

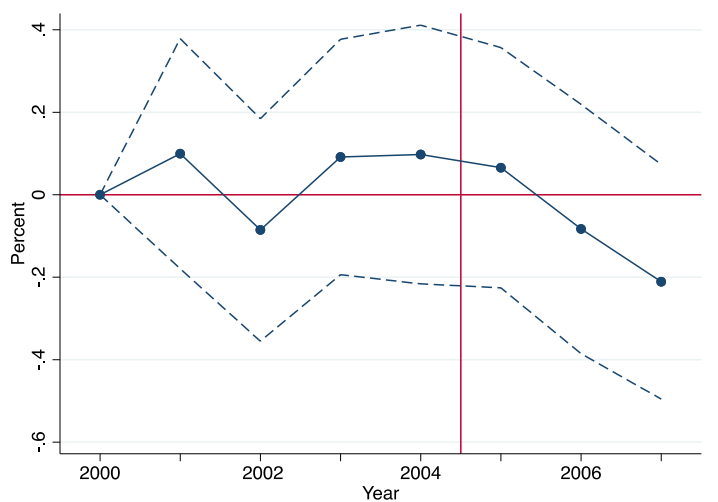

Panel E: Total OOP Medical Spending

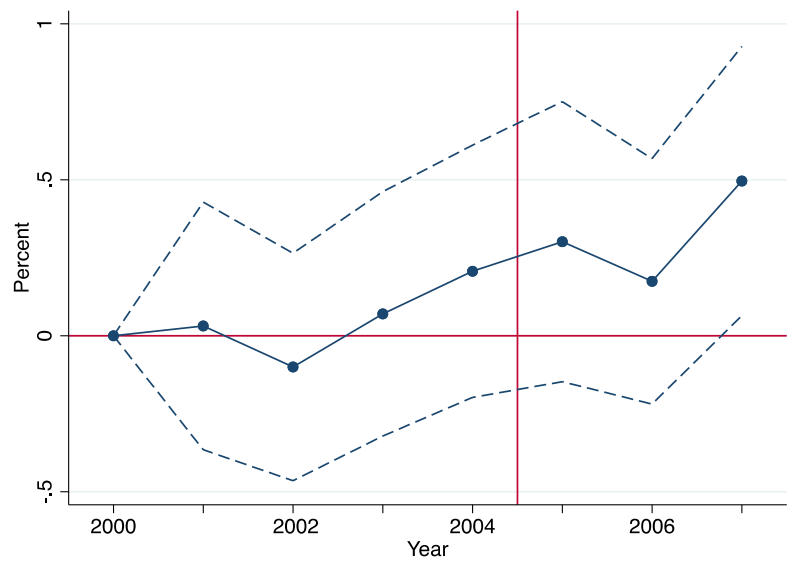

Panel B: Probability of Being Uninsured

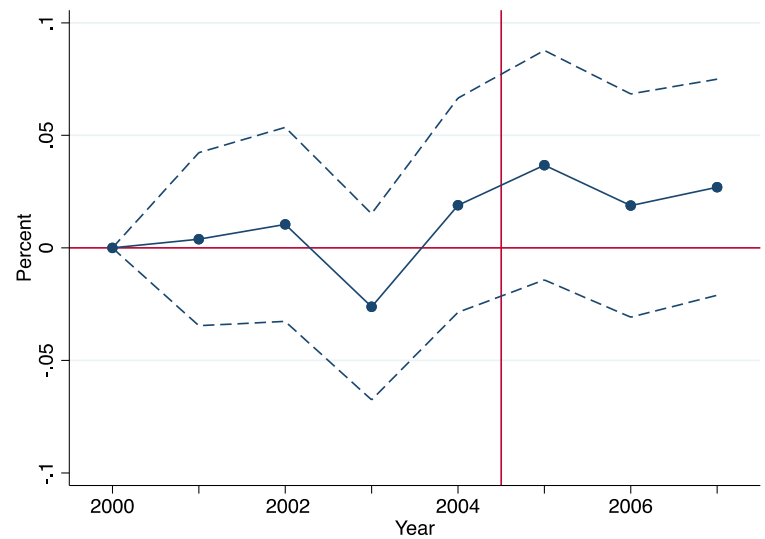

Panel D: Total Medical Spending



Panel F: Likelihood of Having Any OOP Spending



Notes: Based on authors' calculations using the restricted version of the Medical Expenditure Panel Survey (MEPS) data. Dots represent coefficient estimates, while dashed lines show 95 percent confidence intervals calculated using a block bootstrap. Spending variables are natural logs. The control group includes all states that border Missouri, except Tennessee. 
Figure 2: Map of Border Discontinuity



Figure 3: Unemployment Rate and GDP Growth in Missouri versus U.S. Overall

Panel A: Unemployment



Panel B: Income

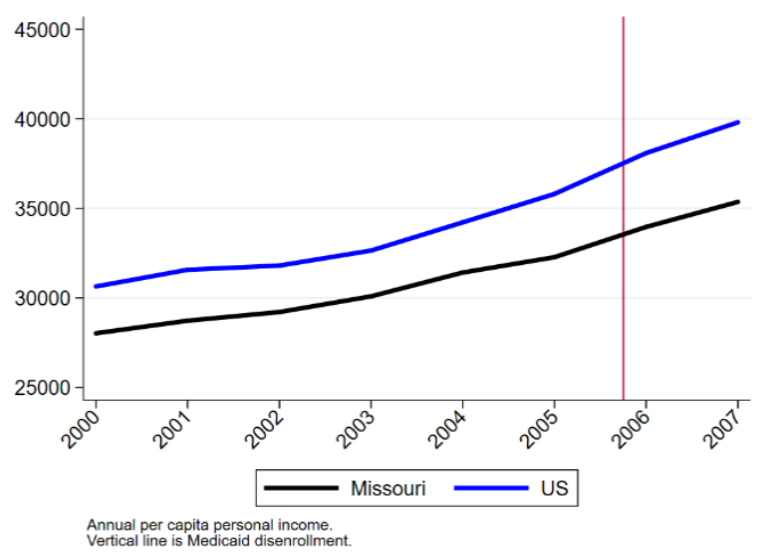

Notes: Figures based on authors' calculations using data from the U.S. Bureau of Labor Statistics and the U.S. Bureau of Economic Analysis. 
Figure 4: CCP Event Study Results

Panel A: Total Bankcard Balance



Panel C: Amount Delinquent on Bankcards



Panel E: Amount in Third-Party Collections



Panel B: Number of Bankcards

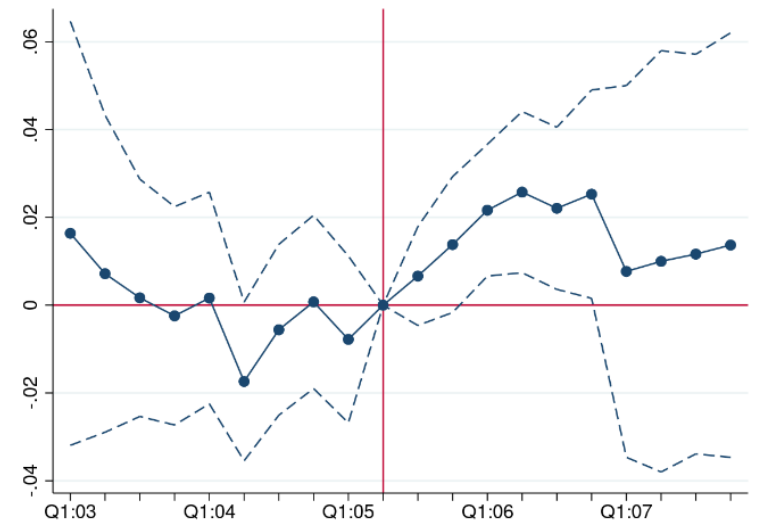

Panel D: Number of Accounts in Third-Party Collections

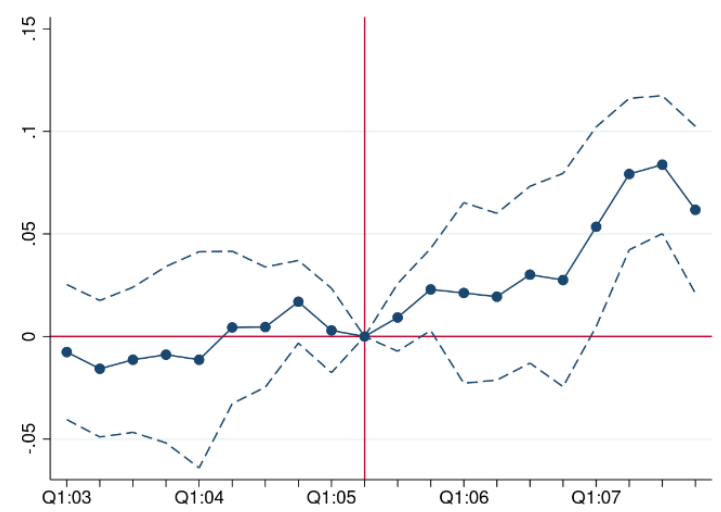

Panel F: Risk Score Points

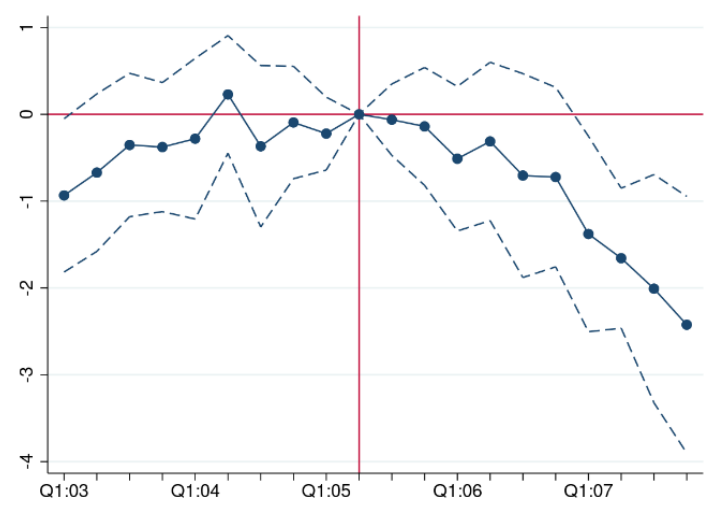

Notes: Based on authors' calculations using the CCP. Risk Score is the Equifax Risk Score. The omitted time period is Q2:2005. Estimates in Panels A, C, and E are measured in dollars. Dots represent coefficient estimates, while bands show 95 percent confidence intervals based on block bootstrapped standard errors. 
Figure 5: City Border Discontinuity

Kansas City

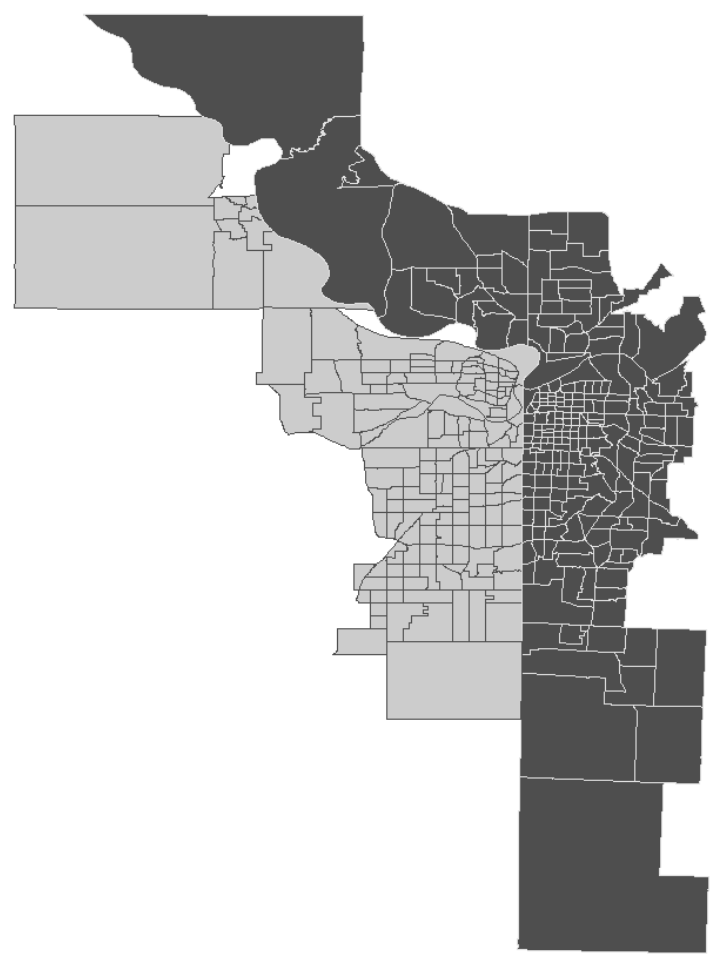

St. Louis

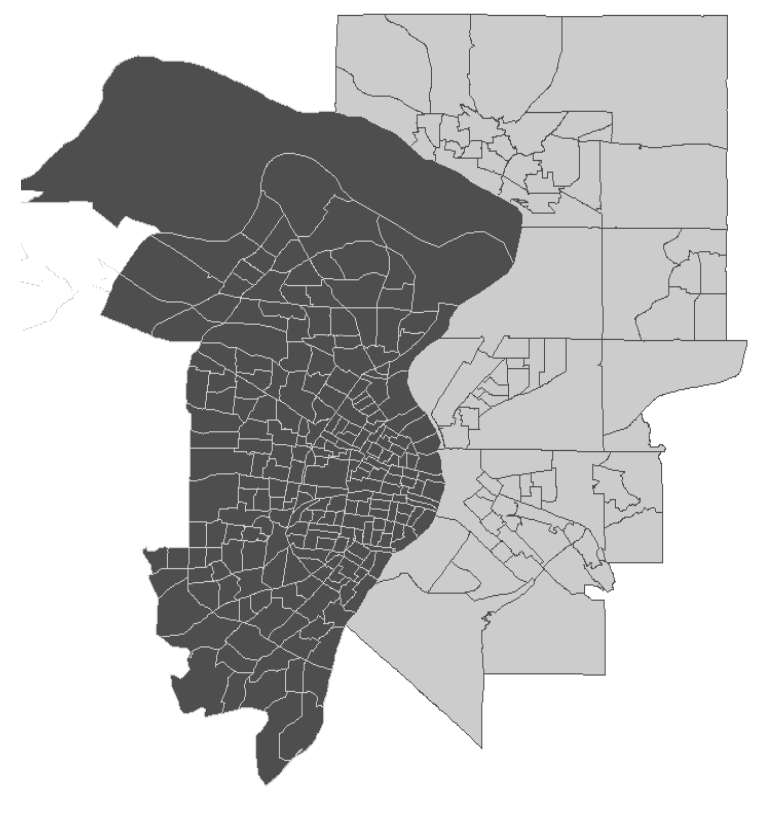

Notes: The Missouri part of each city is the darker shade. 
Figure 6: Border City (Kansas City/St. Louis) Event Study Results

Panel A: Total Bankcard Balance

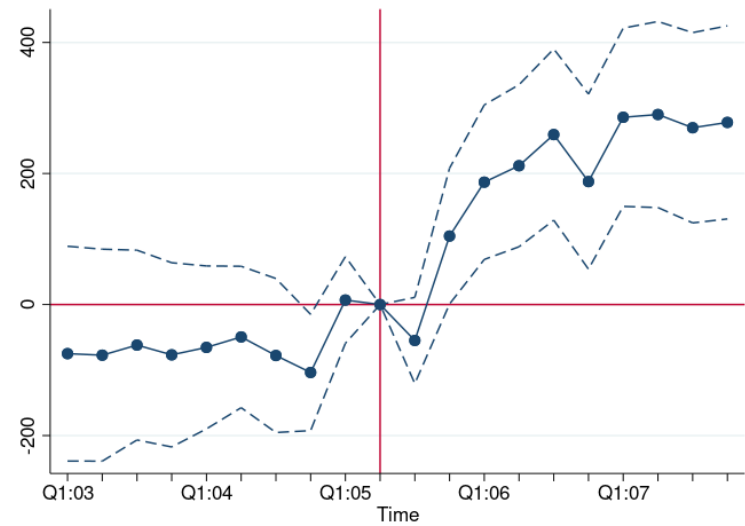

Panel C: Amount Delinquent on Bankcards

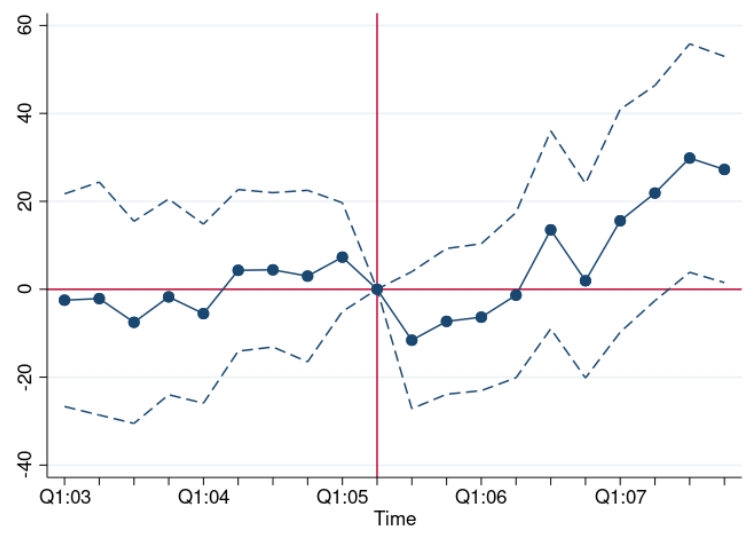

Panel E: Amount in Third-Party Collections

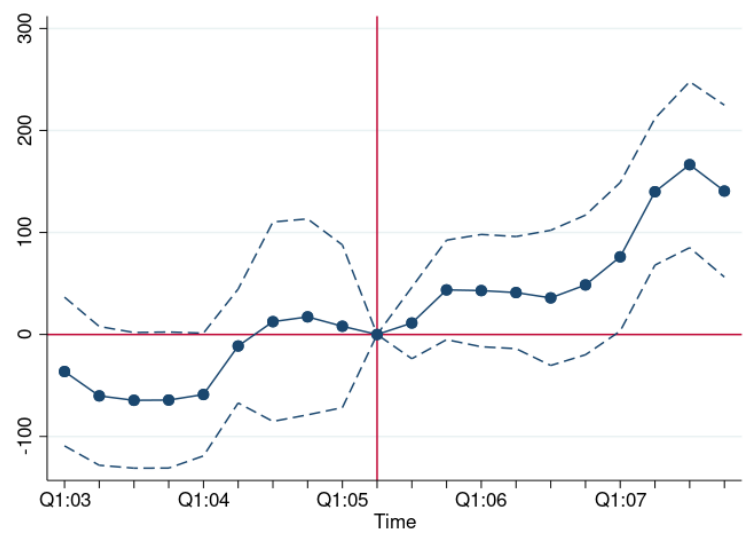

Panel B: Number of Bankcards

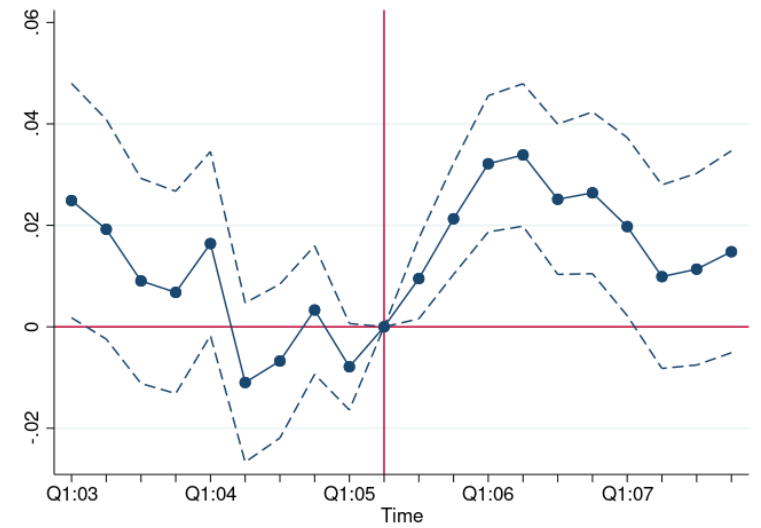

Panel D: Number of Accounts in Third-Party Collections

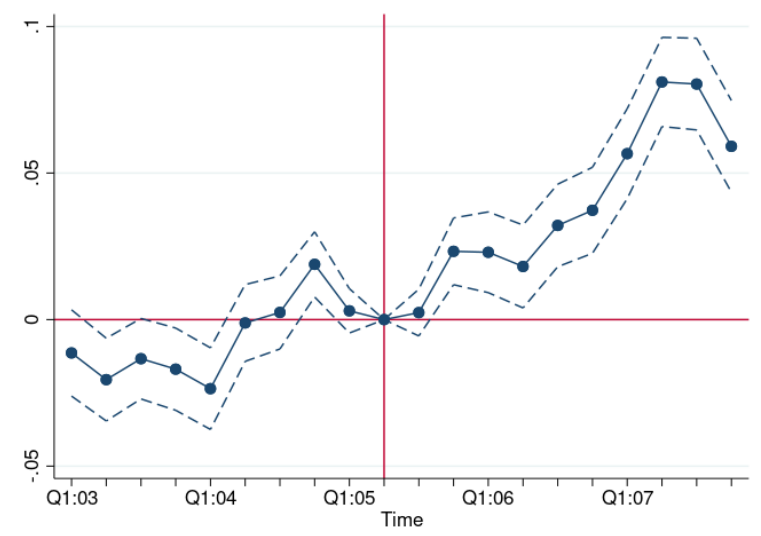

Panel F: Risk Score Points

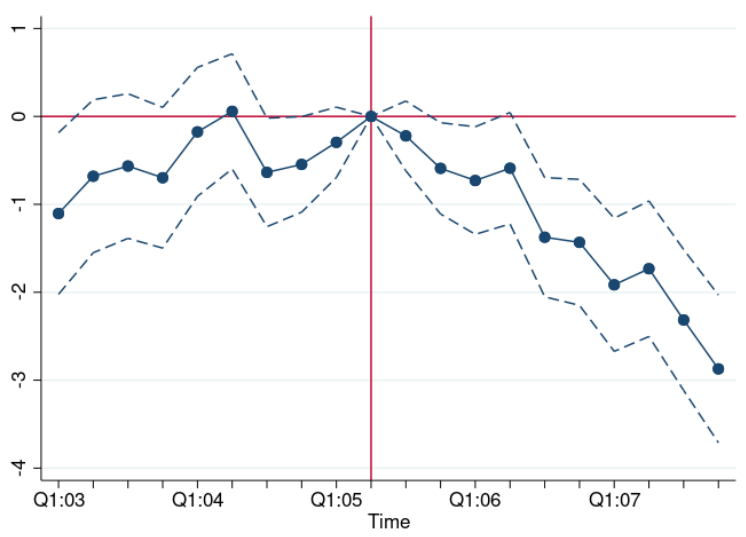

Notes: Based on authors' calculations using data from the CCP. Risk Score is the Equifax Risk Score. Omitted time period is Q2:2005. Estimates in Panels A, C, and E are measured in dollars. Standard errors clustered at the census tract level. This specification includes county fixed effects. 


\section{Appendix A}

Table 1A: Summary Statistics for MEPS Data; Pre- and Post-2005 Reform (All States)

\begin{tabular}{lcc}
\hline & $2000-2004$ & $2006-2007$ \\
\hline Medicaid & $11.5 \%$ & $12.9 \%$ \\
Privately Insured & $67.6 \%$ & $64.0 \%$ \\
Uninsured & $11.9 \%$ & $12.9 \%$ \\
Total Medicaid Spending & $\$ 331$ & $\$ 340$ \\
Total OOP Spending & $\$ 664$ & $\$ 679$ \\
Total Health-Care Spending & $\$ 3,334$ & $\$ 3,826$ \\
Total Private Insurance Spending & $\$ 1,393$ & $\$ 1,613$ \\
Family Size & 3.2 & 3.2 \\
Male & $48.9 \%$ & $49.0 \%$ \\
Black & $7.5 \%$ & $12.3 \%$ \\
Asian & $7.6 \%$ & $4.4 \%$ \\
Hispanic & $13.6 \%$ & $15.3 \%$ \\
Married & $41.6 \%$ & $41.0 \%$ \\
High School Graduate & $58.7 \%$ & $60.7 \%$ \\
College Graduate & $18.2 \%$ & $20.3 \%$ \\
Age & 36.0 & 36.7 \\
\hline
\end{tabular}

Notes: Based on authors' calculations using data from the restricted Medical Expenditure Panel Survey (MEPS) data. 
Table 2A (Table 3 Without Weights): Effect of Missouri Medicaid Cut on Insurance Status and Spending

\begin{tabular}{lcccccc}
\hline & $\begin{array}{c}\text { Medicaid } \\
\text { Receipt }\end{array}$ & Uninsured & $\begin{array}{c}\text { Medicaid } \\
\text { Spending }\end{array}$ & $\begin{array}{c}\text { OOP } \\
\text { Spending }\end{array}$ & $\begin{array}{c}\text { Any OOP } \\
\text { Spending }\end{array}$ & $\begin{array}{c}\text { Total } \\
\text { Spending }\end{array}$ \\
\hline $\begin{array}{l}\text { Missouri }_{i} \\
\times \text { Post2005 }_{t}\end{array}$ & $\begin{array}{c}-0.035^{* *} \\
(0.017)\end{array}$ & $\begin{array}{c}0.023^{*} \\
(0.012)\end{array}$ & $\begin{array}{c}-0.174 \\
(0.122)\end{array}$ & $\begin{array}{c}0.274^{* * *} \\
(0.101)\end{array}$ & 0.012 & 0.095 \\
& & & & & & \\
& Yes & Yes & Yes & Yes & Yes & Yes \\
State FEs & Yes & Yes & Yes & Yes & Yes & Yes \\
Year FEs & 0.20 & 0.12 & 0.12 & 0.27 & 0.14 & 0.20 \\
$R^{2}$ & 28,053 & 28,053 & 28,053 & 28,053 & 28,053 & 28,053 \\
$N$ & & & & & & \\
\hline
\end{tabular}

Notes: Based on authors' calculations using the restricted Medical Expenditure Panel Survey (MEPS) data. Spending dependent variables are natural logs of spending plus one. Standard errors calculated using a block bootstrap are reported in parentheses. $* * *$ indicates $\mathrm{p}<0.01, * *$ indicates $\mathrm{p}<0.05, *$ indicates $\mathrm{p}<0.10$. Control variables include state and year fixed effects, sex, race (Black, Asian), ethnicity (Hispanic), education (high school grad, college grad), marital status, family size, and age (dummies for each year). Data are from 2000-2007 with 2005 omitted as partially treated since the contraction happened halfway through the year. Spending is measured in constant 2012 dollars. Control states are Oklahoma, Kansas, Nebraska, lowa, Illinois, Kentucky, and Arkansas; Tennessee is omitted because of its own Medicaid reform in 2005. 
Table 3A: Observations per State in MEPS Data

\begin{tabular}{|l|l|}
\hline State & Total Number of Observations \\
\hline Arkansas & 3,326 \\
\hline Illinois & 10,199 \\
\hline lowa & 1,707 \\
\hline Kansas & 1,410 \\
\hline Kentucky & 5,084 \\
\hline Missouri & 5,053 \\
\hline Nebraska & 2,407 \\
\hline Oklahoma & 3,032 \\
\hline
\end{tabular}

Notes: Total number of observations in the MEPS data from 2000-2007. 
Table 4A: Effect of Missouri Medicaid Cut on Insurance Status and Spending (3 or more family members)

\begin{tabular}{lcccccc}
\hline & $\begin{array}{c}\text { Medicaid } \\
\text { Receipt }\end{array}$ & Uninsured & $\begin{array}{c}\text { Medicaid } \\
\text { Spending }\end{array}$ & $\begin{array}{c}\text { OOP } \\
\text { Spending }\end{array}$ & $\begin{array}{c}\text { Any OOP } \\
\text { Spending }\end{array}$ & $\begin{array}{c}\text { Total } \\
\text { Spending }\end{array}$ \\
\hline $\begin{array}{l}\text { Missouri }_{i} \\
\times \text { Post2005t }_{t}\end{array}$ & $\begin{array}{c}\text {-0.059*** } \\
(0.022)\end{array}$ & 0.026 & -0.225 & 0.256 & -0.001 & 0.051 \\
& & $(0.017)$ & $(0.146)$ & $(0.159)$ & $(0.022)$ & $(0.179)$ \\
& Yes & Yes & Yes & Yes & Yes & Yes \\
State FEs & Yes & Yes & Yes & Yes & Yes & Yes \\
Year FEs & 0.15 & 0.11 & 0.09 & 0.17 & 0.10 & 0.13 \\
$R^{2}$ & 16,521 & 16,521 & 16,521 & 16,521 & 16,521 & 16,521 \\
$N$ & & & & & & \\
\hline
\end{tabular}

Notes: Based on authors' calculations using the restricted Medical Expenditure Panel Survey (MEPS) data. Spending dependent variables are natural logs of spending plus one. Standard errors calculated using a block bootstrap are reported in parentheses. ${ }^{* * *}$ indicates $p<0.01,{ }^{* *}$ indicates $p<0.05,{ }^{*}$ indicates $p<0.10$. Control variables include state and year fixed effects, sex, race (Black, Asian), ethnicity (Hispanic), education (high school grad, college grad), marital status, family size, and age (dummies for each year). Data are from 2000-2007 with 2005 omitted as partially treated since the contraction happened halfway through the year. Spending is measured in constant 2012 dollars. Control states are Oklahoma, Kansas, Nebraska, lowa, Illinois, Kentucky, and Arkansas; Tennessee is omitted because of its own Medicaid reform in 2005. 
Table 5A: Effect of Missouri Medicaid Cut on Insurance Status and Spending (Under Age 65)

\begin{tabular}{lcccccc}
\hline & $\begin{array}{c}\text { Medicaid } \\
\text { Receipt }\end{array}$ & Uninsured & $\begin{array}{c}\text { Medicaid } \\
\text { Spending }\end{array}$ & $\begin{array}{c}\text { OOP } \\
\text { Spending }\end{array}$ & $\begin{array}{c}\text { Any OOP } \\
\text { Spending }\end{array}$ & $\begin{array}{c}\text { Total } \\
\text { Spending }\end{array}$ \\
\hline $\begin{array}{l}\text { Missouri }_{i} \\
\times \text { Post2005t }_{t}\end{array}$ & $\begin{array}{c}-0.038^{* *} \\
(0.016)\end{array}$ & 0.020 & -0.166 & $0.409 * * *$ & 0.028 & $0.230^{* *}$ \\
& & $(0.015)$ & $(0.113)$ & $(0.113)$ & $(0.018)$ & $(0.113)$ \\
& Yes & Yes & Yes & Yes & Yes & Yes \\
State FEs & Yes & Yes & Yes & Yes & Yes & Yes \\
Year FEs & 0.15 & 0.09 & 0.09 & 0.19 & 0.10 & 0.15 \\
$R^{2}$ & 23,409 & 23,409 & 23,409 & 23,409 & 23,409 & 23,409 \\
$N$ & & & & & & \\
\hline
\end{tabular}

Note: Based on authors' calculations using the restricted Medical Expenditure Panel Survey (MEPS) data. Spending dependent variables are natural logs of spending plus one. Standard errors calculated using a block bootstrap are reported in parentheses. $* * *$ indicates $\mathrm{p}<0.01, * *$ indicates $\mathrm{p}<0.05, *$ indicates $\mathrm{p}<0.10$. Control variables include state and year fixed effects, sex, race (Black, Asian), ethnicity (Hispanic), education (high school grad, college grad), marital status, family size, and age (dummies for each year). Data are from 2000-2007 with 2005 omitted as partially treated since the contraction happened halfway through the year. Spending is measured in constant 2012 dollars. Control states are Oklahoma, Kansas, Nebraska, lowa, Illinois, Kentucky, and Arkansas; Tennessee is omitted because of its own Medicaid reform in 2005. 
Table 6A: Effect of Missouri Medicaid Cut on Insurance Status and Spending (No IndividualLevel Controls)

\begin{tabular}{lcccccc}
\hline & $\begin{array}{c}\text { Medicaid } \\
\text { Receipt }\end{array}$ & Uninsured & $\begin{array}{c}\text { Medicaid } \\
\text { Spending }\end{array}$ & $\begin{array}{c}\text { OOP } \\
\text { Spending }\end{array}$ & $\begin{array}{c}\text { Any OOP } \\
\text { Spending }\end{array}$ & $\begin{array}{c}\text { Total } \\
\text { Spending }\end{array}$ \\
\hline $\begin{array}{l}\text { Missouri }_{i} \\
\times \text { Post2005 }_{t}\end{array}$ & $-0.045^{* * *}$ & 0.009 & $-0.212^{* *}$ & $0.493^{* * *}$ & $0.032^{*}$ & $0.319^{* *}$ \\
& $(0.016)$ & $(0.014)$ & $(0.106)$ & $(0.136)$ & $(0.019)$ & $(0.144)$ \\
& & & & & & \\
State FEs & Yes & Yes & Yes & Yes & Yes & Yes \\
Year FEs & Yes & Yes & Yes & Yes & Yes & Yes \\
$R^{2}$ & 0.01 & 0.01 & 0.01 & 0.01 & 0.01 & 0.01 \\
$N$ & 26,714 & 26,714 & 26,714 & 26,714 & 26,714 & 26,714 \\
\hline
\end{tabular}

Notes: Based on authors' calculations using the restricted Medical Expenditure Panel Survey (MEPS) data. Spending dependent variables are natural logs of spending plus one. Standard errors calculated using a block bootstrap are reported in parentheses. $* * *$ indicates $\mathrm{p}<0.01, * *$ indicates $\mathrm{p}<0.05, *$ indicates $\mathrm{p}<0.10$. Control variables include state and year fixed effects. Data are from 2000-2007 with 2005 omitted as partially treated since the contraction happened halfway through the year. Spending is measured in constant 2012 dollars. Control states are Oklahoma, Kansas, Nebraska, lowa, Illinois, Kentucky, and Arkansas; Tennessee is omitted because of its own Medicaid reform in 2005. 
Table 7A: Placebo Test: Effect of Missouri Medicaid Cut on Demographics

\begin{tabular}{lcccccc}
\hline & & & & & & \\
& Family Size & Male & Black & Hispanic & Married & HS Grad \\
\hline $\begin{array}{l}\text { Missouri }_{i} \\
\times \text { Post2005 }_{t}\end{array}$ & -0.076 & -0.006 & 0.015 & $0.020^{* *}$ & 0.017 & 0.019 \\
& $(0.095)$ & $(0.021)$ & $(0.012)$ & $(0.009)$ & $(0.026)$ & $(0.021)$ \\
& & & & & & \\
State FEs & Yes & Yes & Yes & Yes & Yes & Yes \\
Year FEs & Yes & Yes & Yes & Yes & Yes & Yes \\
$R^{2}$ & 0.01 & 0.01 & 0.05 & 0.03 & 0.01 & 0.01 \\
$N$ & 26,714 & 26,714 & 26,714 & 26,714 & 26,714 & 26,714 \\
\hline
\end{tabular}

Notes: Based on authors' calculations using the restricted Medical Expenditure Panel Survey (MEPS) data. Spending dependent variables are natural logs of spending plus one. Standard errors calculated using a block bootstrap are reported in parentheses. ${ }^{* * *}$ indicates $\mathrm{p}<0.01,{ }^{* *}$ indicates $\mathrm{p}<0.05,{ }^{*}$ indicates $\mathrm{p}<0.10$. Control variables include state and year fixed effects, sex, race (Black, Asian), ethnicity (Hispanic), education (high school grad, college grad), marital status, family size, and age (dummies for each year) [naturally, none of these are used as controls in the same regression where they are the dependent variable]. Data are from 2000-2007 with 2005 omitted as partially treated since the contraction happened halfway through the year. Control states are Oklahoma, Kansas, Nebraska, lowa, Illinois, Kentucky, and Arkansas; Tennessee is omitted because of its own Medicaid reform in 2005. 
Table 8A: Effect of Missouri Medicaid Cut on Dollars Spent (non-logged)

\begin{tabular}{|c|c|c|c|}
\hline & $\begin{array}{l}\text { Medicaid } \\
\text { Spending }\end{array}$ & $\begin{array}{c}\text { OOP } \\
\text { Spending }\end{array}$ & $\begin{array}{c}\text { Total } \\
\text { Spending }\end{array}$ \\
\hline \multicolumn{4}{|l|}{ Missouri $_{i}$} \\
\hline$\times$ Post $2005_{t}$ & $\begin{array}{l}-70.67 \\
(73.40)\end{array}$ & $\begin{array}{c}150.11 * * \\
(65.46)\end{array}$ & $\begin{array}{c}112.37 \\
(414.19)\end{array}$ \\
\hline State FEs & Yes & Yes & Yes \\
\hline Year FEs & Yes & Yes & Yes \\
\hline$R^{2}$ & 0.01 & 0.10 & 0.07 \\
\hline$N$ & 26,714 & 26,714 & 26,714 \\
\hline
\end{tabular}

Notes: Based on authors' calculations using the restricted Medical Expenditure Panel Survey (MEPS) data. Standard errors calculated using a block bootstrap are reported in parentheses. $* * *$ indicates $\mathrm{p}<0.01, * *$ indicates $\mathrm{p}<0.05, *$ indicates $p<0.10$. Control variables include state and year fixed effects, sex, race (Black, Asian), ethnicity (Hispanic), education (high school grad, college grad), marital status, family size, and age (dummies for each year). Data are from 2000-2007 with 2005 omitted as partially treated since the contraction happened halfway through the year. Spending is measured in constant 2012 dollars. Control states are Oklahoma, Kansas, Nebraska, lowa, Illinois, Kentucky, and Arkansas; Tennessee is omitted because of its own Medicaid reform in 2005. 
Table 9A: Summary Statistics for the CCP Data and Control Variables

\begin{tabular}{lccccc} 
& \multicolumn{2}{c}{ Treatment Group } & \multicolumn{2}{c}{ Control Group } & \\
& $\mathrm{N}$ & Mean & $\mathrm{N}$ & Mean & Mean Difference \\
\hline Card balance & 567,753 & 4192.69 & 324,458 & 4466.36 & $-273.66^{* * *}$ \\
Number of cards & 909,144 & 1.99 & 497,054 & 2.08 & $-0.085^{* * *}$ \\
Amount delinquent on cards & 665,780 & 230.44 & 370,861 & 206.11 & $24.33^{* * *}$ \\
Number of collections & 936,307 & 0.27 & 510,498 & 0.24 & $0.032^{* * *}$ \\
Amount in collections & 327,945 & 408.03 & 154,727 & 394.78 & 13.25 \\
Risk Score & 891,959 & 676.74 & 493,812 & 685.35 & $-8.61^{* * *}$ \\
Unemployment rate & 993,528 & 6.09 & 539,475 & 6.12 & $-0.029^{* * *}$ \\
Percent in poverty & 993,528 & 12.32 & 539,475 & 11.16 & $1.16^{* * *}$ \\
Proportion disabled & 993,528 & 0.031 & 539,475 & 0.028 & $0.0029 * * *$ \\
Proportion Black & 993,528 & 0.18 & 539,475 & 0.093 & $0.087^{* * *}$ \\
Age & 953,828 & 48.19 & 518,845 & 48.18 & 0.016 \\
\hline
\end{tabular}

Notes: Based on authors' calculations using the CCP data from Q1:2003 to Q2:2005. Age is individual level based on year of birth in the CCP. The Risk Score is the Equifax Risk Score. The county-level demographic data are from the BLS's Local Area Unemployment Statistics, the U.S. Census Bureau, the Small Area Income and Poverty Estimates, and the Old Age, Survivors and Disability Insurance data. 
Table 10A: Summary Statistics for the CCP Data in Missouri Border and Non-Border Regions

\begin{tabular}{lccccc} 
& \multicolumn{2}{c}{ MO Border Blocks } & MO Non-Border Blocks & \\
& $\mathrm{N}$ & Mean & $\mathrm{N}$ & Mean & Mean Difference \\
\hline Card balance & $1,180,094$ & 4209.8 & $1,531,478$ & 4293.7 & $-83.91^{* * *}$ \\
Number of cards & $1,935,068$ & 1.943 & $2,344,693$ & 2.030 & $-0.087^{* * *}$ \\
Amount delinquent on cards & $1,373,257$ & 258.0 & $1,728,682$ & 217.3 & $40.78^{* * *}$ \\
Number of collections & $1,980,483$ & 0.317 & $2,384,752$ & 0.242 & $0.075^{* * *}$ \\
Amount in collections & 724,097 & 479.5 & 709,240 & 453.7 & $25.84^{* * *}$ \\
Risk Score & $1,868,253$ & 678.8 & $2,303,767$ & 691.9 & $-13.07^{* * *}$ \\
Unemployment rate & $2,126,918$ & 5.657 & $2,520,483$ & 5.236 & $0.42^{* * *}$ \\
Percent in poverty & $2,126,918$ & 12.67 & $2,520,483$ & 13.33 & $-0.65^{* * *}$ \\
Proportion disabled & $2,126,918$ & 0.0318 & $2,520,483$ & 0.0375 & $-0.0057^{* * *}$ \\
Proportion Black & $2,126,918$ & 0.183 & $2,520,483$ & 0.0692 & $0.11^{* * *}$ \\
Age & $2,026,664$ & 48.37 & $2,430,170$ & 48.53 & $-0.16^{* * *}$ \\
\hline
\end{tabular}

Notes: Based on authors' calculations using the CCP data. Age is individual level, based on year of birth in the CCP. The Risk Score is the Equifax Risk Score. The county-level demographic data are from the BLS's Local Area Unemployment Statistics, the U.S. Census Bureau, the Small Area Income and Poverty Estimates, and the Old Age, Survivors and Disability Insurance data. 
Table 11A: Differences-in-Differences Results from the Consumer Credit Panel (CCP)

\begin{tabular}{|c|c|c|c|c|c|c|}
\hline & $\begin{array}{c}\text { Total } \\
\text { Bankcard } \\
\text { Balance } \\
(\$)\end{array}$ & $\begin{array}{l}\text { Number of } \\
\text { Bankcards }\end{array}$ & $\begin{array}{l}\text { Amount } \\
\text { Delinquent } \\
\text { on } \\
\text { Bankcards } \\
\text { (\$) }\end{array}$ & $\begin{array}{l}\text { Number of } \\
\text { Accounts } \\
\text { in Third- } \\
\text { Party } \\
\text { Collections }\end{array}$ & $\begin{array}{l}\text { Amount in } \\
\text { Third- } \\
\text { Party } \\
\text { Collections } \\
\text { (\$) }\end{array}$ & $\begin{array}{c}\text { Risk Score } \\
\text { (points) }\end{array}$ \\
\hline \multicolumn{7}{|l|}{ Post-Reform } \\
\hline \multicolumn{7}{|l|}{ Missouri $_{i}$} \\
\hline \multirow[t]{2}{*}{$\times \operatorname{Post} 2005_{t}$} & $130.4 * *$ & $0.0161^{*}$ & 7.808 & $0.0430 * * *$ & $63.66 * * *$ & $-0.563^{*}$ \\
\hline & $(40.65)$ & $(0.00644)$ & $(7.972)$ & $(0.00397)$ & $(19.31)$ & $(0.233)$ \\
\hline Adj. $R^{2}$ & 0.694 & 0.841 & 0.510 & 0.432 & 0.142 & 0.884 \\
\hline \multicolumn{7}{|c|}{ Post-Reform: Short Run and Long Run } \\
\hline \multicolumn{7}{|c|}{ Missouri $_{i}$} \\
\hline \multirow[t]{2}{*}{$\times$ Post_SR } & 79.94* & $0.0165^{* *}$ & -0.751 & $0.0211 * * *$ & 8.168 & 0.116 \\
\hline & $(38.02)$ & $(0.00604)$ & $(7.475)$ & $(0.00419)$ & $(20.84)$ & $(0.222)$ \\
\hline \multicolumn{7}{|l|}{ Missouri $_{i}$} \\
\hline \multirow[t]{2}{*}{$\times$ Post_LR } & $169.6 * * *$ & $0.0157^{*}$ & 14.38 & $0.0593 * * *$ & $107.9 * * *$ & $-1.071 * * *$ \\
\hline & $(48.01)$ & $(0.00743)$ & $(9.750)$ & $(0.00482)$ & $(23.69)$ & $(0.279)$ \\
\hline Adj. $R^{2}$ & 0.694 & 0.841 & 0.510 & 0.432 & 0.143 & 0.884 \\
\hline$N$ & $1,773,783$ & $2,759,387$ & $2,048,214$ & $2,835,830$ & 982,218 & $2,724,908$ \\
\hline
\end{tabular}

Notes: Authors' calculations using data from the CCP. Missouri $i_{i}$ is an indicator variable for individuals living within 10 miles of the Missouri side of the Missouri border. In the top panel, Post $2005_{t}$ is a dummy variable equal to one for quarters between Q3:2005 and Q4:2007. In the bottom panel, Post_SR is a dummy variable equal to one for quarters between Q3:2005 and Q2:2006 and Post_LR is a dummy variable equal to one for quarters between Q3:2006 and Q4:2007. Robust standard errors are clustered at the census tract level and reported in parentheses. $* * *, * *, *$ - denote significance at the $0.01,0.05$, and 0.10 levels. Risk Score is the Equifax Risk Score. 
Table 12A: The Effect of Missouri Medicaid Cut on Bankruptcy and Severely Delinquent Debt

\begin{tabular}{|c|c|c|c|c|}
\hline & $\begin{array}{c}\text { Presence of } \\
\text { Bankcard } \\
\text { Severely } \\
\text { Delinquent }\end{array}$ & $\begin{array}{l}\text { Number of } \\
\text { Bankcards } \\
\text { Severely } \\
\text { Delinquent }\end{array}$ & $\begin{array}{c}\text { Share of Bankcard } \\
\text { Balance Severely } \\
\text { Delinquent }\end{array}$ & $\begin{array}{c}\text { First } \\
\text { Declaration of } \\
\text { Bankruptcy }\end{array}$ \\
\hline \multicolumn{5}{|l|}{ Post-Reform } \\
\hline \multicolumn{5}{|l|}{ Missouri $_{i}$} \\
\hline \multirow{2}{*}{$\times$ Post $2005_{t}$} & 0.000545 & 0.0000824 & $0.00357 * *$ & $0.000308^{*}$ \\
\hline & $(0.00116)$ & $(0.00234)$ & $(0.00118)$ & $(0.000137)$ \\
\hline Adj. $R^{2}$ & 0.572 & 0.522 & 0.744 & 0.109 \\
\hline \multicolumn{5}{|c|}{ Post-Reform: Short Run and Long Run } \\
\hline \multicolumn{5}{|c|}{ Missouri $_{i}$} \\
\hline \multirow[t]{2}{*}{$\times$ Post_SRt } & 0.000386 & 0.000378 & 0.00138 & 0.000318 \\
\hline & $(0.00116)$ & $(0.00231)$ & $(0.00116)$ & $(0.000191)$ \\
\hline \multicolumn{5}{|l|}{ Missouri $_{i}$} \\
\hline \multirow[t]{2}{*}{$\times P o s t_{-} L R_{t}$} & 0.000663 & -0.000137 & $0.00528 * * *$ & $0.000301 *$ \\
\hline & $(0.00135)$ & $(0.00270)$ & $(0.00142)$ & $(0.000135)$ \\
\hline Adj. $R^{2}$ & 0.572 & 0.522 & 0.744 & 0.109 \\
\hline$N$ & $2,779,978$ & $2,779,978$ & $1,747,720$ & $2,878,948$ \\
\hline
\end{tabular}

Notes: Authors' calculations using data from the CCP. Missouri $i_{i}$ is an indicator variable for individuals living within 10 miles of the Missouri side of the Missouri border. In the top panel, Post $2005_{t}$ is a dummy variable equal to one for quarters between Q3:2005 and Q4:2007. In the bottom panel, Post_SR is a dummy variable equal to one for quarters between Q3:2005 and Q2:2006 and Post_LR is a dummy variable equal to one for quarters between Q3:2006 and Q4:2007. Robust standard errors are clustered at the census tract level and reported in parentheses. $* * *, * *, *$ - denote significance at the $0.01,0.05$, and 0.10 levels. Risk Score is the Equifax Risk Score. 
Table 13A: The Effect of Missouri Medicaid Cut on Bankruptcy and Severely Delinquent Debt (Event Study Coefficients)

\begin{tabular}{|c|c|c|c|c|}
\hline & \multirow{2}{*}{$\begin{array}{c}\text { Presence of } \\
\text { Bankcard Severely } \\
\text { Delinquent }\end{array}$} & \multicolumn{3}{|c|}{ Share of Bankcard } \\
\hline & & $\begin{array}{l}\text { Number of Bankcards } \\
\text { Severely Delinquent }\end{array}$ & $\begin{array}{c}\text { Balance Severely } \\
\text { Delinquent }\end{array}$ & $\begin{array}{c}\text { First Declaration of } \\
\text { Bankruptcy }\end{array}$ \\
\hline \multirow[t]{2}{*}{ Missouri $_{i} \times Q 1: 2003_{t}$} & 0.00257 & $0.00975^{* *}$ & $-0.00489 *$ & -0.000273 \\
\hline & (0.00189) & $(0.00377)$ & (0.00199) & $(0.000445)$ \\
\hline \multirow[t]{2}{*}{ Missouri $_{i} \times Q 2: 2003_{t}$} & 0.00207 & 0.00457 & $-0.00620 * * *$ & -0.0000886 \\
\hline & $(0.00178)$ & $(0.00366)$ & $(0.00188)$ & $(0.000441)$ \\
\hline \multirow{2}{*}{ Missouri $_{i} \times Q 3: 2003_{t}$} & -0.000965 & -0.000351 & $-0.00642 * * *$ & -0.000606 \\
\hline & $(0.00176)$ & $(0.00353)$ & $(0.00182)$ & $(0.000443)$ \\
\hline \multirow{2}{*}{ Missouri $_{i} \times Q 4: 2003_{t}$} & 0.00283 & 0.00636 & $-0.00354^{*}$ & -0.000567 \\
\hline & $(0.00167)$ & $(0.00346)$ & $(0.00172)$ & $(0.000449)$ \\
\hline \multirow{2}{*}{ Missouri $_{i} \times Q 1: 2004_{t}$} & 0.00218 & 0.00632 & $-0.00375^{*}$ & 0.0000445 \\
\hline & (0.00160) & $(0.00330)$ & $(0.00163)$ & $(0.000438)$ \\
\hline \multirow{2}{*}{ Missouri $_{i} \times Q 2: 2004_{t}$} & 0.000748 & 0.00211 & -0.00284 & -0.000401 \\
\hline & $(0.00154)$ & $(0.00311)$ & $(0.00156)$ & $(0.000459)$ \\
\hline \multirow{2}{*}{ Missouri $_{i} \times Q 3: 2004_{t}$} & 0.00193 & 0.00412 & $-0.00291^{*}$ & -0.000199 \\
\hline & $(0.00142)$ & (0.00284) & $(0.00147)$ & $(0.000435)$ \\
\hline \multirow{2}{*}{ Missouri $_{i} \times Q 4: 2004_{t}$} & -0.00189 & -0.000815 & $-0.00286^{*}$ & -0.000336 \\
\hline & $(0.00131)$ & $(0.00260)$ & $(0.00130)$ & $(0.000463)$ \\
\hline \multirow{2}{*}{ Missouri $_{i} \times Q 1: 2005_{t}$} & -0.000405 & 0.000187 & 0.000364 & -0.000339 \\
\hline & $(0.00112)$ & $(0.00211)$ & $(0.00105)$ & $(0.000441)$ \\
\hline \multirow{2}{*}{ Missouri $_{i} \times Q 3: 2005_{t}$} & -0.000197 & 0.000878 & $-0.00249^{*}$ & 0.000287 \\
\hline & $(0.00105)$ & $(0.00184)$ & (0.00109) & $(0.000467)$ \\
\hline \multirow{2}{*}{ Missouri $_{i} \times Q 4: 2005_{t}$} & 0.00123 & 0.00291 & -0.00164 & 0.000303 \\
\hline & $(0.00127)$ & $(0.00233)$ & $(0.00135)$ & $(0.000541)$ \\
\hline \multirow{2}{*}{ Missouri $_{i} \times Q 1: 2006_{t}$} & $0.00272 *$ & $0.00627^{*}$ & -0.000854 & -0.000226 \\
\hline & $(0.00136)$ & $(0.00255)$ & $(0.00146)$ & $(0.000373)$ \\
\hline \multirow[t]{2}{*}{ Missouri $_{i} \times Q 2: 2006_{t}$} & 0.00113 & 0.00358 & -0.00156 & -0.000193 \\
\hline & (0.00143) & (0.00267) & $(0.00153)$ & $(0.000375)$ \\
\hline \multirow{2}{*}{ Missouri $_{i} \times Q 3: 2006_{t}$} & 0.00169 & 0.00286 & -0.000291 & -0.000127 \\
\hline & $(0.00151)$ & $(0.00287)$ & $(0.00160)$ & $(0.000395)$ \\
\hline \multirow{2}{*}{ Missouri $_{i} \times Q 4: 2006_{t}$} & 0.00103 & 0.00160 & 0.00142 & 0.0000184 \\
\hline & $(0.00159)$ & $(0.00307)$ & $(0.00169)$ & $(0.000394)$ \\
\hline \multirow{2}{*}{ Missouri $_{i} \times Q 1: 2007_{t}$} & 0.000255 & 0.00147 & 0.00241 & -0.000329 \\
\hline & $(0.00164)$ & $(0.00320)$ & $(0.00177)$ & $(0.000407)$ \\
\hline \multirow[t]{2}{*}{ Missouri $_{i} \times Q 2: 2007_{t}$} & 0.00138 & 0.00230 & 0.00183 & 0.0000672 \\
\hline & (0.00171) & (0.00328) & $(0.00181)$ & $(0.000403)$ \\
\hline \multirow[t]{2}{*}{ Missouri $_{i} \times Q 3: 2007_{t}$} & 0.00187 & 0.00284 & 0.00339 & 0.000265 \\
\hline & $(0.00176)$ & $(0.00335)$ & $(0.00187)$ & $(0.000393)$ \\
\hline \multirow[t]{2}{*}{ Missouri $_{i} \times Q 4: 2007_{t}$} & 0.00267 & 0.00606 & $0.00537^{* *}$ & 0.000295 \\
\hline & $(0.00183)$ & $(0.00350)$ & $(0.00194)$ & $(0.000404)$ \\
\hline$R^{2}$ & 0.572 & 0.522 & 0.744 & 0.109 \\
\hline$N$ & $2,779,978$ & $2,779,978$ & $1,747,720$ & $2,878,948$ \\
\hline
\end{tabular}

Note: Based on authors' calculations using data from the CCP. The omitted period is Q2:2005. Risk Score is the Equifax Risk Score. Missouri $i$ is an indicator variable for living within 10 miles of the Missouri border. Robust standard errors are clustered at the census tract level and reported in parentheses. ***, **, and * denote significance at the $0.01,0.05$, and 0.10 levels, respectively. 
Table 14A: Summary of Pre-ACA State Medicaid Changes

\begin{tabular}{|l|c|c|c|l|}
\hline \multicolumn{1}{|c|}{ State } & $\begin{array}{c}\text { Year of } \\
\text { Policy } \\
\text { Change }\end{array}$ & $\begin{array}{c}\text { Number of } \\
\text { Individuals } \\
\text { Affected }\end{array}$ & $\begin{array}{c}\text { One Year Change } \\
\text { in Medicaid } \\
\text { Spending }\end{array}$ & \multicolumn{1}{|c|}{ Study/Source } \\
\hline Missouri & 2005 & 470,000 & $-3 \%$ & $\begin{array}{l}\text { Zuckerman, Miller, and } \\
\text { Page (2009) }\end{array}$ \\
\hline Massachusetts & 2006 & 409,000 & $11 \%$ & Doonan and Tull (2010) \\
\hline Arizona & 2001 & $10,500-51,000$ & $34 \%$ & $\begin{array}{l}\text { Coughlin, Long, Graves, } \\
\text { and Yemane (2006); } \\
\text { Mann, Artiga, and Guyer } \\
\text { (2003) }\end{array}$ \\
\hline Maine & 2002 & 16,300 & $19 \%$ & $\begin{array}{l}\text { Coughlin, Long, Graves, } \\
\text { and Yemane (2006) }\end{array}$ \\
\hline California & 2011 & 515,000 & $14 \%$ & $\begin{array}{l}\text { Sommers, Kenney, and } \\
\text { Epstein (2014) }\end{array}$ \\
\hline $\begin{array}{l}\text { Washington, } \\
\text { D.C. }\end{array}$ & 2010 & 49,000 & $10 \%$ & $\begin{array}{l}\text { Sommers, Kenney, and } \\
\text { Epstein (2014) }\end{array}$ \\
\hline Connecticut & 2010 & 91,000 & $2 \%$ & $\begin{array}{l}\text { Sommers, Kenney, and } \\
\text { Epstein (2014) }\end{array}$ \\
\hline Minnesota & 2011 & 87,000 & $6 \%$ & $\begin{array}{l}\text { Sommers, Kenney, and } \\
\text { Epstein (2014) }\end{array}$ \\
\hline Tennessee & 2005 & 170,000 & $-16 \%$ & $\begin{array}{l}\text { Farrar, Eichenthal, } \\
\text { Coleman, and Reese } \\
\text { (2007) }\end{array}$ \\
\hline New York & 2001 & $500,000-650,000$ & $13 \%$ & $\begin{array}{l}\text { Coughlin and Zuckerman } \\
\text { (2008); Fiorentini (2013) }\end{array}$ \\
\hline Illinois & 2002 & $114,000-275,000$ & $8 \%$ & $\begin{array}{l}\text { Coughlin, Long, Graves, } \\
\text { and Yemane (2006); } \\
\text { Centers for Medicare and } \\
\text { Medicaid Services (2008) }\end{array}$ \\
\hline
\end{tabular}

Note: Changes in Medicaid spending based on authors' calculations using data from the CMS (Centers for Medicare and Medicaid Services, 2017). Total Medicaid spending is deflated to 2013 dollars. 
Table 15A: The Effect of Missouri Medicaid Cut on Consumer Credit Outcomes in Subsamples

\begin{tabular}{|c|c|c|c|c|c|c|}
\hline & $\begin{array}{c}\text { Total } \\
\text { Bankcard } \\
\text { Balance } \\
(\$)\end{array}$ & $\begin{array}{c}\text { Number of } \\
\text { Bankcards }\end{array}$ & $\begin{array}{c}\text { Amount } \\
\text { Delinquent } \\
\text { on } \\
\text { Bankcards } \\
(\$) \\
\end{array}$ & $\begin{array}{l}\text { Number of } \\
\text { Accounts in } \\
\text { Third-Party } \\
\text { Collections }\end{array}$ & $\begin{array}{l}\text { Amount in } \\
\text { Third-Party } \\
\text { Collections } \\
\text { (\$) }\end{array}$ & $\begin{array}{c}\text { Risk Score } \\
\text { (points) }\end{array}$ \\
\hline \multirow[t]{2}{*}{$<$ age 65} & $110.7^{*}$ & 0.0138 & 7.849 & $0.0493 * * *$ & $69.15^{* * *}$ & $-0.592 *$ \\
\hline & $(48.61)$ & $(0.00736)$ & $(9.015)$ & $(0.00490)$ & $(20.50)$ & $(0.277)$ \\
\hline \multirow[t]{2}{*}{$>$ age 65} & $161.6^{*}$ & 0.0183 & 8.967 & $0.0139 * * *$ & 2.030 & -0.346 \\
\hline & $(68.09)$ & $(0.0128)$ & $(16.44)$ & $(0.00371)$ & (44.89) & $(0.418)$ \\
\hline \multirow[t]{2}{*}{$<$ proportion Black } & 48.88 & $0.0275^{*}$ & -4.010 & $0.0182 * *$ & 26.12 & 0.327 \\
\hline & $(60.43)$ & $(0.0113)$ & $(13.94)$ & $(0.00684)$ & $(35.59)$ & $(0.387)$ \\
\hline \multirow{2}{*}{ > proportion Black } & $272.6 * * *$ & 0.00169 & 14.57 & $0.0678 * * *$ & $73.45 * *$ & $-0.833^{*}$ \\
\hline & $(58.11)$ & $(0.00851)$ & $(11.22)$ & $(0.00607)$ & $(25.79)$ & $(0.338)$ \\
\hline \multirow[t]{2}{*}{$<$ proportion disabled } & -24.02 & $0.0324 * *$ & -1.541 & $0.0190 * *$ & 67.54 & -0.223 \\
\hline & $(63.04)$ & $(0.0107)$ & $(11.04)$ & $(0.00602)$ & $(52.42)$ & $(0.361)$ \\
\hline \multirow[t]{2}{*}{$>$ proportion disabled } & $171.9 * *$ & $0.0195^{*}$ & 0.596 & $0.0394 * * *$ & 36.32 & 0.253 \\
\hline & $(56.60)$ & $(0.00903)$ & $(12.93)$ & $(0.00616)$ & $(22.10)$ & $(0.340)$ \\
\hline \multirow[t]{2}{*}{$<$ proportion poverty } & -8.493 & $0.0367 * * *$ & -1.754 & 0.00534 & 22.83 & -0.599 \\
\hline & $(59.37)$ & $(0.00985)$ & $(9.806)$ & $(0.00556)$ & $(48.13)$ & $(0.336)$ \\
\hline \multirow[t]{2}{*}{$>$ proportion poverty } & $226.7^{* * *}$ & 0.00576 & 3.316 & $0.0601 * * *$ & $94.18 * * *$ & 0.397 \\
\hline & $(57.77)$ & $(0.00885)$ & $(12.48)$ & $(0.00620)$ & $(19.98)$ & $(0.335)$ \\
\hline \multirow[t]{2}{*}{$<$ unemployment rate } & 9.420 & $0.0220 *$ & 1.793 & $0.0331 * * *$ & $86.87 * *$ & $-0.700 *$ \\
\hline & $(50.15)$ & $(0.00856)$ & (9.917) & $(0.00492)$ & $(32.07)$ & $(0.295)$ \\
\hline \multirow[t]{2}{*}{$>$ unemployment rate } & $258.9 * * *$ & $0.0225^{*}$ & 9.168 & $0.0543 * * *$ & 46.74 & 0.190 \\
\hline & $(75.44)$ & $(0.0108)$ & $(15.87)$ & $(0.00789)$ & $(27.81)$ & $(0.427)$ \\
\hline \multirow[t]{2}{*}{ Not KC/STL } & -21.42 & 0.0215 & 0.569 & $0.0334 * * *$ & 74.04 & 0.487 \\
\hline & $(71.26)$ & $(0.0123)$ & $(17.29)$ & $(0.00861)$ & $(37.93)$ & $(0.438)$ \\
\hline \multirow[t]{2}{*}{$\mathrm{KC} / \mathrm{STL}$} & $235.1 * * *$ & $0.0167^{*}$ & 5.771 & $0.0434 * * *$ & $88.27 * * *$ & $-0.896 * *$ \\
\hline & $(54.03)$ & $(0.00793)$ & $(8.747)$ & $(0.00471)$ & $(23.10)$ & $(0.290)$ \\
\hline
\end{tabular}

Notes: Based on authors' calculations using data from the CCP. The table above presents the results of the main difference-in-differences model along six different heterogeneity cuts. The median value is used for making the cuts of proportion Black, proportion disabled, percent in poverty, and unemployment rate. Age is individual level, based on year of birth in the CCP. The Risk Score is the Equifax Risk Score. The county-level demographic data are from the BLS's Local Area Unemployment Statistics, the Census Bureau, the Small Area Income and Poverty Estimates, and the Old Age, Survivors and Disability Insurance data. Risk Score is the Equifax Risk Score. ${ }^{* * *},{ }^{* *}$, and ${ }^{*}$ denote significance at the $0.01,0.05$, and 0.10 levels, respectively. 
Table 16A: Differences-in-Differences Results from the Consumer Credit Panel (CCP) for Kansas City/St. Louis Sample with Different Clustering Options

\begin{tabular}{|c|c|c|c|c|c|c|}
\hline $\begin{array}{l}\text { Standard error } \\
\text { method }\end{array}$ & $\begin{array}{c}\text { Total } \\
\text { Bankcard } \\
\text { Balance (\$) }\end{array}$ & $\begin{array}{c}\text { Number } \\
\text { of } \\
\text { Bankcards }\end{array}$ & $\begin{array}{c}\text { Amount } \\
\text { Delinquent } \\
\text { on } \\
\text { Bankcards } \\
\text { (\$) }\end{array}$ & $\begin{array}{l}\text { Number of } \\
\text { Accounts in } \\
\text { Third-Party } \\
\text { Collections }\end{array}$ & $\begin{array}{c}\text { Amount in } \\
\text { Third-Party } \\
\text { Collections } \\
\text { (\$) }\end{array}$ & $\begin{array}{c}\text { Risk Score } \\
\text { (points) }\end{array}$ \\
\hline $\begin{array}{l}\text { Clustering by } \\
\text { census tract }\end{array}$ & $\begin{array}{c}235.1 * * * \\
(54.03)\end{array}$ & $\begin{array}{c}0.0167^{*} \\
(0.00793)\end{array}$ & $\begin{array}{c}5.771 \\
(8.747)\end{array}$ & $\begin{array}{l}0.0434 * * * \\
(0.00471)\end{array}$ & $\begin{array}{c}88.27^{* * *} \\
(23.10)\end{array}$ & $\begin{array}{c}-0.896 * * \\
(0.290)\end{array}$ \\
\hline $\begin{array}{l}\text { Heteroskedasticity } \\
\text { robust }\end{array}$ & $\begin{array}{c}235.1 * * * \\
(22.70)\end{array}$ & $\begin{array}{c}0.0167 * * * \\
(0.00307)\end{array}$ & $\begin{array}{c}5.771 \\
(3.921)\end{array}$ & $\begin{array}{c}0.0434 * * * \\
(0.00248)\end{array}$ & $\begin{array}{c}88.27^{* * *} \\
(14.54)\end{array}$ & $\begin{array}{c}-0.896 * * * \\
(0.129)\end{array}$ \\
\hline No clustering & $\begin{array}{c}235.1 * * * \\
(21.10)\end{array}$ & $\begin{array}{c}0.0167 * * * \\
(0.00307)\end{array}$ & $\begin{array}{c}5.771 \\
(3.894)\end{array}$ & $\begin{array}{c}0.0434 * * * \\
(0.00254)\end{array}$ & $\begin{array}{c}88.27 * * * \\
(16.88)\end{array}$ & $\begin{array}{c}-0.896 * * * \\
(0.130)\end{array}$ \\
\hline Adj. R2 & 0.693 & 0.844 & 0.515 & 0.439 & 0.144 & 0.886 \\
\hline$N$ & $1,347,815$ & $2,078,696$ & $1,555,993$ & $2,134,076$ & 736,088 & $2,048,047$ \\
\hline Bootstrap & $\begin{array}{c}172.7^{* * * *} \\
(22.50)\end{array}$ & $\begin{array}{l}0.0216 * * * \\
(0.00291)\end{array}$ & $\begin{array}{c}7.868 \\
(4.067)\end{array}$ & $\begin{array}{l}0.0483 * * * \\
(0.00237)\end{array}$ & $\begin{array}{c}68.08 * * * \\
(12.59)\end{array}$ & $\begin{array}{c}-1.385^{* * *} \\
(0.121)\end{array}$ \\
\hline Adj. R2 & 0.692 & 0.843 & 0.514 & 0.439 & 0.145 & 0.886 \\
\hline $\mathrm{N}$ & $1,350,870$ & $2,079,289$ & $1,557,934$ & $2,134,604$ & 737,598 & $2,048,697$ \\
\hline
\end{tabular}

Notes: Based on authors' calculations using data from the CCP. The table above presents the results of the main difference-in-differences model using four separate clustering specifications: 1) clustering at the census tract level, 2) heteroskedasticity robust (i.e., Hubert/White sandwich estimator), 3) no clustering (i.e., OLS), and 4) bootstrap clustering with 300 repetitions. Standard errors differ in clustering specification and are reported in parentheses. Adjusted $\mathrm{R}^{2}$ and $\mathrm{N}$ are the same for tests 1 ) to 3 ) and are reported only once. The difference between estimates in models (1)-(3) and model (4) comes from different ways of specifying fixed effects (reghdfe versus areg commands in Stata). Risk Score is the Equifax Risk Score. ***,**, and * denote significance at the 0.01, 0.05, and 0.10 levels, respectively. 
Table 17A: CCP Event Study Results Coefficients with Bootstrapped Standard Errors

\begin{tabular}{|c|c|c|c|c|c|c|}
\hline & $\begin{array}{c}\text { Total } \\
\text { Bankcard } \\
\text { Balance (\$) }\end{array}$ & $\begin{array}{l}\text { Number of } \\
\text { Bankcards }\end{array}$ & $\begin{array}{c}\text { Amount } \\
\text { Delinquent on } \\
\text { Bankcards (\$) }\end{array}$ & $\begin{array}{c}\text { \# of Accounts } \\
\text { in Third-Party } \\
\text { Collections }\end{array}$ & $\begin{array}{c}\text { Amount in } \\
\text { Third-Party } \\
\text { Collections (\$) }\end{array}$ & $\begin{array}{c}\text { Risk Score } \\
\text { (points) }\end{array}$ \\
\hline Missouri $_{i} \times Q 1: 2003_{t}$ & $\begin{array}{c}56.545 \\
(105.134)\end{array}$ & $\begin{array}{c}0.016 \\
(0.025)\end{array}$ & $\begin{array}{l}-11.115 \\
(14.922)\end{array}$ & $\begin{array}{l}-0.008 \\
(0.017)\end{array}$ & $\begin{array}{c}-21.273 \\
(51.741)\end{array}$ & $\begin{array}{c}-0.934^{* *} \\
(0.450)\end{array}$ \\
\hline Missouri $_{i} \times Q 2: 2003_{t}$ & $\begin{array}{c}24.691 \\
(97.567)\end{array}$ & $\begin{array}{c}0.007 \\
(0.018)\end{array}$ & $\begin{array}{l}-10.085 \\
(15.408)\end{array}$ & $\begin{array}{l}-0.016 \\
(0.017)\end{array}$ & $\begin{array}{l}-27.345 \\
(54.812)\end{array}$ & $\begin{array}{l}-0.672 \\
(0.463)\end{array}$ \\
\hline Missouri $_{i} \times Q 3: 2003_{t}$ & $\begin{array}{c}32.179 \\
(73.608)\end{array}$ & $\begin{array}{l}0.002 \\
(0.014)\end{array}$ & $\begin{array}{l}-16.113 \\
(12.577)\end{array}$ & $\begin{array}{l}-0.011 \\
(0.018)\end{array}$ & $\begin{array}{l}-43.352 \\
(43.481)\end{array}$ & $\begin{array}{l}-0.353 \\
(0.421)\end{array}$ \\
\hline Missouri $_{i} \times Q 4: 2003_{t}$ & $\begin{array}{c}9.071 \\
(76.665)\end{array}$ & $\begin{array}{l}-0.002 \\
(0.013)\end{array}$ & $\begin{array}{l}-10.805 \\
(13.472)\end{array}$ & $\begin{array}{l}-0.009 \\
(0.022)\end{array}$ & $\begin{array}{l}-42.872 \\
(43.864)\end{array}$ & $\begin{array}{l}-0.377 \\
(0.379)\end{array}$ \\
\hline Missouri $_{i} \times Q 1: 2004_{t}$ & $\begin{array}{c}5.705 \\
(63.328)\end{array}$ & $\begin{array}{c}0.002 \\
(0.012)\end{array}$ & $\begin{array}{l}-13.038 \\
(10.302)\end{array}$ & $\begin{array}{l}-0.011 \\
(0.027)\end{array}$ & $\begin{array}{l}-36.525 \\
(48.096)\end{array}$ & $\begin{array}{l}-0.281 \\
(0.472)\end{array}$ \\
\hline Missouri $_{i} \times Q 2: 2004_{t}$ & $\begin{array}{l}-13.945 \\
(59.881)\end{array}$ & $\begin{array}{l}-0.017^{*} \\
(0.009)\end{array}$ & $\begin{array}{l}-6.868 \\
(9.264)\end{array}$ & $\begin{array}{c}0.004 \\
(0.019)\end{array}$ & $\begin{array}{c}1.664 \\
(46.441)\end{array}$ & $\begin{array}{c}0.230 \\
(0.346)\end{array}$ \\
\hline Missouri $_{i} \times Q 3: 2004_{t}$ & $\begin{array}{l}-64.318 \\
(56.862)\end{array}$ & $\begin{array}{l}-0.006 \\
(0.010)\end{array}$ & $\begin{array}{l}-4.152 \\
(9.715)\end{array}$ & $\begin{array}{c}0.005 \\
(0.015)\end{array}$ & $\begin{array}{c}22.414 \\
(58.363)\end{array}$ & $\begin{array}{l}-0.368 \\
(0.474)\end{array}$ \\
\hline Missouri $_{i} \times Q 4: 2004_{t}$ & $\begin{array}{l}-62.092 \\
(46.248)\end{array}$ & $\begin{array}{c}0.001 \\
(0.010)\end{array}$ & $\begin{array}{l}-2.271 \\
(7.668)\end{array}$ & $\begin{array}{l}0.017^{*} \\
(0.010)\end{array}$ & $\begin{array}{c}40.759 \\
(55.226)\end{array}$ & $\begin{array}{l}-0.094 \\
(0.330)\end{array}$ \\
\hline Missouri $_{i} \times Q 1: 2005_{t}$ & $\begin{array}{c}-9.63 \\
(37.286)\end{array}$ & $\begin{array}{l}-0.008 \\
(0.010)\end{array}$ & $\begin{array}{c}3.459 \\
(6.709)\end{array}$ & $\begin{array}{c}0.003 \\
(0.010)\end{array}$ & $\begin{array}{c}24.116 \\
(49.657)\end{array}$ & $\begin{array}{l}-0.222 \\
(0.214)\end{array}$ \\
\hline Missouri $_{i} \times Q 3: 2005_{t}$ & $\begin{array}{c}-37.51 \\
(38.497)\end{array}$ & $\begin{array}{c}0.007 \\
(0.006)\end{array}$ & $\begin{array}{c}-10.370^{*} \\
(6.147)\end{array}$ & $\begin{array}{c}0.009 \\
(0.008)\end{array}$ & $\begin{array}{c}-9.338 \\
(23.971)\end{array}$ & $\begin{array}{l}-0.062 \\
(0.21)\end{array}$ \\
\hline Missouri $_{i} \times Q 4: 2005_{t}$ & $\begin{array}{c}52.464 \\
(182.928)\end{array}$ & $\begin{array}{l}0.014^{*} \\
(0.008)\end{array}$ & $\begin{array}{l}-12.188 \\
(11.499)\end{array}$ & $\begin{array}{l}0.023^{* *} \\
(0.010)\end{array}$ & $\begin{array}{c}8.355 \\
(48.847)\end{array}$ & $\begin{array}{l}-0.139 \\
(0.346)\end{array}$ \\
\hline Missouri $_{i} \times Q 1: 2006_{t}$ & $\begin{array}{c}100.321 \\
(178.042)\end{array}$ & $\begin{array}{c}0.022^{* * *} \\
(0.008)\end{array}$ & $\begin{array}{l}-11.283 \\
(11.306)\end{array}$ & $\begin{array}{c}0.021 \\
(0.022)\end{array}$ & $\begin{array}{c}-9.791 \\
(67.468)\end{array}$ & $\begin{array}{l}-0.511 \\
(0.425)\end{array}$ \\
\hline Missouri $_{i} \times Q 2: 2006_{t}$ & $\begin{array}{c}140.302 \\
(199.759)\end{array}$ & $\begin{array}{c}0.026 * * * \\
(0.009)\end{array}$ & $\begin{array}{l}-9.192 \\
(12.67)\end{array}$ & $\begin{array}{c}0.019 \\
(0.021)\end{array}$ & $\begin{array}{c}12.157 \\
(53.793)\end{array}$ & $\begin{array}{l}-0.313 \\
(0.465)\end{array}$ \\
\hline Missouri $_{i} \times Q 3: 2006_{t}$ & $\begin{array}{c}116.811 \\
(188.342)\end{array}$ & $\begin{array}{c}0.022^{* *} \\
(0.009)\end{array}$ & $\begin{array}{c}-1.373 \\
(18.483)\end{array}$ & $\begin{array}{c}0.030 \\
(0.022)\end{array}$ & $\begin{array}{c}38.245 \\
(47.414)\end{array}$ & $\begin{array}{l}-0.705 \\
(0.599)\end{array}$ \\
\hline Missouri $_{i} \times Q 4: 2006_{t}$ & $\begin{array}{c}77.227 \\
(190.531)\end{array}$ & $\begin{array}{c}0.025^{* *} \\
(0.012)\end{array}$ & $\begin{array}{c}-4.714 \\
(13.395)\end{array}$ & $\begin{array}{c}0.028 \\
(0.027)\end{array}$ & $\begin{array}{c}31.58 \\
(38.540)\end{array}$ & $\begin{array}{l}-0.723 \\
(0.527)\end{array}$ \\
\hline Missouri $_{i} \times Q 1: 2007_{t}$ & $\begin{array}{c}147.545 \\
(201.778)\end{array}$ & $\begin{array}{c}0.008 \\
(0.022)\end{array}$ & $\begin{array}{c}-0.929 \\
(17.076)\end{array}$ & $\begin{array}{c}0.053^{* *} \\
(0.025)\end{array}$ & $\begin{array}{c}73.212 \\
(48.013)\end{array}$ & $\begin{array}{c}-1.378^{* *} \\
(0.575)\end{array}$ \\
\hline Missouri $_{i} \times Q 2: 2007_{t}$ & $\begin{array}{c}182.785 \\
(194.936)\end{array}$ & $\begin{array}{c}0.010 \\
(0.024)\end{array}$ & $\begin{array}{c}5.302 \\
(16.076)\end{array}$ & $\begin{array}{c}0.079 * * * \\
(0.019)\end{array}$ & $\begin{array}{c}149.910^{* * *} \\
(42.525)\end{array}$ & $\begin{array}{c}-1.657^{* * *} \\
(0.411)\end{array}$ \\
\hline Missouri $_{i} \times Q 3: 2007_{t}$ & $\begin{array}{c}167.95 \\
(216.051)\end{array}$ & $\begin{array}{c}0.012 \\
(0.023)\end{array}$ & $\begin{array}{c}10.51 \\
(22.122)\end{array}$ & $\begin{array}{c}0.084^{* * *} \\
(0.017)\end{array}$ & $\begin{array}{c}170.166^{* * *} \\
(48.589)\end{array}$ & $\begin{array}{c}-2.008 * * * \\
(0.671)\end{array}$ \\
\hline Missouri $_{i} \times Q 4: 2007_{t}$ & $\begin{array}{c}173.728 \\
(225.648)\end{array}$ & $\begin{array}{c}0.014 \\
(0.025)\end{array}$ & $\begin{array}{c}9.454 \\
(21.032)\end{array}$ & $\begin{array}{c}0.062 * * * \\
(0.021)\end{array}$ & $\begin{array}{l}143.3^{* * *} \\
(51.234)\end{array}$ & $\begin{array}{c}-2.424 * * * \\
(0.754)\end{array}$ \\
\hline$R^{2}$ & 0.694 & 0.840 & 0.510 & 0.431 & 0.143 & 0.884 \\
\hline$N$ & $1,773,808$ & $2,759,405$ & $2,048,236$ & $2,835,850$ & 982,240 & $2,724,926$ \\
\hline
\end{tabular}

Notes: Based on authors' calculations using data from the CCP. The omitted period is Q2:2005. Risk Score is the Equifax Risk Score. Missouri i is an indicator variable for living within 10 miles of the Missouri border. Bootstrapped standard errors are reported in parentheses. ${ }^{* * *},{ }^{* *}$, and ${ }^{*}$ denote significance at the $0.01,0.05$, and 0.10 levels, respectively. 
Figure A1: CCP Event Study Results

Panel A: Total Bankcard Balance

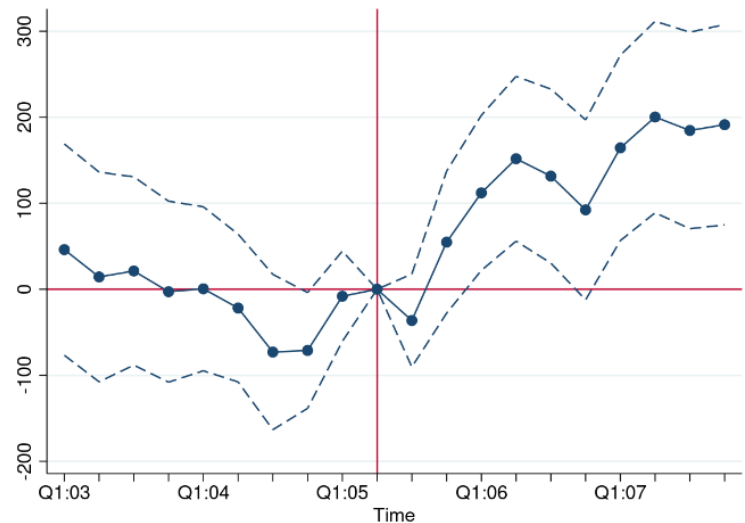

Panel C: Amount Delinquent on Bankcards

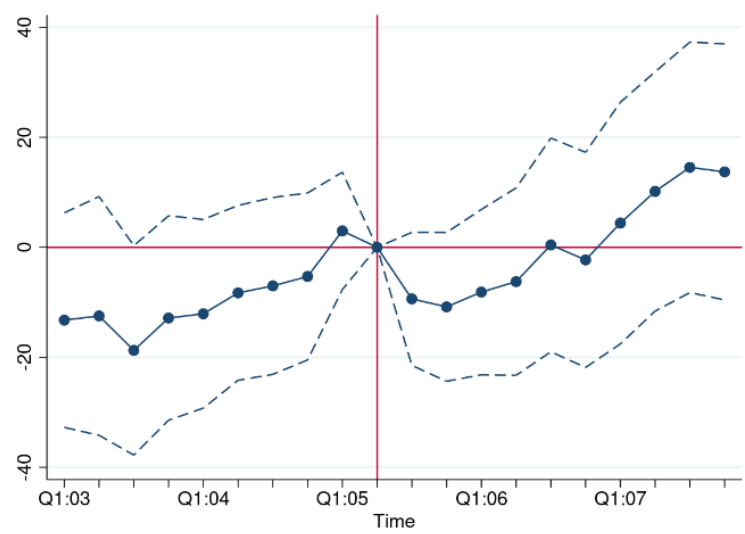

Panel E: Amount in Third-Party Collections

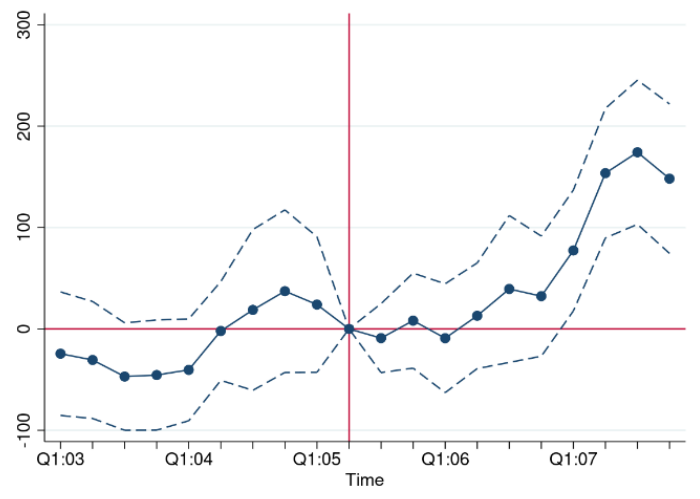

Panel B: Number of Bankcards

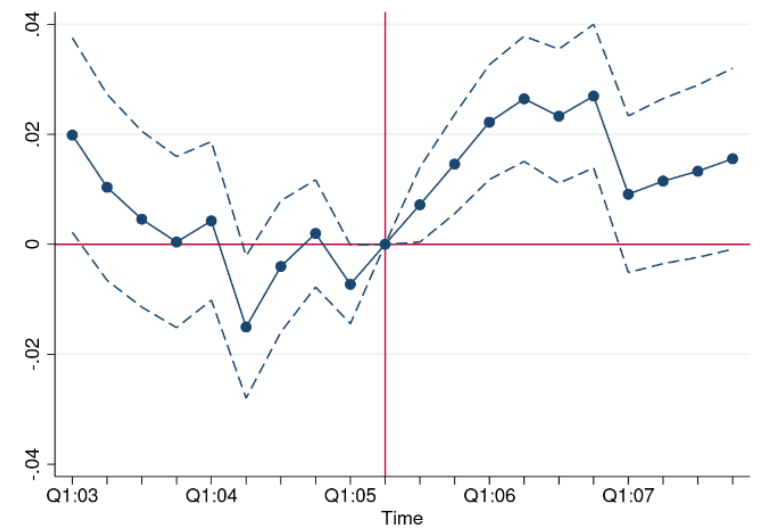

Panel D: Number of Accounts in Third-Party Collections

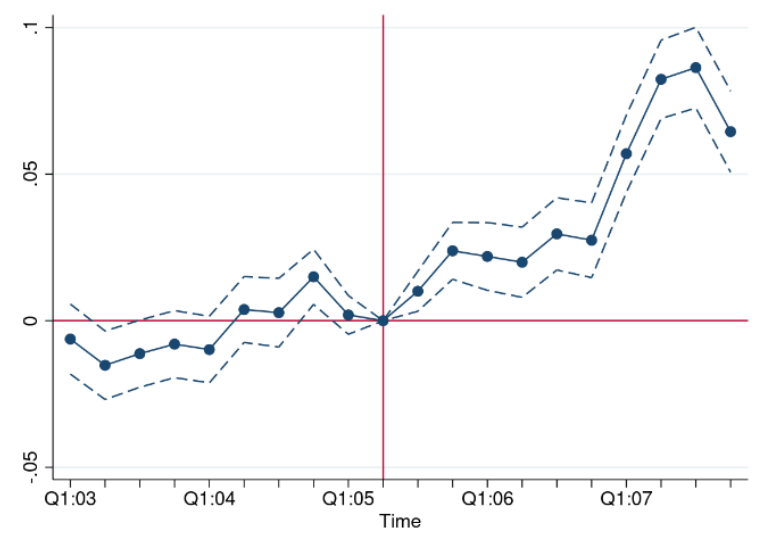

Panel F: Risk Score Points

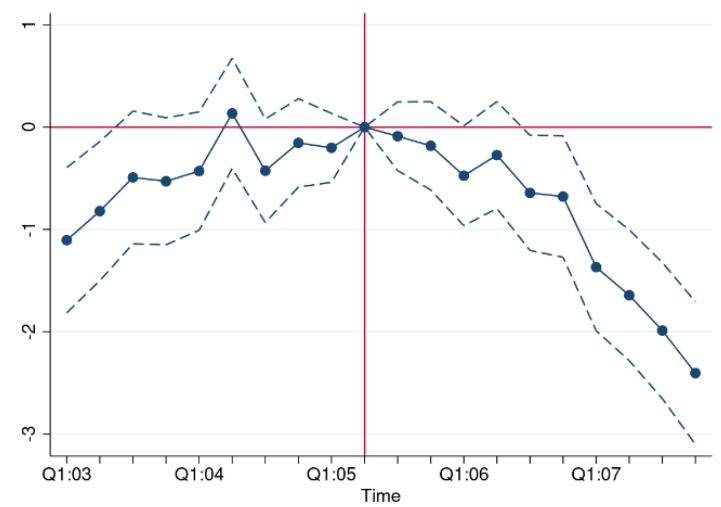

Notes: Based on authors' calculations using the CCP. Risk Score is the Equifax Risk Score. The omitted time period is Q2:2005. Estimates in Panels A, C, and E are measured in dollars. Standard errors clustered at the census tract level. This specification includes county fixed effects. Dots represent coefficient estimates, while dashed lines show 95 percent confidence intervals. 
Figure A2: Non-Movers Event Study Results

Panel A: Total Bankcard Balance

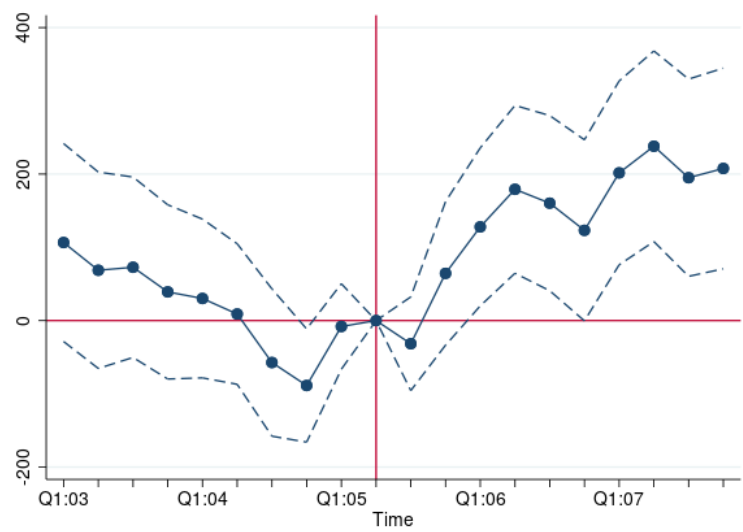

Panel C: Amount Delinquent on Bankcards

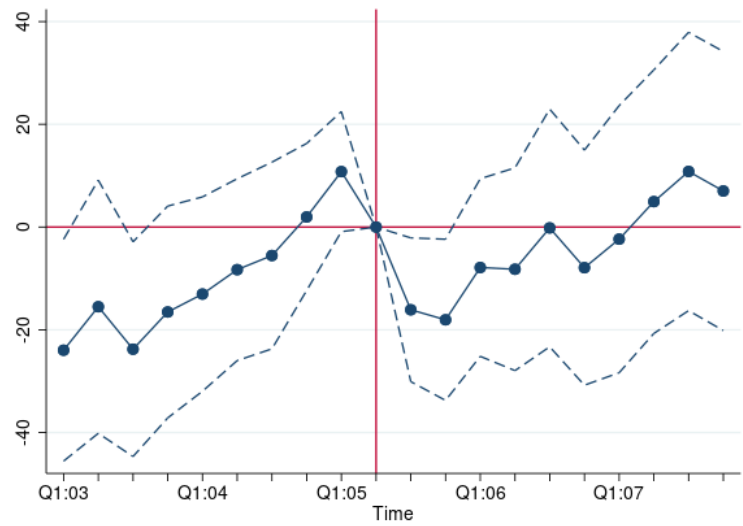

Panel E: Amount in Third-Party Collections

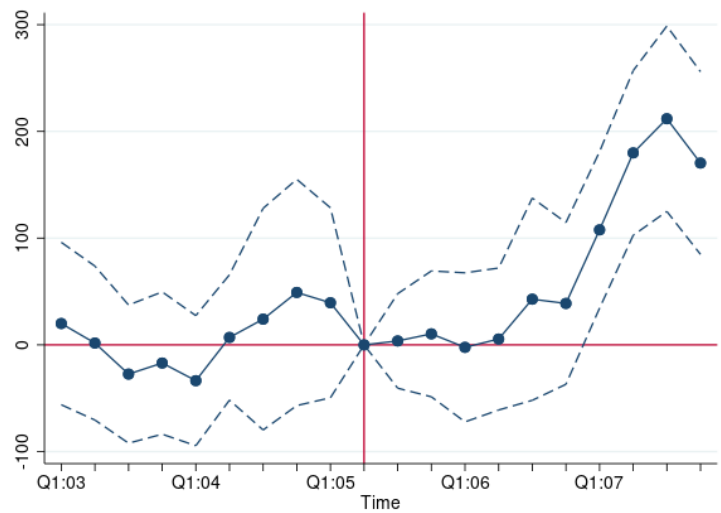

Panel B: Number of Bankcards

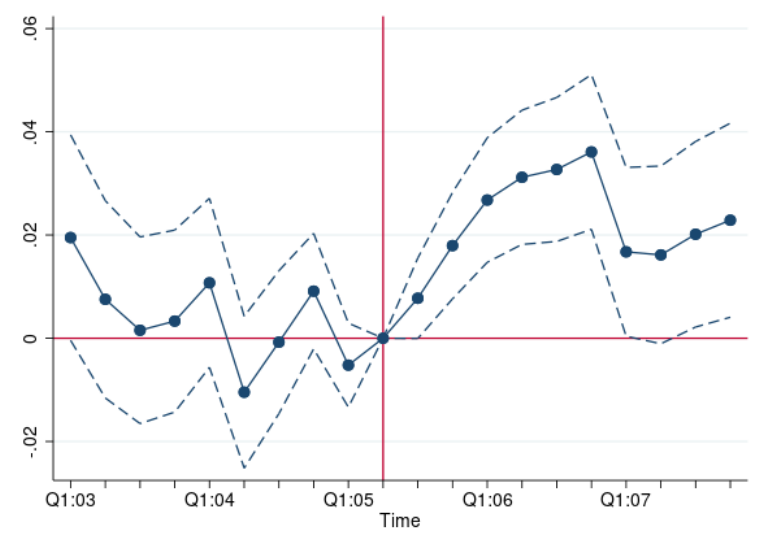

Panel D: Number of Accounts in Third-Party Collections

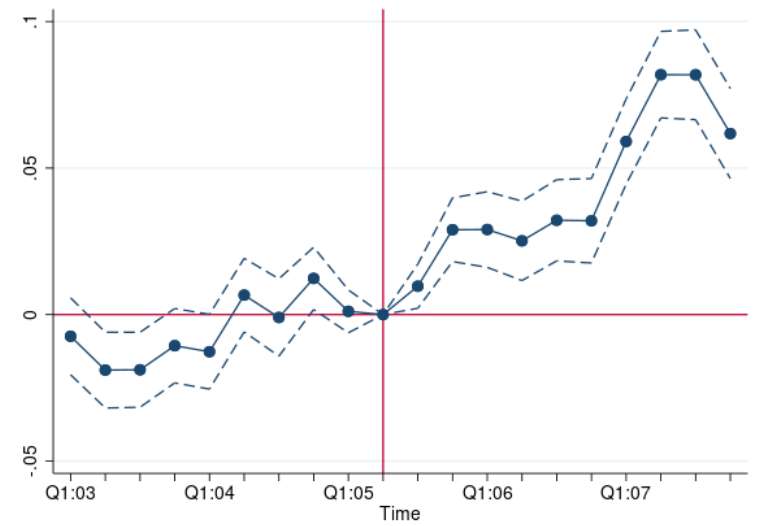

Panel F: Risk Score Points

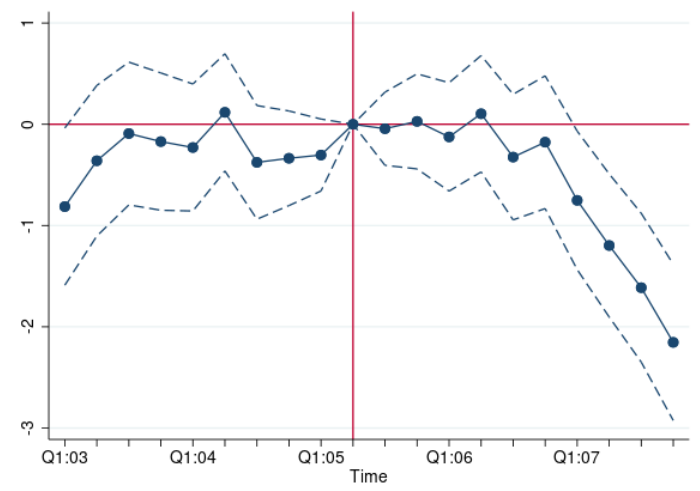

Notes: Based on authors' calculations using data from the CCP. Risk Score is the Equifax Risk Score. Omitted time period is Q2:2005. Estimates in Panels A, C, and E are measured in dollars. Standard errors clustered at the census tract level. This specification includes county fixed effects. Dots represent coefficient estimates, while dashed lines show 95 percent confidence intervals. 
Figure A3: Balanced Panel Event Study Results

Panel A: Total Bankcard Balance

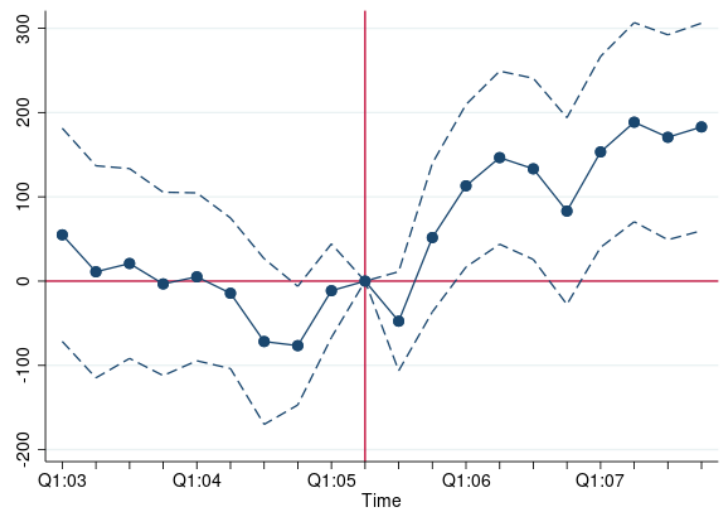

Panel C: Amount Delinquent on Bankcards

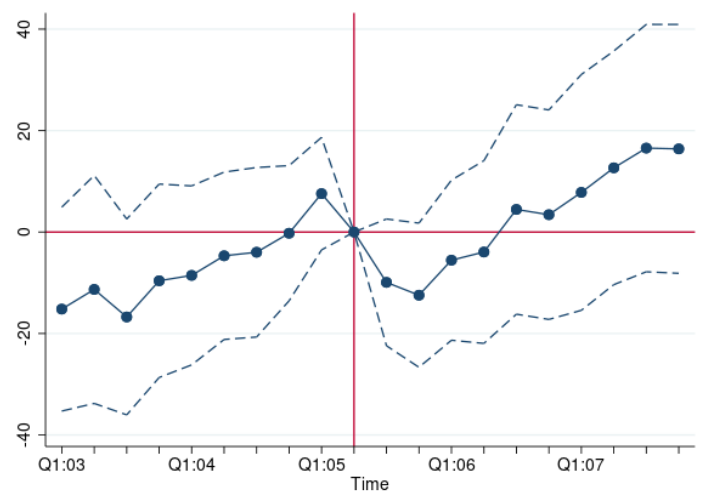

Panel E: Amount in Third-Party Collections

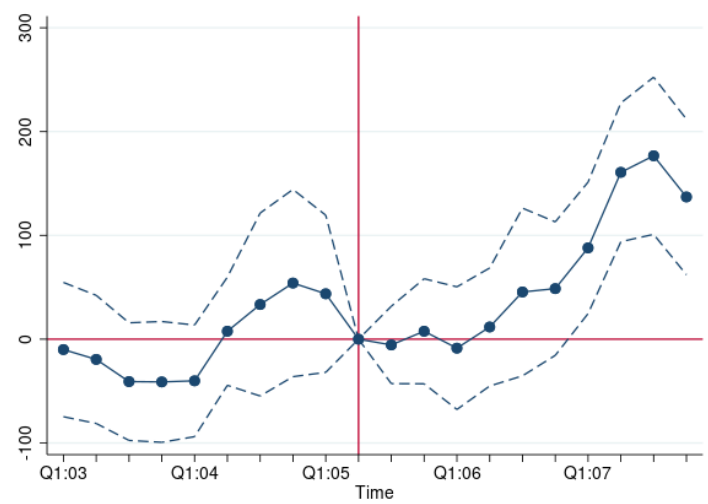

Panel B: Number of Bankcards

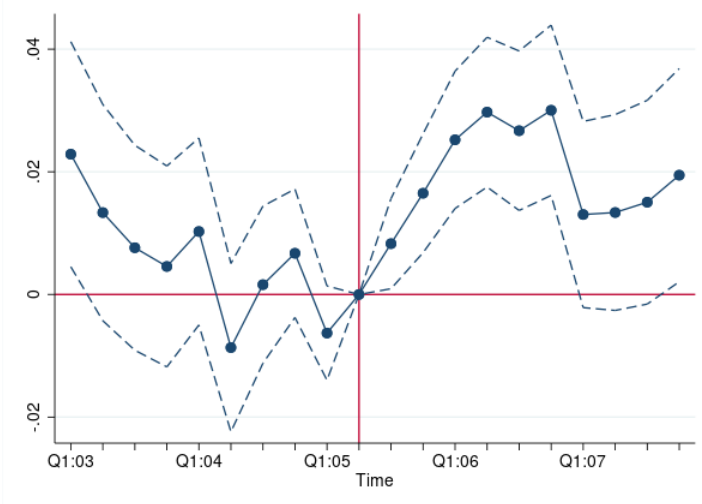

Panel D: Number of Accounts in Third-Party Collections

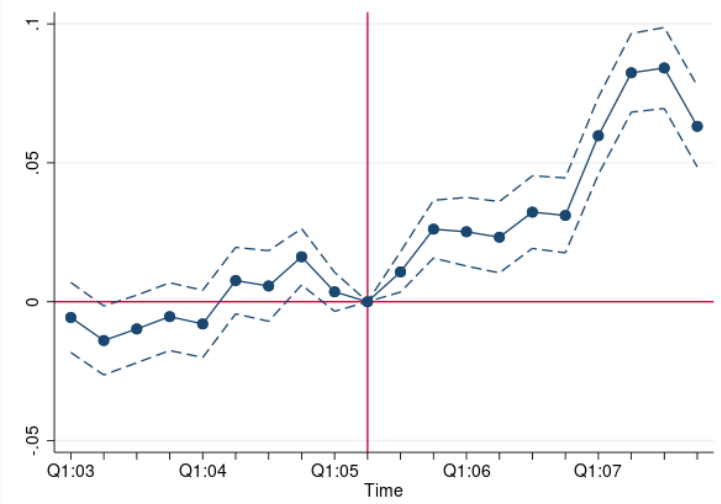

Panel F: Risk Score Points

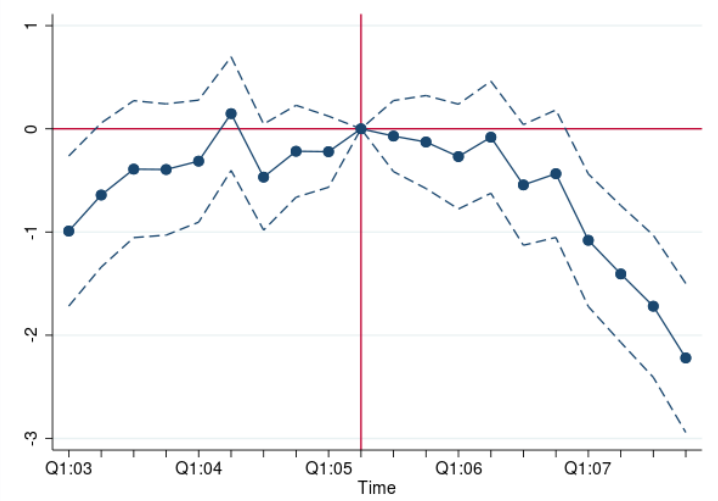

Notes: Based on authors' calculations using data from the CCP. Risk Score is the Equifax Risk Score. Omitted time period is Q2:2005. Estimates in Panels A, C, and E are measured in dollars. Standard errors clustered at the census tract level. This specification includes county fixed effects. Dots represent coefficient estimates, while dashed lines show 95 percent confidence intervals. 


\section{Figure A4: Event Study Results for Individuals Under Age 65}

Panel A: Total Bankcard Balance

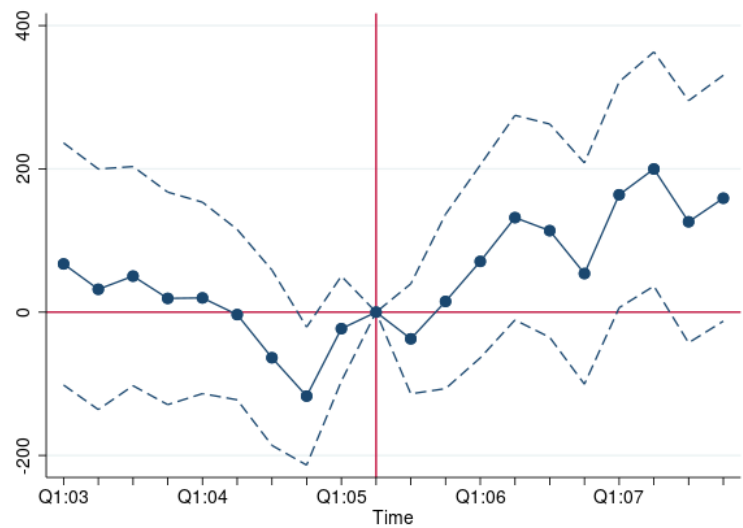

Panel C: Amount Delinquent on Bankcards

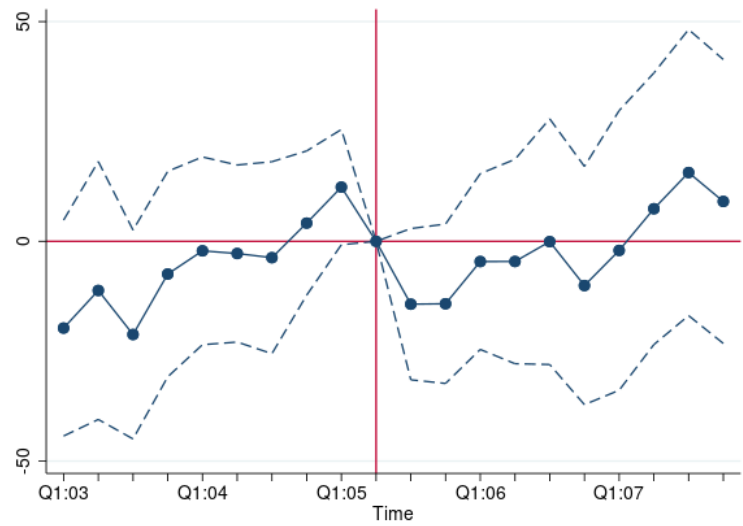

Panel E: Amount in Third-Party Collections

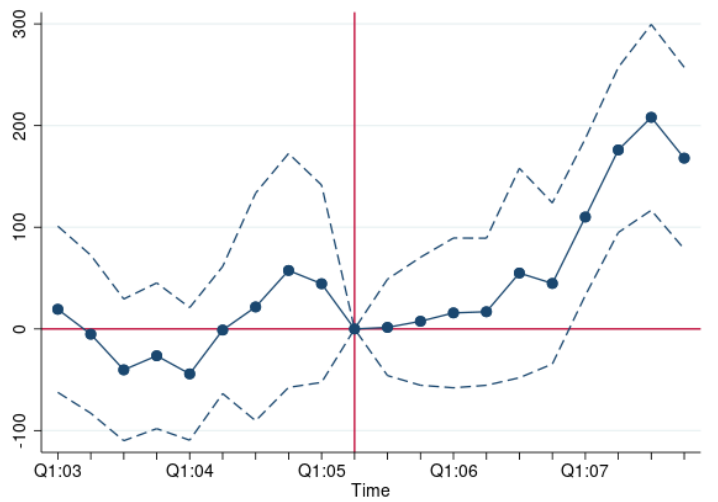

Panel B: Number of Bankcards

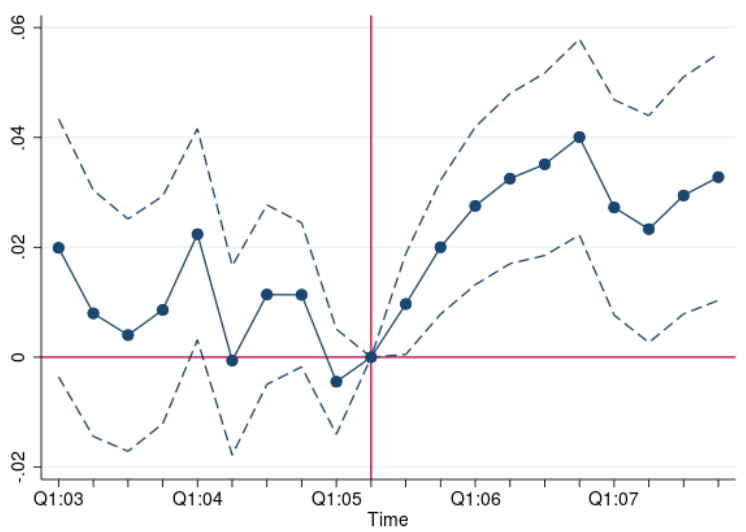

Panel D: Number of Accounts in Third-Party Collections

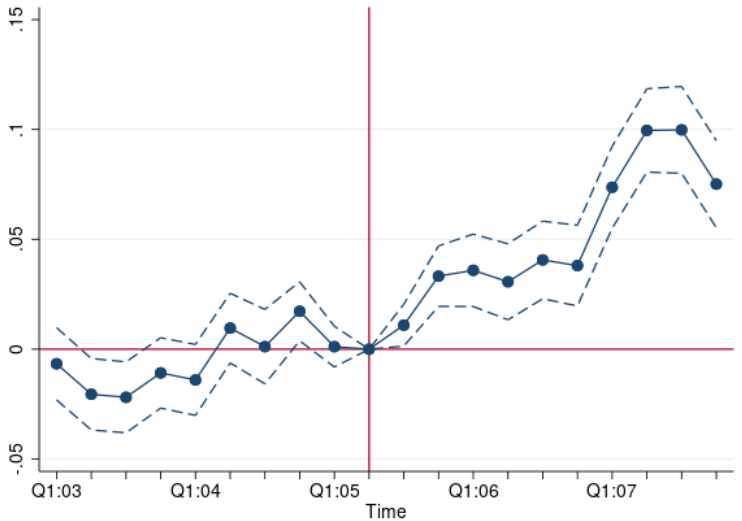

Panel F: Risk Score Points

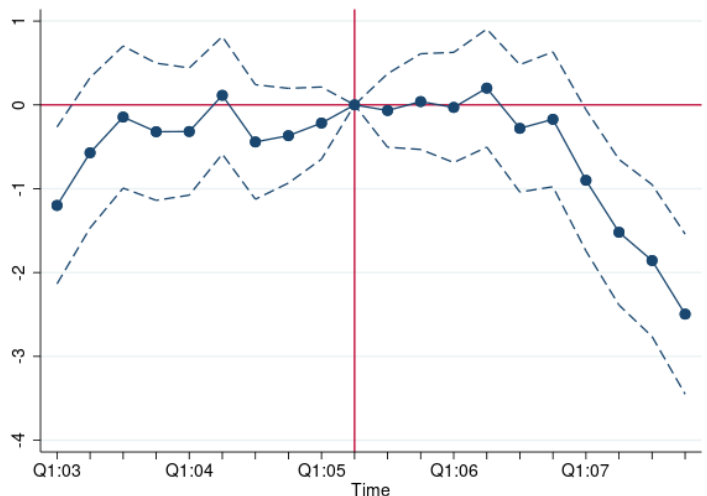

Notes: Based on authors' calculations using data from the CCP. Risk Score is the Equifax Risk Score. Omitted time period is Q2:2005. Estimates in Panels A, C, and E are measured in dollars. Standard errors clustered at the census tract level. This specification includes county fixed effects. Dots represent coefficient estimates, while dashed lines show 95 percent confidence intervals. 
Figure A5: MEPS Event Study Results with No Individual-Level Controls

Panel A: Probability of Having Medicaid

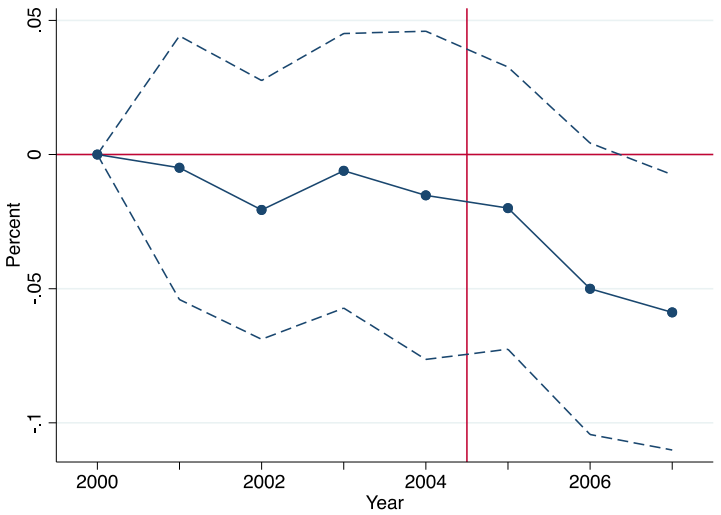

Panel C: Medicaid Spending

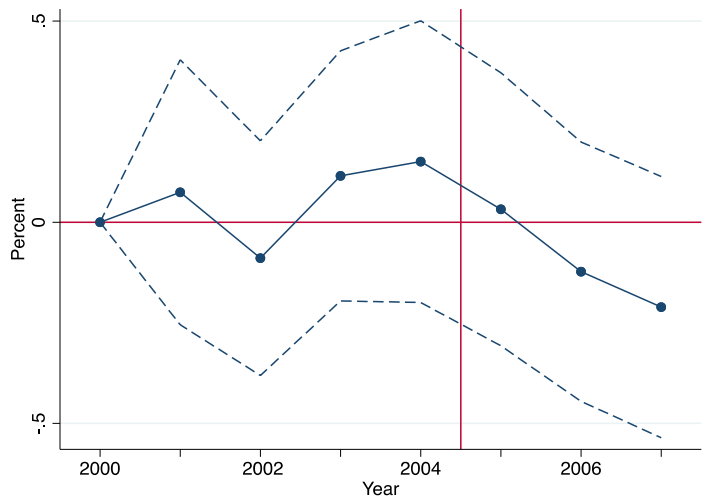

Panel E: Total OOP Medical Spending

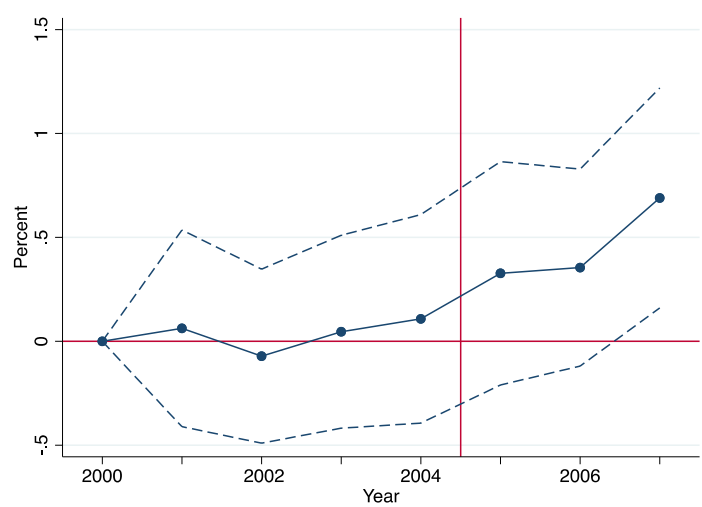

Panel B: Probability of Being Uninsured

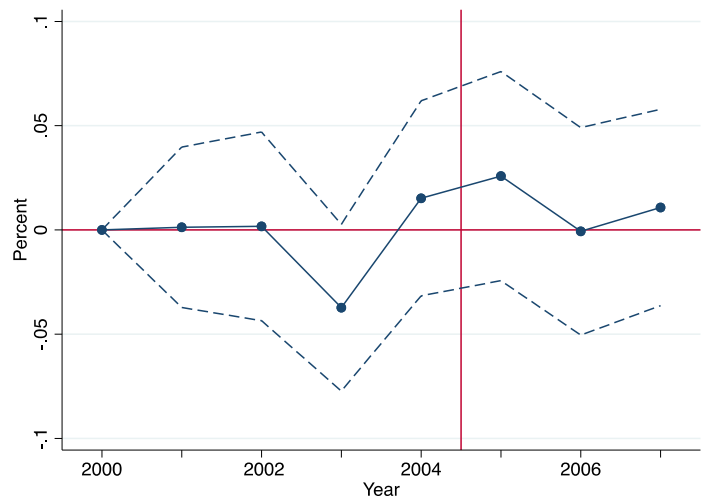

Panel D: Total Medical Spending

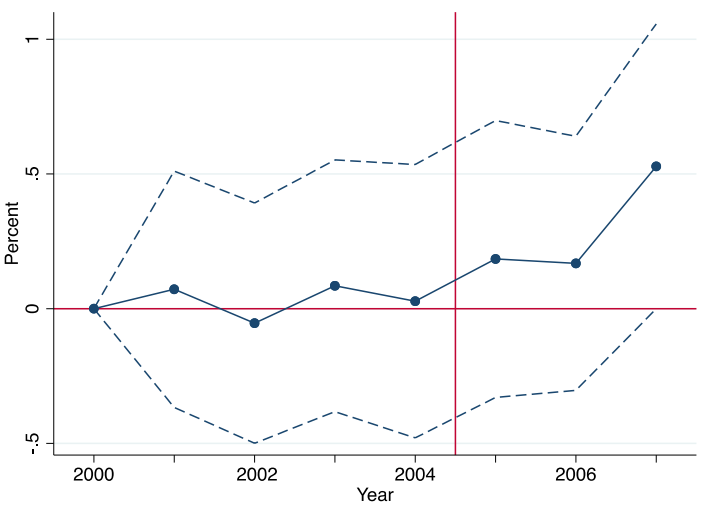

Panel F: Likelihood of Having Any OOP Spending

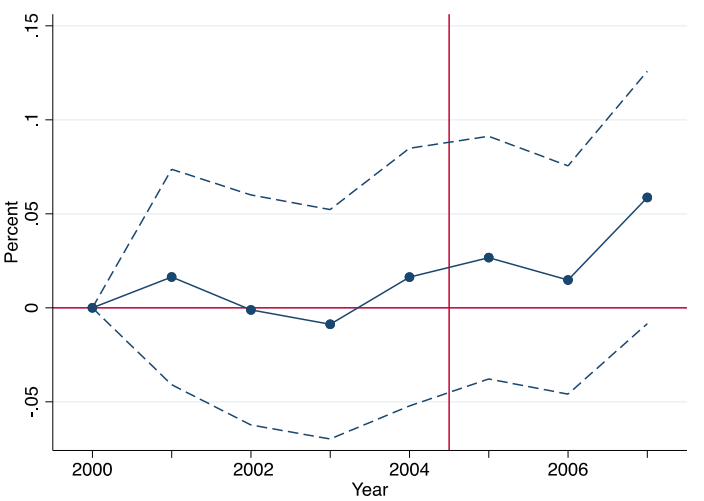

Notes: Based on authors' calculations using the restricted version of the Medical Expenditure Panel Survey (MEPS) data. Dots represent coefficient estimates, while bands show 95 percent confidence intervals calculated using a block bootstrap. Spending variables are natural logs. The control group includes all states that border Missouri, except Tennessee. Dots represent coefficient estimates, while dashed lines show 95 percent confidence intervals. 
Figure A6: MEPS Event Study Placebo Tests

Panel A: Average Family Size

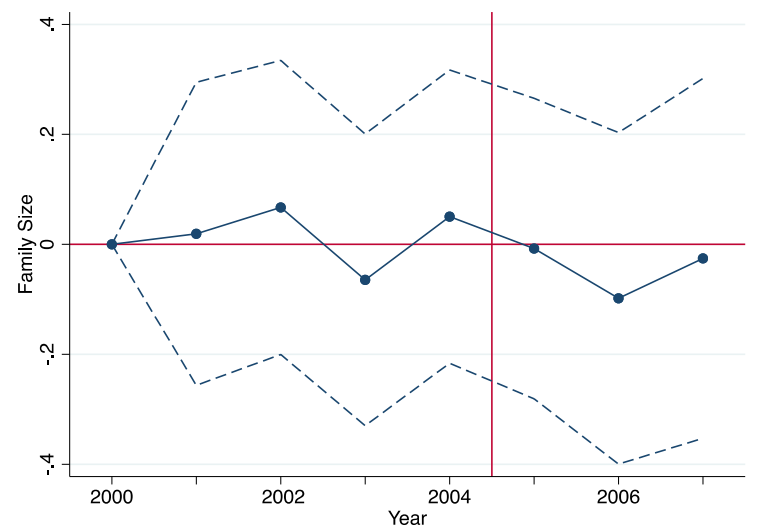

Panel C: Percent Black

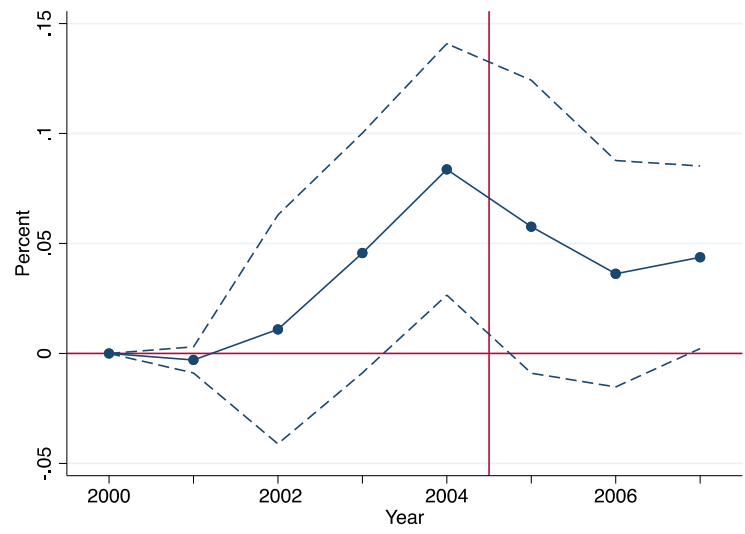

Panel E: Percent Married

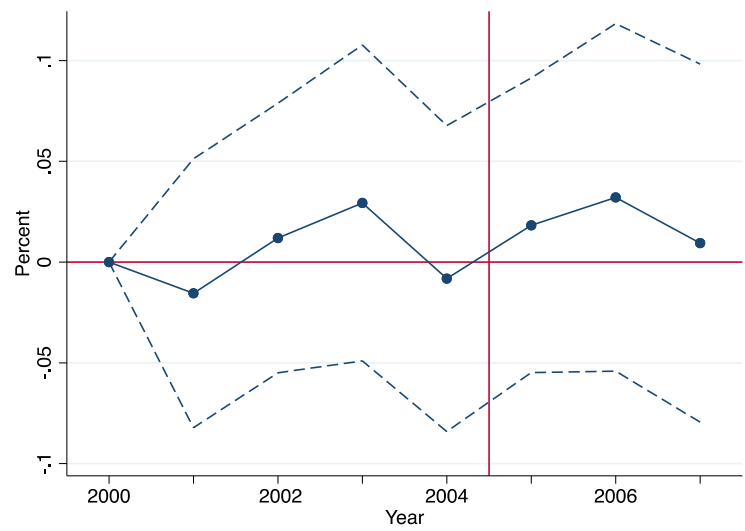

Panel B: Percent Male

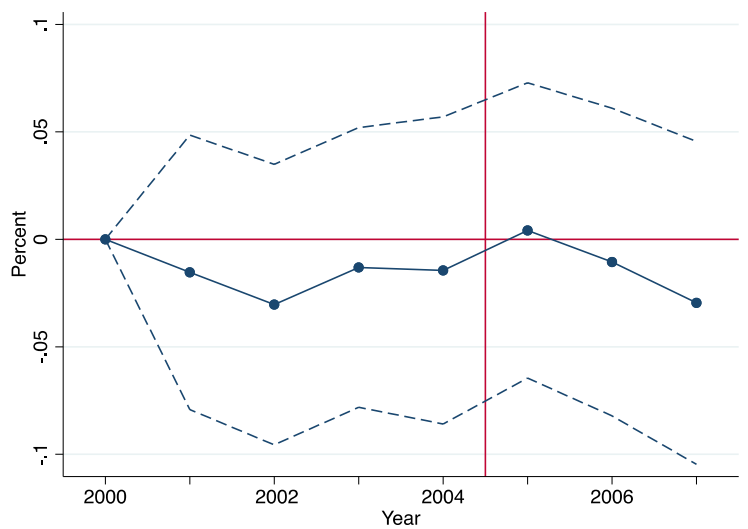

Panel D: Percent Hispanic

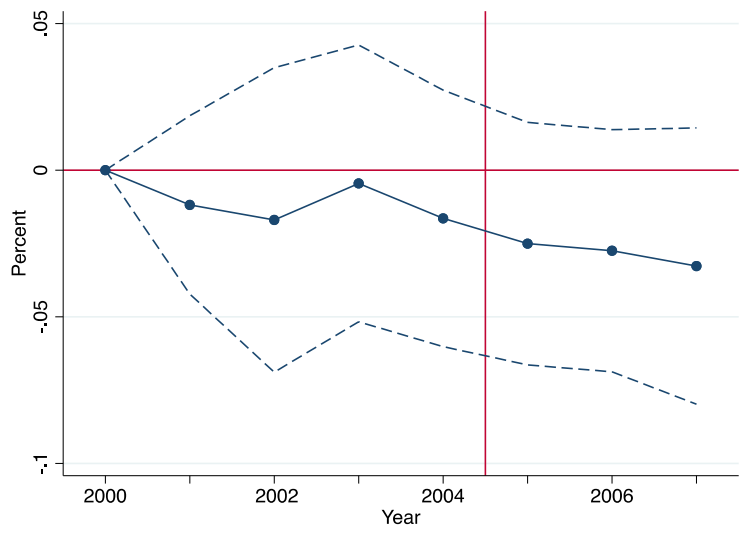

Panel F: Percent High School Graduates

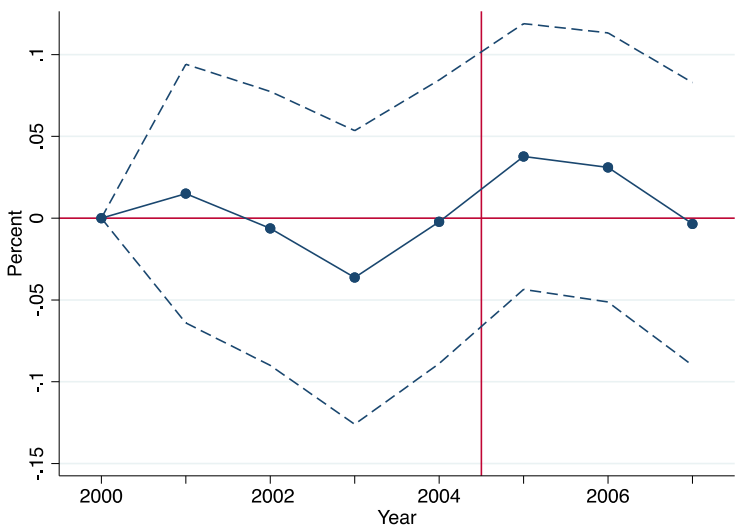

Notes: Based on authors' calculations using the restricted version of the Medical Expenditure Panel Survey (MEPS) data. Dots represent coefficient estimates, while bands show 95 percent confidence intervals calculated using a block bootstrap. The control group includes all states that border Missouri, except Tennessee. Dots represent coefficient estimates, while dashed lines show 95 percent confidence intervals. 
Figure A7: MEPS Event Study Results with Non-Logged Spending Variables

Panel C: Medicaid Spending

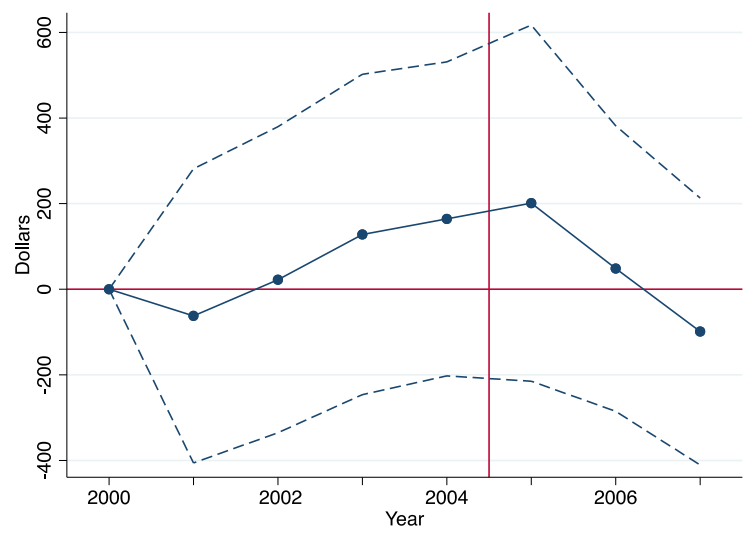

Panel E: Total OOP Medical Spending

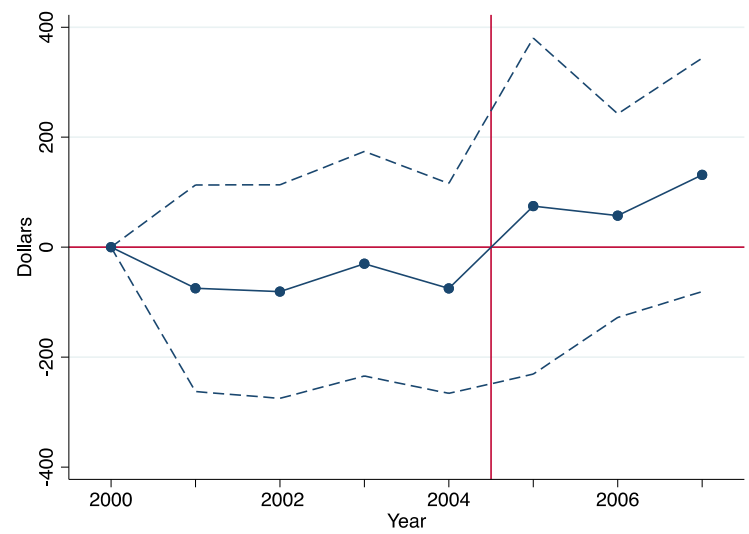

Panel D: Total Medical Spending

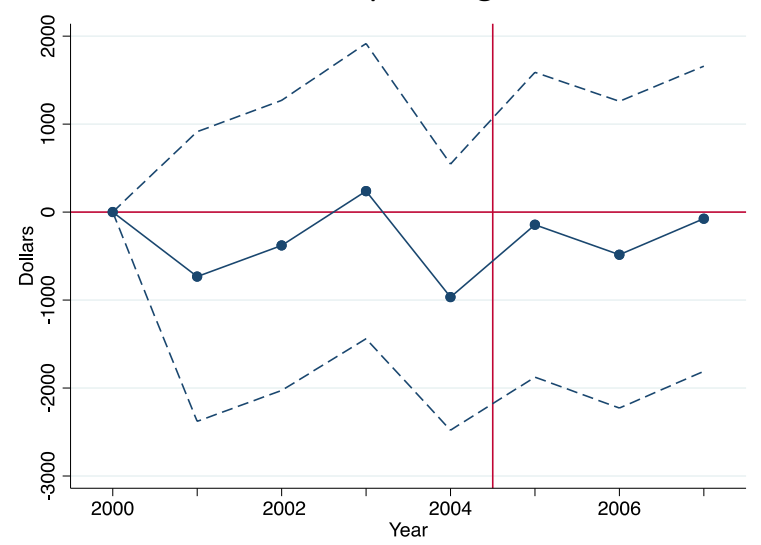

Notes: Based on authors' calculations using the restricted version of the Medical Expenditure Panel Survey (MEPS) data. Dots represent coefficient estimates, while bands show 95 percent confidence intervals calculated using a block bootstrap. Spending variables are in non-logged dollars. The control group includes all states that border Missouri, except Tennessee. Dots represent coefficient estimates, while dashed lines show 95 percent confidence intervals. 
Figure A8: Event Study Results for Bankruptcy and Severely Delinquent Debt

Panel A: First Declaration of Bankruptcy

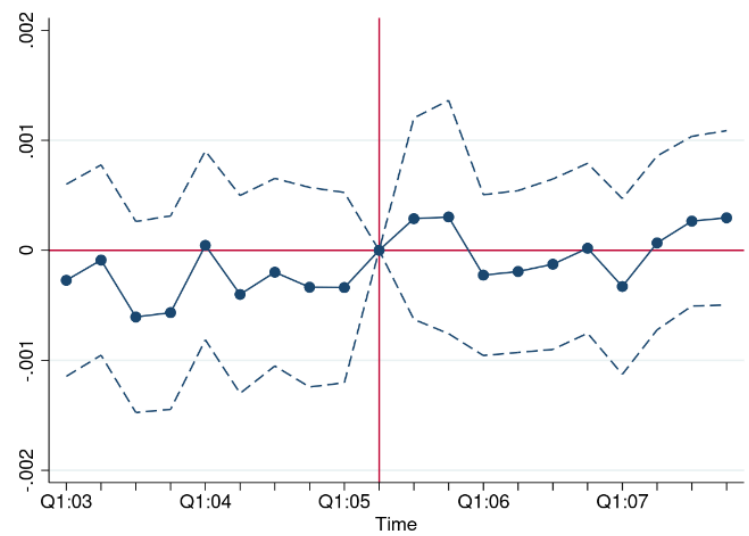

Panel C: Presence of Severely Delinquent Bankcard

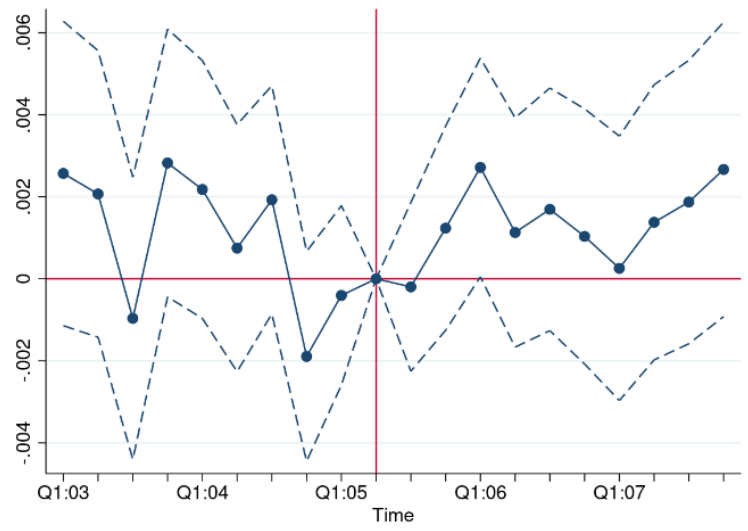

Panel B: Severely Delinquent Share of Bankcard Balance

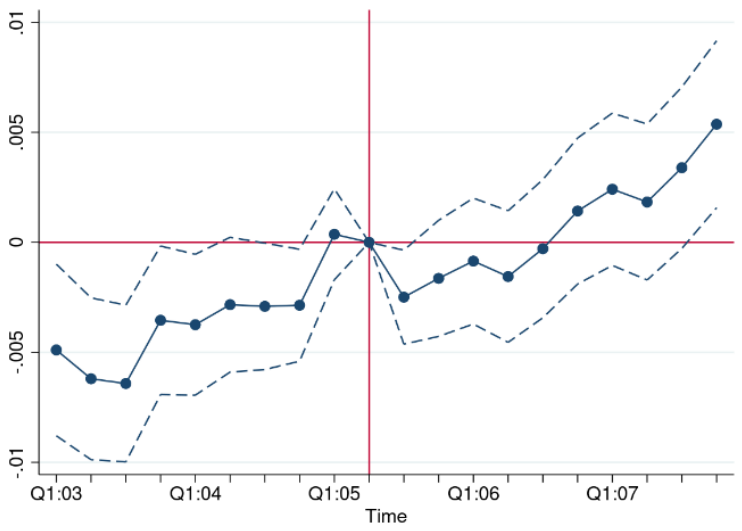

Panel D: Number of Severely Delinquent Bankcards

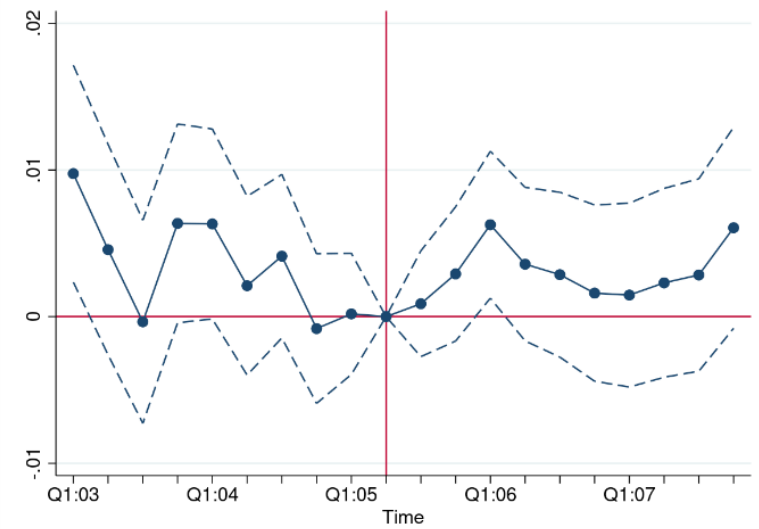

Notes: Based on authors' calculations using data from the CCP. First Declaration of Bankruptcy is a 0-1 indicator variable that is coded as 1 in the quarter a consumer declares bankruptcy and coded as missing in all subsequent quarters. Severely delinquent is considered here to be any balance that is over 90 days past due. Omitted time period is Q2:2005. Dots represent coefficient estimates, while dashed lines show 95 percent confidence intervals. 


\section{Appendix B: Monte Carlo Simulations Comparing Block-Bootstrapped Standard Errors with}

Other Standard Error Estimation Methods

The standard method for calculating standard errors in a difference-in-differences framework involves accounting for serial correlation by clustering at the level of treatment assignment (Bertrand, Duflo, and Mullinathan, 2004; Cameron and Miller, 2015). By accounting for serial correlation, we minimize the risk that the estimated standard errors of our regression coefficients of interest $\hat{\beta}$ understate the true standard deviations of $\hat{\beta}$. However, in our empirical setting where treatment is assigned at the state level, we have very few clusters in our sample, only one of the clusters is treated, and we have significant variation in cluster size. Because of these elements, clustering our standard errors at the state level is not appropriate.

As shown in Mackinnon and Webb (2017), the standard error of $\hat{\beta}$ can be severely underestimated using standard clustering strategies when the number of treated clusters is small. This includes procedures such as the wild bootstrap (Cameron, Gelbach, and Miller, 2008). Therefore, we must consider alternate procedures to estimate standard errors and perform statistical inference. Although there is no definitive lower bound for the number of clusters necessary to meet the asymptotic assumptions required for statistical inference, we only have eight clusters (with only one treated) in total. Because we have a small, fixed number of control clusters, this rules out a number of the alternate procedures in the literature that require asymptotic assumptions, such as the randomization inference (RI) procedures outlined by Conley and Taber (2011), Ferman and Pinto (2019), and MacKinnon and Webb (2019, 2020). In addition, we have significantly different cluster sizes, which is further evidence that RI procedures are not appropriate in this context (MacKinnon and Webb, 2020). Hagemann (2020) introduces a procedure to perform statistical inference in settings with a finite number of heterogeneous clusters and only one cluster receiving treatment, but his test is only appropriate for 10 or more clusters.

Given the limitations of these other procedures, we conduct Monte Carlo simulations to compare how a variety of different standard error estimation procedures perform relative to our version of the modified block bootstrap method, which is based on Garthwaite et al. (2014) and 
Tello-Trillo (2021). We perform our simulations on our CCP data because the CCP is a panel data set, which is different than the Garthwaite et al. and Tello-Trillo studies, which use repeated cross-sectional data. Because of this difference in the data and the lower number of clusters, we assume that the simulation results from these previous studies may not hold in our setting.

To evaluate the performance of these different standard error estimation methods, we calculate the rejection rates of a simple null hypothesis and compare these rates with a rejection threshold of $p=0.05$. The best performing standard error calculation method is the one that rejects the null hypothesis at the rate closest to the rejection threshold. We provide details for our Monte Carlo simulations below.

\section{A. Setup}

To perform our Monte Carlo simulations, we closely follow the procedure outlined in the Appendix of Tello-Trillo (2021). We first generate our $y_{s t}$ by imposing the null hypothesis that the difference-in-difference coefficient $\beta_{1}$ on the post $_{t} \times M O_{s}$ term is equal to zero using our CCP data sample using the following equation (B1):

$$
\begin{gathered}
y_{s t}=\alpha_{0}+\alpha_{1} \text { post }_{t}+\alpha_{2} M O_{s}+\beta_{1}\left(\text { post }_{t} \times M O_{s}\right)+X \Phi \\
\widehat{y_{s t}}=\widehat{\alpha_{0}}+\widehat{\alpha_{1}} \text { post }_{t}+\widehat{\alpha_{2}} \mathrm{MO}_{\mathrm{s}}+0 \times\left(\text { post }_{\mathrm{t}} \times M \mathrm{MO}_{\mathrm{s}}\right)+\mathrm{X} \widehat{\Phi} .
\end{gathered}
$$

We then generate predicted values for $y_{s t}$ with the null hypothesis of the DID term being zero $\left(\widehat{y_{s t}}\right)$, shown in equation (B2). We then generate error terms, allowing the variance of the errors to vary by state:

$$
\begin{gathered}
\epsilon_{s t}=\phi_{s t}+\eta_{s t} \\
\phi_{s t} \sim N(0,1)
\end{gathered}
$$

$\eta_{s t} \sim N(0, S)$, where $S$ is the FIPS code of the state. 
The errors are added to our predicted $\widehat{y_{s t}}$ with the null hypothesis imposed, generating $\breve{y}_{s t}$. Finally, we regress $\breve{y}_{s t}$ on the DID term, knowing that $\beta_{1}$ should be zero. Our modified block bootstrap procedure is a two-stage process: In the first stage, we sample states with replacement, omitting any repetition where Missouri is not selected. For those repetitions that include Missouri, we resample individuals within each state. Because our CCP data are panel data, we resample entire panels when we select individuals in the second stage. For computational efficiency, we collapse our resampled data into state-quarter cells. We perform the simulation 10,000 times for each standard error method and count the number of times the null hypothesis that $\beta_{1}=0$ is rejected. ${ }^{23}$ The rejection rates are reported in Table B1.

We use the standard rejection threshold of $p=0.05$ as our benchmark for evaluating the performance of the various standard error calculation methods. This implies that we would want the null hypothesis rejected 5 percent of the time. If a method's rejection rate is above 0.05 , this indicates that the standard errors would over reject the null hypothesis, leading us to conclude that there is an effect when there is no effect; values below 0.05 imply under rejection, which would lead us to conclude that there is no effect when there is an effect. Results from our version of the modified block bootstrap are in column 1 and results from the other standard error methods are in columns $2-5$ of Table B1.

Unsurprisingly, both standard clustering at the state level and the wild bootstrap perform the worst out of all the methods. OLS and robust (i.e., the standard Huber/White sandwich estimator) standard errors perform significantly better than clustered standard errors, but still over reject the null hypothesis. Our modified block bootstrap procedure is closest to our target rejection threshold of 0.05 , though it does under reject the null hypothesis. Based on these rejection rates, we conclude that the modified block bootstrap is appropriate to use in our empirical setting.

\footnotetext{
${ }^{23}$ Rejection rates are calculated simply by dividing the number of times the null hypothesis was rejected by the total number of repetitions (in this case, 10,000).
} 


\section{Appendix References}

Bertrand, Marianne, Esther Duflo, and Sendhil Mullainathan. (2004). "How Much Should We Trust Differences-in-Differences Estimates?" The Quarterly Journal of Economics 119(1), 249-275. https://doi.org/10.1162/003355304772839588.

Cameron, A. Colin, Jonah B. Gelbach, and Douglas L. Miller. (2008). "Bootstrap-Based Improvements for Inference with Clustered Errors." The Review of Economics and Statistics 90(3), 414-427. https://doi.org/10.1162/rest.90.3.414.

Centers for Medicare and Medicaid Services. (2017). Health Expenditures by State of Provider. Retrieved 8/4/2020 at http://www.cms.gov/Research-Statistics-Data-andSystems/Statistics-Trends-and-Reports/NationalHealthExpendData/Downloads/providerstate2014.zip.

Centers for Medicare and Medicaid Services. (2008). Illinois Health Insurance Flexibility and Accountability (HIFA) Initiative Fact Sheet [Fact Sheet]. https://downloads.cms.gov/cmsgov/archiveddownloads/MedicaidStWaivProgDemoPGI/downloads/IllinoisKidCareHIFACurrentFactshee t.pdf.

Conley, Timothy G., and Christopher R. Taber. (2011). "Inference with 'Difference in Differences' with a Small Number of Policy Changes." The Review of Economics and Statistics 93(1): 113-125. https://doi.org/10.1162/REST a 00049.

Coughlin, Teresa, Sharon Long, John Graves, and Alshadye Yemane. (2006). "An Early Look at Ten State HIFA Medicaid Waivers." Health Affairs 25(1). https://doi.org/10.1377/h/thaff.25.w204.

Coughlin, Teresa, and Stephen Zuckerman. (2008). "State Responses to New Flexibility in Medicaid." The Milbank Quarterly 86(2), 209-240. 10.1111/j.1468-0009.2008.00520.x.

Doonan, Michael, and Tull, Katharine. (2010). "Health Care Reform in Massachusetts: Implementation of Coverage Expansions and a Health Insurance Mandate." The Milbank Quarterly 88(1), 54-80. 10.1111/j.1468-0009.2010.00589.x

Farrar, Ione, David Eichenthal, Benjamin Coleman, and Chad Reese. (2007). "TennCare Reform, One Year Later: As Assessment of the Impact of the 2005-2006 Changes in the TennCare Program." Robert Wood Johnson Foundation.

http://www.statecoverage.org/files/TennCare\%20Reform\%200ne\%20Year\%20Later\%20\%20An\%20Assessment\%20of\%20the\%20Impact\%20of\%20the\%2020052006\%20Changes\%20in\%20the\%20TennCare\%20Program.pdf. 
Ferman, Bruno, and Cristine Pinto. (2019). "Inference in Differences-in-Differences with Few Treated Groups and Heteroskedasticity." The Review of Economics and Statistics 101(3), 452-467. https://doi.org/10.1162/rest a 00759.

Fiorentini, Christina. (2013). Growth in New York's Medicaid Enrollment and Costs: While Enrollment Highest in the City, Recent Increases Mostly in the Suburbs and Update. New York City Independent Budget Office. https://ibo.nyc.ny.us/iboreports/medicaid2013.pdf.

Hagemann, Andreas. (2020). "Inference with a Single Treated Cluster." Working Paper. Accessed from https://hgmn.github.io/.

Mann, Cindy, Samantha Artiga, and Jocelyn Guyer. (2003). Medicaid and the Uninsured: Assessing the Role of Recent Waivers in Providing New Coverage. Kaiser Family Foundation. https://www.kff.org/wp-content/uploads/2013/01/assessing-the-role-ofrecent-waivers-in-providing-new-coverage.pdf.

MacKinnon, James G., and Matthew D. Webb. (2017). "Wild Bootstrap Inference for Wildly Different Cluster Sizes." Journal of Applied Econometrics 32, 233-254. https://doi.org/10.1002/iae.2508.

MacKinnon, James G., and Matthew D. Webb. "Wild Bootstrap Randomization Inference for Few Treated Clusters." The Econometrics of Complex Survey Data: Theory and Applications Vol. 39, edited by Kim Huynh, David Jacho-Chavez, and Gautam Tripathi, Emerald 2019, 61-85. https://doi.org/10.1108/S0731-905320190000039003.

Sommers, Benjamin, Genevieve Kenney, and Arnold Epstein. (2014). "New Evidence on the Affordable Care Act: Coverage Impacts of Early Medicaid Expansions." Health Affairs 33(1), 78-87. https://doi.org/10.1377/hlthaff.2013.1087.

Tello-Trillo, Sebastian. (2021). "Losing Public Health Insurance on Preventative Care, Health, and Emergency Department Use: Evidence from the TennCare Disenrollment." Southern Economic Journal, 88(1): 322-366.

Zuckerman, Stephen, Dawn M. Miller, and Emily Shelton Pape. (2009). "Missouri's 2005 Medicaid Cuts: How Did They Affect Enrollees and Providers?" Health Affairs 28(2): 335345. 
Table B1: Monte Carlo Simulation Results

\begin{tabular}{|l|c|c|c|c|c|}
\hline & $\begin{array}{c}(1) \\
\text { Modified } \\
\text { Block } \\
\text { Bootstrap }\end{array}$ & $\begin{array}{c}(2) \\
\text { OLS }\end{array}$ & $\begin{array}{c}\text { (3) } \\
\text { State-Level } \\
\text { Clustering }\end{array}$ & $\begin{array}{c}\text { (4) } \\
\text { Robust } \\
\text { (Hubert/White) }\end{array}$ & $\begin{array}{c}\text { Wild } \\
\text { Bootstrap }\end{array}$ \\
\hline Rejection Rate & 0.042 & 0.074 & 0.455 & 0.067 & 0.45 \\
\hline
\end{tabular}

Notes: Monte Carlo simulation results from an empirical specification with 8 total clusters, 1 treated cluster, and 10,000 repetitions. Rejection threshold is $p=0.05$. 